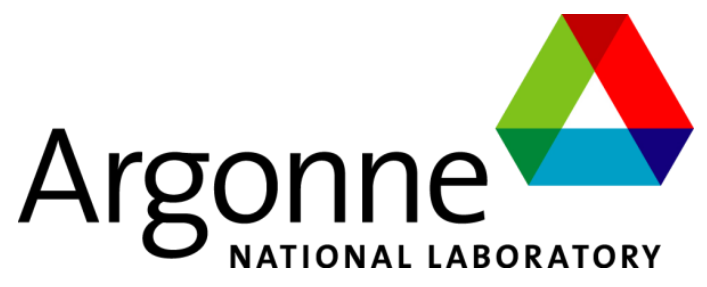

ANL-19/60

\title{
Three-Dimensional Flow Analysis Methodology for Assessing Stream Stability and Channel Migration
}

Nuclear Science and Engineering Division 


\begin{abstract}
About Argonne National Laboratory
Argonne is a U.S. Department of Energy laboratory managed by UChicago Argonne, LLC under contract DE-AC02-06CH11357. The Laboratory's main facility is outside Chicago, at 9700 South Cass Avenue, Argonne, Illinois 60439. For information about Argonne and its pioneering science and technology programs, see www.anl.gov.
\end{abstract}

\title{
DOCUMENT AVAILABILITY
}

Online Access: U.S. Department of Energy (DOE) reports produced after 1991 and a growing number of pre-1991 documents are available free at OSTI.GOV

(http://www.osti.gov/), a service of the U.S. Dept. of Energy's Office of Scientific and

Technical Information

\section{Reports not in digital format may be purchased by the public from the} National Technical Information Service (NTIS):

U.S. Department of Commerce

National Technical Information Service

5301 Shawnee Rd

Alexandra, VA 22312

www.ntis.gov

Phone: (800) 553-NTIS (6847) or (703) 605-6000

Fax: (703) 605-6900

Email: orders@ntis.gov

Reports not in digital format are available to DOE and DOE contractors from the Office of Scientific and Technical Information (OSTI):

U.S. Department of Energy

Office of Scientific and Technical Information

P.O. Box 62

Oak Ridge, TN 37831-0062

www.osti.gov

Phone: (865) 576-8401

Fax: (865) 576-5728

Email: reports@osti.gov

Disclaimer

This report was prepared as an account of work sponsored by an agency of the United States Government. Neither the United States Government nor any agency thereof, nor UChicago Argonne, LLC, nor any of their employees or officers, makes any warranty, express or implied, or assumes any legal liability or responsibility for the accuracy, completeness, or usefulness of any information, apparatus, product, or process disclosed, or represents that its use would not infringe privately owned rights. Reference herein to any specific commercial product, process, or service by trade name, trademark, manufacturer, or otherwise, does not necessarily constitute or imply its endorsement, recommendation, or favoring by the United States Government or any agency thereof. The views and opinions of document authors expressed herein do not necessarily state or reflect those of the United States Government or any agency thereof, Argonne National Laboratory, or UChicago Argonne, LLC. 


\section{Three Dimensional Flow Analysis Methodology for Assessing Stream Stability and Channel Migration}

prepared by

S.A. Lottes, M.A. Sitek, and N. Sinha

Nuclear Engineering and Science Division, Argonne National Laboratory

December 2019 


\section{Table of Contents}

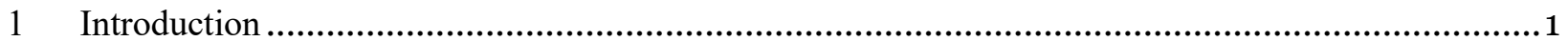

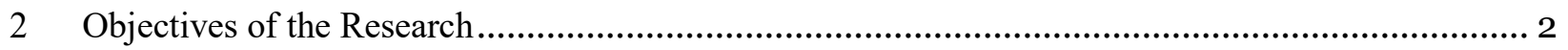

3 Description of the Computational Fluid Dynamics Model ......................................................... 2

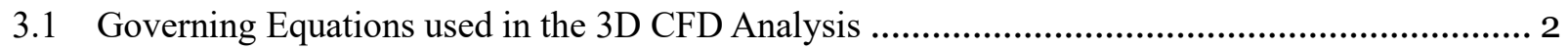

3.2 Development of the Model Geometry ...................................................................... 4

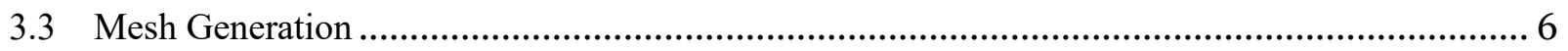

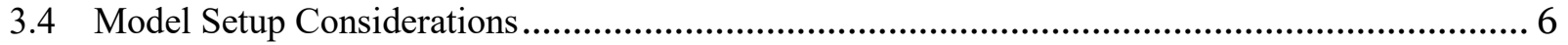

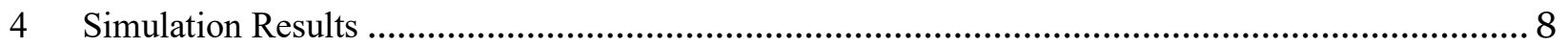

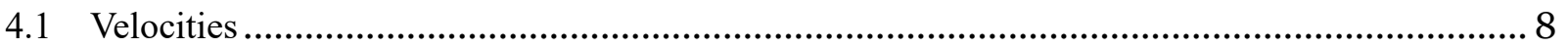

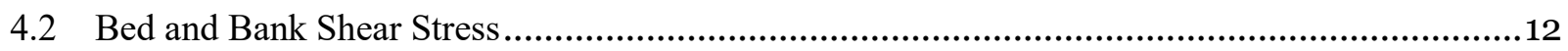

5 Estimation of the Stream Bank Erosion Rate and Migration Distance ........................................14

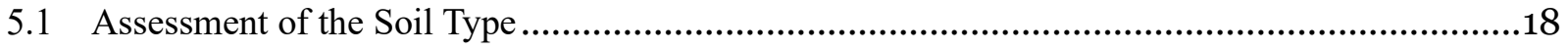

5.2 Near-bank Shear Stress Distribution Obtained from CFD Models ......................................18

5.3 Stream Bank Lateral Erosion Rate and Distance ..........................................................18

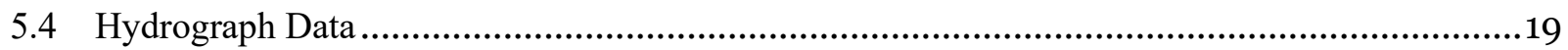

5.5 Using Historic Channel Imagery to Tune the Erosion Rate Function ...................................20

5.5.1 Determination of the Bank Migration Direction from Imagery .................................. 22

5.5.2 Determination of the Bank Migration Distance from Imagery ................................... 23

5.5.3 Tuned Erosion Rate Parameters ........................................................................ 25

5.6 Calculated Bank Migration for the Period 2006-2015 ....................................................... 30

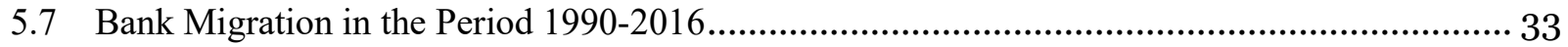

6 Testing Scenarios for Future 10-Year Migration of the Stream Bends ....................................... 38

6.1 Scenario 1: Hydrograph Repeats Previous Ten Years.................................................... 38

6.2 Scenario 2: Daily Discharge Increases by 75 Cubic Feet per Second .................................... 40

6.3 Scenario 3: Additional Extreme Events with Same Mean Daily Discharge................................41

6.4 Scenario 4: One Additional 10,000 cfs Discharge Event per Year .......................................... 43

6.5 Summary of Future Scenario Tests................................................................................ 45

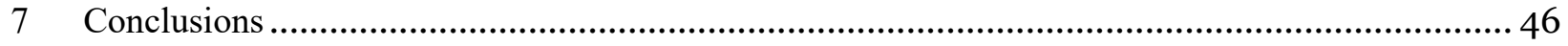

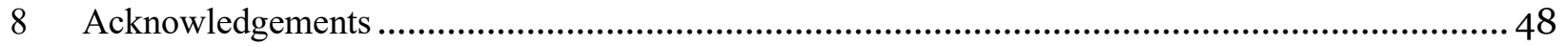

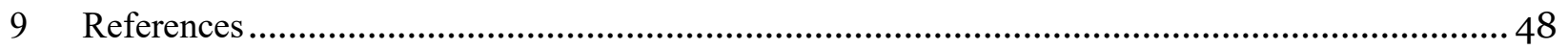

Three-Dimensional Flow Analysis Methodology for Assessing Stream Stability and Channel Migration 


\section{List of Figures}

Figure 1-1. An aerial view of the Maple River [1] .....................................................................

Figure 3-1. Lidar point cloud of the site showing approximately 63000 points ….............................. 5

Figure 3-2. A screenshot of a triangulated surface of the stream and surroundings. A general view on the left and a close-up view of two horseshoe bends on the right of the modeled stream reach.................... 5

Figure 3-3. An example mesh cut through in the domain showing vertical layers of cells...................... 6

Figure 4-1: Surface velocity distributions for discharges from 1,000 to 20,000 cfs ............................. 9

Figure 4-2: Velocity vector plots in a bend cross section for flow rates of 2,000, 9,000 and 12,000 cfs,

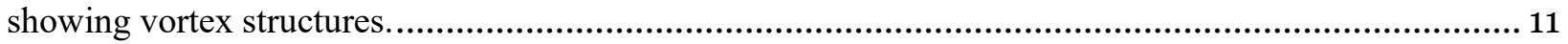

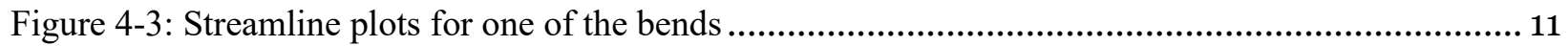

Figure 4-4: Shear stress distribution on the bed surface for discharges 1,000 to 20,000 cfs...................13

Figure 5-1. Schematic of stream bank migration estimation methodology for long time periods............15

Figure 5-2: Images of the meanders of the Maple River closest to Highway 175 in (a) and (b). A snapshot of river from highway 175 in (c). In 2016 the riverbank near bend-1 was less than $140 \mathrm{ft}$ away from pavement and $80 \mathrm{ft}$ from the highway shoulder. Source: Maple River at [42 $155^{\prime} 57.51^{\prime \prime} \mathrm{N}, 95^{\circ} 40^{\prime} 42.17^{\prime \prime} \mathrm{W}$ ], Google Earth.

Figure 5-3: The boring location (in green circle) on left [image source: google earth] and the boring log data analysis on right from Iowa DOT Project HR-292 (1989) [11]

Figure 5-4: The model surface of the riverbed with area used for shear stress averaging (marked in red) 18

Figure 5-5: Hydrograph for the Maple River from a gage located near Mapleton (USGS gage number 06607200) U.S. Geological Survey, 2018, National Water Information System data [1]...................... 20

Figure 5-6: Historic imagery for Maple River at [42 $\left.15^{\prime} 57.51^{\prime \prime} \mathrm{N}, 95^{\circ} 40^{\prime} 42.17^{\prime \prime} \mathrm{W}\right]$ from 1990 to 2016. Accessed via Google Earth historic imagery from google earth V7.1.8.3036 (February 2, 2018) .......... 22

Figure 5-7: Determination of the migration direction of meander loops based on the movement of the

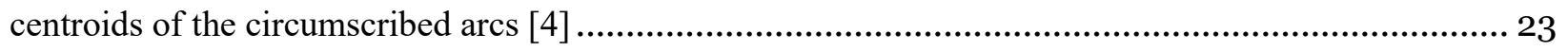

Figure 5-8: Historic migration of the banks during (a) a 25-year period (1990-2015), and (b) a 10-year period between 2006 and 2015 . 24

Figure 5-9: Migration distance analysis of the river banks at location 3; (a) image of the area in 2016, (b)

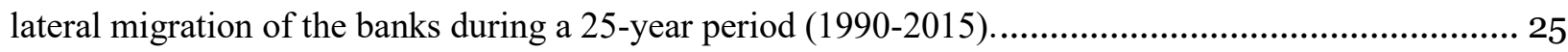

Figure 5-10: Percentage difference between the estimated and historical migration distance ................ 30

Figure 5-11: Hydrograph for years 2006-2016 .......................................................................

Three-Dimensional Flow Analysis Methodology for Assessing Stream Stability and Channel Migration 
Figure 5-12: Historical and computed bank migration distance in years 2006-2016

Figure 5-13: Migration distances between 2005 and 2016 32

Figure 5-14: Comparison of historical vs. computed lateral migration distances for each bend for period 2005-2016, (a) bend 1, (b) bend 2, (c) bend 3, (d) bend 4 33

Figure 5-15: Hydrograph for the period from 1990-2016. 34

Figure 5-16: Historical and computed bank migration distance in years 1990-2015..... 34

Figure 5-17: Hydrograph for the period from 1990-2016. 35

Figure 5-18: Historical and computed bank migration distance in years 1990-2015 36

Figure 5-19: Aerial view of the 1990 stream with the shape of the 2016 stream (yellow dashed line). The distances between the bends are given. 36

Figure 5-20: Comparison of historical vs. computed lateral migration distances for each bend for period 1990-2016, (a) bend 1, (b) bend 2, (c) bend 3, (d) bend 4 . 38

Figure 6-1: Lateral migration distances predicted for the bends in Scenario 1. Yellow line at bend-5 is estimated bank location based on current migration rate. 39

Figure 6-2: Lateral migration distance between the bends in location 3. Historical data for years 2005-2016 with a linear extrapolation until 2023

Figure 6-3: A hydrograph showing the monthly and annual discharge curves in the Maple River at the gage in Mapleton, IA between 1941 and 2016

Figure 6-4: Aerial view of the Maple River from 2016. The forecasted bank lines for year 2026 according to the Scenario 2 were marked with red lines. Yellow line at bend- 5 is the estimated bank location based on the current migration rate.

Figure 6-5: A comparison of the hypothetical hydrographs for the period 2016-2026 used in Scenario 1 (blue line) and used in Scenario 3 (orange line)

Figure 6-6: Aerial view of the Maple River from 2016. The forecasted bank lines for year 2026 according to the Scenario 3 were marked with red lines. Yellow line at bend-5 is the estimated bank location based on current migration rate. 43

Figure 6-7: A comparison of the hypothetical hydrographs for the period 2016-2026 used in Scenario 1 (blue line) and used in Scenario 4 (orange line)......

Figure 6-8: Aerial view of the Maple River from 2016. The forecasted bank lines for year 2026 according to the Scenario 4 were marked with red lines. Yellow line at bend-5 is estimated bank location based on current migration rate. 44 


\section{List of Tables}

Table 1: Averaged CFD Results for Discharges up to 12,000 cfs .................................................. 27

Table 2: Bend Bank Shear Stress and Bankfull Fraction Interpolated from Table 1 with Discharge on

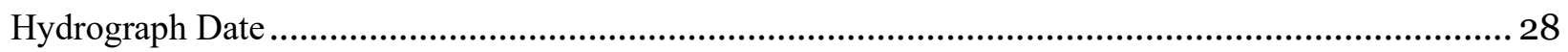

Table 3: Daily Bank Migration Estimate Calculated from Table 2 ............................................... 29

Table 4: Percentage Difference Between the Estimated and Historical Migration of the Bends .............. 30

Table 5: Summary of Future Ten Year Stream Flow Scenarios with Bend Migrations .......................... 46

Three-Dimensional Flow Analysis Methodology for Assessing Stream Stability and Channel Migration 


\section{Introduction}

Increases in the frequency and magnitude of weather events that deviate significantly from average are being observed both globally and in the U.S. Adaptation strategies need to account for and mitigate increased risks to transportation infrastructure that result from more extreme weather. The present study is a part of a project that covers a sensitivity study of the potential impacts of increases in stream flows due to rain events and floods on an active section of the Maple River near Iowa Highway 175 and Danbury, Iowa, which is shown in Figure 1-1. This study focuses on the use of advanced three-dimensional (3D) computational fluid dynamics (CFD) techniques to enhance the assessment of increased risks to stream stability of a section of the Maple River that may erode into Iowa Highway 175. The methodology developed and presented can be applied to a wide variety of streams and rivers that may face increased risk of migration due to changes in weather patterns and severity of weather events. The Maple River is a laterally active channel flowing through agricultural land that has migrated several hundred feet in recent decades and is currently within approximately 100 feet of the Highway 175 Right-of-Way. In addition to the nearterm threat to the highway from the closest river meander, there is also a concern that other river meanders could develop into longer-term threats, especially if increasing intensity or frequency of rain events increase the rate of meander development and channel migration by changing the long-term hydrology of the Maple River.

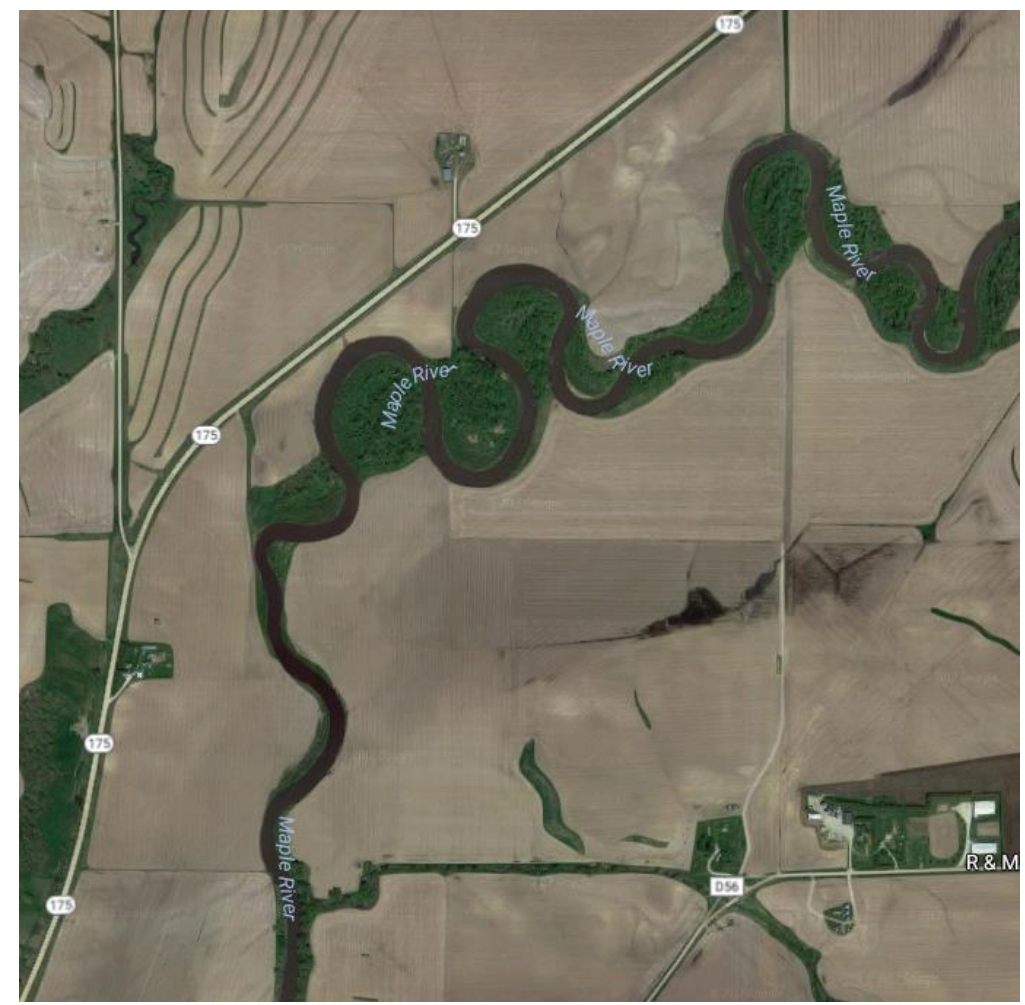

Figure 1-1. An aerial view of the Maple River [1] 


\section{Objectives of the Research}

The objectives of this project were to investigate the use of three dimensional computational fluid dynamics (CFD) to obtain a detailed distribution of shear stress on stream banks, to use the shear stress on the banks to obtain erosion rates, and to develop a methodology to use this more refined estimate of bank erosion rates to evaluate the potential future increase in the instability of streams, in this case the Maple River channel, as well as its potential for undermining Iowa Route 175 if a meander reaches the highway. The impact of increasing intensity and frequency of extreme rain events over different periods of time was explored by analyzing four "what if" scenarios with variations of future ten-year daily hydrographs, including variations in the overall volume and standard deviation of discharge that passes through the channel.

In a previous phase of the study, 1D equations based on Hydrologic Engineering Center's (CEIWR-HEC) River Analysis System (HEC-RAS) [2] and 2D models, with the use of SRH-2D software [3], were developed by Tetra Tech [4] for use with a model domain extending over an area approximately $9,000 \mathrm{ft}$ long by 3,000 ft wide, covering approximately 3.5 miles $(18,500 \mathrm{ft})$ of river reach. The extent of the model was selected to keep boundaries an adequate distance from the primary area of interest and to approximately cover the floodplains during extreme discharge events.

Three-dimensional computational fluid dynamics (CFD) simulations were performed by the researchers at the Transportation Research and Analysis Computing Center (TRACC) at Argonne National Laboratory and are the topic of this report. The analysis was performed using one of the high-performance parallel computer clusters available at TRACC. The same section of the river and adjacent terrain, as used for 1D and 2D computations in Tetra Tech's analysis [4], was chosen for the 3D CFD analysis. The models were developed with the goal of being used in the next phase of the research project to establish hydraulic variables for use in geomorphic analysis and for testing alternative designs of countermeasures. The 2D models provided the inlet boundary conditions for the $3 \mathrm{D}$ CFD models in terms of mean flow velocity and water surface elevation, which were needed to set the downstream boundary conditions.

\section{Description of the Computational Fluid Dynamics Model}

\subsection{Governing Equations used in the 3D CFD Analysis}

The Unsteady Reynolds-Averaged Navier-Stokes (URANS) equations were used with a k-epsilon turbulence model in the 3D CFD study. The URANS equations are obtained from the NavierStokes equations by decomposing the instantaneous velocity and pressure fields into a mean value and a fluctuating component and averaging the equations. Turbulence model terms replace crosscorrelations of fluctuating quantities in the URANS equations. The governing unsteady form of the equations in the STAR-CCM+ User Guide [5] are as follows. 
Conservation of mass is given by:

$$
\frac{\partial}{\partial t} \int_{V} \rho d V+\oint_{A} \rho\left(v-v_{g}\right) \cdot d \boldsymbol{a}=0
$$

Conservation of momentum, Newton's $2^{\text {nd }}$ law for fluid motion is:

$$
\frac{\partial}{\partial t} \int_{V} \rho \boldsymbol{v} d V+\oint_{A} \rho \boldsymbol{v} \otimes\left(\boldsymbol{v}-\boldsymbol{v}_{\boldsymbol{g}}\right) \cdot d \boldsymbol{a}=-\oint_{A} p \mathbf{I} \cdot d \boldsymbol{a}+\oint_{A} \mu_{e f f}\left[\nabla \boldsymbol{v}+\nabla \boldsymbol{v}^{T} \mathbf{I}\right] \cdot d \boldsymbol{a}+\int_{V} f_{g} d V .
$$

The transport equation for turbulent kinetic energy, $k$, is:

$$
\frac{\partial}{\partial t} \int_{V} \rho k d V+\oint_{A} \rho k\left(\boldsymbol{v}-\boldsymbol{v}_{\boldsymbol{g}}\right) \cdot d \boldsymbol{a}=\oint_{A}\left(\mu+\frac{\mu_{t}}{\sigma_{k}}\right) \cdot d \boldsymbol{a}+\int_{V}\left[f_{c} \mu_{t} S^{2}-\rho\left(\epsilon-\epsilon_{0}\right)\right] d V .
$$

And the transport equation for the turbulent dissipation rate, $\epsilon$, is:

$$
\frac{\partial}{\partial t} \int_{V} \rho \epsilon d V+\oint_{A} \rho \epsilon\left(\boldsymbol{v}-\boldsymbol{v}_{\boldsymbol{g}}\right) \cdot d \boldsymbol{a}=\oint_{A}\left(\mu+\frac{\mu_{t}}{\sigma_{\epsilon}}\right) \cdot d \boldsymbol{a}+\int_{V}\left[f_{c} C_{\epsilon 1} \epsilon S^{2}-\frac{\epsilon}{k+\sqrt{v \epsilon}} C_{\epsilon 2} \rho\left(\epsilon-\epsilon_{0}\right)\right] d V .
$$

An all $\mathrm{y}^{+}$wall function approach is used to obtain the shear stress, $\tau_{w}$, on the river bank. Variable $\mathrm{y}^{+}$is a nondimensional distance from the river bed or bank given by:

$$
y^{+}=\frac{y}{v} \sqrt{\frac{\tau_{w}}{\rho}}
$$

Standard wall functions giving wall shear stress in the k-epsilon turbulence model work well for $y^{+}$in the range 30 to several hundred. The all $y^{+}$formulation uses a blending function to obtain wall shear in the range $5<y^{+}<30$, and computes shear stress as $\tau_{w}=\mu_{e f f} u / y$, for $y^{+}<5$. The all $y^{+}$formulation works well when the grid near the wall (river bank) and conditions near the wall may vary significantly over the computational domain, such as in the varied topology of a field real stream at full scale.

Variables and symbols in the above equations are:

$\begin{array}{clcl}A & \text { control volume surface } & \boldsymbol{v}_{\boldsymbol{g}} & \text { grid velocity = zero } \\ \boldsymbol{a} & \text { computational cell face area vector } & \otimes & \text { tensor dyadic product } \\ C_{\epsilon 1} & \text { turbulence model coefficient [7] } & \nabla & \text { del operator } \\ C_{\epsilon 2} & \text { turbulence model constant }=1.9 & \epsilon & \text { turbulent dissipation rate } \\ f_{c} & \text { curvature factor } & \epsilon_{0} & \text { dissipation limit for minimum low level } \\ f_{g} & \text { body force due to gravity } & \mu & \text { fluid dynamic viscosity } \\ \mathbf{I} & \text { identity matrix } & \mu_{t} & \text { eddy or turbulent viscosity } \\ p & \text { pressure } & \mu_{e f f} & \text { effective viscosity }=\mu+\mu_{\tau} \\ S & \text { modulus of strain rate tensor } & v & \text { kinematic viscosity } \\ V & \text { computational cell volume } & \rho & \text { density } \\ t & \text { time } & \sigma_{k} & \text { turbulence model constant }=1.0 \\ \boldsymbol{v} & \text { velocity vector } & \sigma_{\epsilon} & \text { turbulence model constant }=1.2 \\ \boldsymbol{v}^{T} & \text { transpose of velocity vector } & \tau_{w} & \text { shear stress at wall, river bed, river bank }\end{array}$


A multiphase Volume of Fluid (VOF) free surface model was used for the stream flow, with two phases being water and air. In the VOF model only one momentum equation is solved because the two phases are assumed to always be separated by the free surface. In mesh cells that contain the free surface, the material properties of the fluid in those cells are determined by averaging as follows:

$$
\begin{aligned}
\rho & =\sum_{i} \rho_{i} \alpha_{i}, \\
\mu & =\sum_{i} \mu_{i} \alpha_{i},
\end{aligned}
$$

where $\alpha_{\mathrm{i}}=V_{i} / V$ is the volume fraction of the $i^{\text {th }}$ phase, $V_{i}$ is the volume occupied by the $i^{\text {th }}$ phase, and $\rho_{i}, \mu_{i}$, and $\left(c_{p}\right)_{i}$ are the density, molecular viscosity of the $i^{\text {th }}$ phase respectively.

The conservation equation that describes the transport of volume fraction of phase $i, \alpha_{i}$, is:

$$
\frac{d}{d t} \int_{V} \alpha_{i} d V+\int_{A} \alpha_{i}\left(v-v_{g}\right) \cdot d \boldsymbol{a}=0 .
$$

For only two phases, air and water, only one phase volume fraction equation needs to be solved because the volume fraction of the other phase is one minus that of the solved for volume fraction.

Additional details on the complete model governing equations can be found in the STAR-CCM+ User Guide [5].

The Realizable Two-Layer k- $\varepsilon$ turbulence model was used with the all y+ wall treatment and wall functions to calculate bed and bank shear stress since this model usually works well when there are varying mesh densities in the domain.

Roughness of the bed, bank, and flood plains were available as Manning's n values, however, CFD calculations require an equivalent sand gain roughness height $\left(k_{s}\right)$ on the bed and bank surface. The two roughness measures can be related by:

$$
k_{s}=12.27 d\left(10^{\frac{d^{(1 / 6)}}{(-2.03) n \sqrt{8 g}}}\right),
$$

where $\mathrm{d}(\mathrm{m})$ is the flow depth, $\mathrm{n}$ is Manning's coefficient, and $g$ is the gravitational acceleration, $9.81 \mathrm{~m} / \mathrm{s}^{2}$. Details can be found in [6].

\subsection{Development of the Model Geometry}

The computational study consisted of a set of full-scale three-dimensional geometries of the Maple River channel in a reach that contains four large horseshoe bends and its surroundings. Each model had a different topology, depending on the flow conditions. Away from the stream, it was obtained from onsite light detection and ranging (LIDAR) mapping [7]. Along the stream, the flow depth was estimated from the mean daily discharge and the water surface slope approximated from the LiDAR data. The depth estimates were then combined with the over bank LiDAR data to reconstruct the bed contour across the water surface width at a large set of cross sections along the stream. Figure 3-1 shows a screenshot of the data point cloud obtained for the study site. The accuracy of the bed topology for existing conditions is limited to that of the provided point cloud with distance between points ranging from one to several feet. Triangulation of the surface was done with the use of LS-PrePost [8], a free pre and post processor for finite Three-Dimensional Flow Analysis Methodology for Assessing Stream Stability and Channel Migration 
element modeling in the LS-DYNA software package. The geometry was modified by removing triangles in some locations far from the stream to limit the size of the computational domain because they were not essential for the CFD study and would have made the CFD runs too time consuming. In some cases, only the stream geometry was kept, and the flood plains were removed when there was no flow in those areas. The cleaned-up geometry was exported as a stereolithography (stl) file, a format that could be easily imported in StarCCM+ for CFD domain geometry construction. The triangulated surface of one of the simulation cases is shown in Figure 3-2.

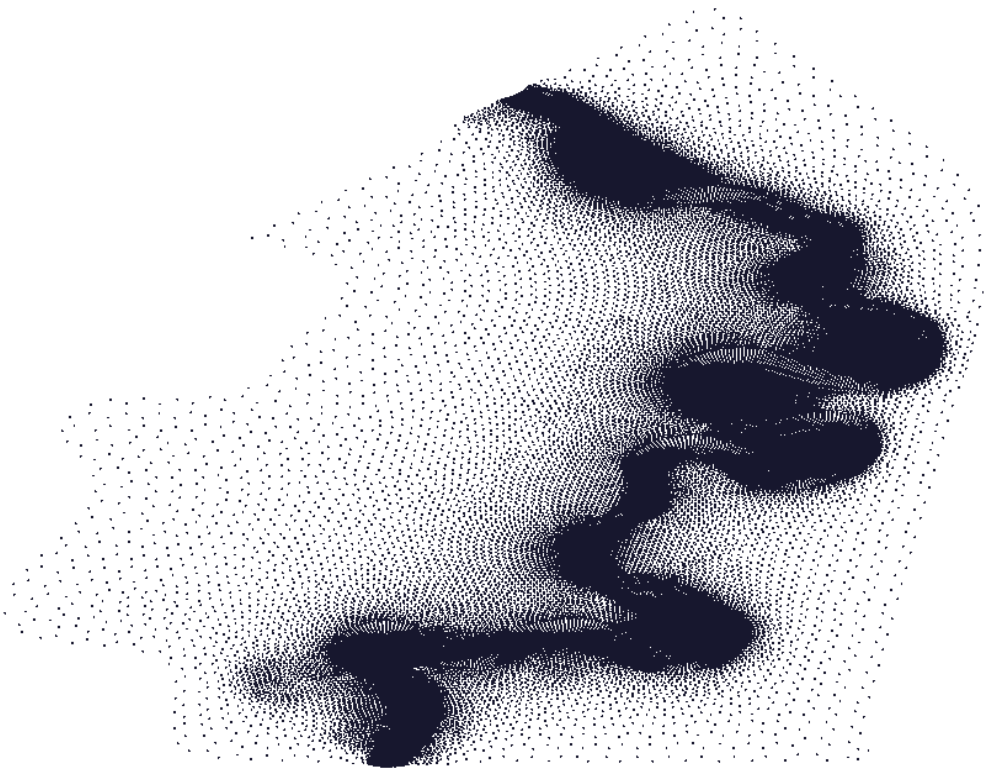

Figure 3-1. LIDAR point cloud of the site showing approximately 63000 points
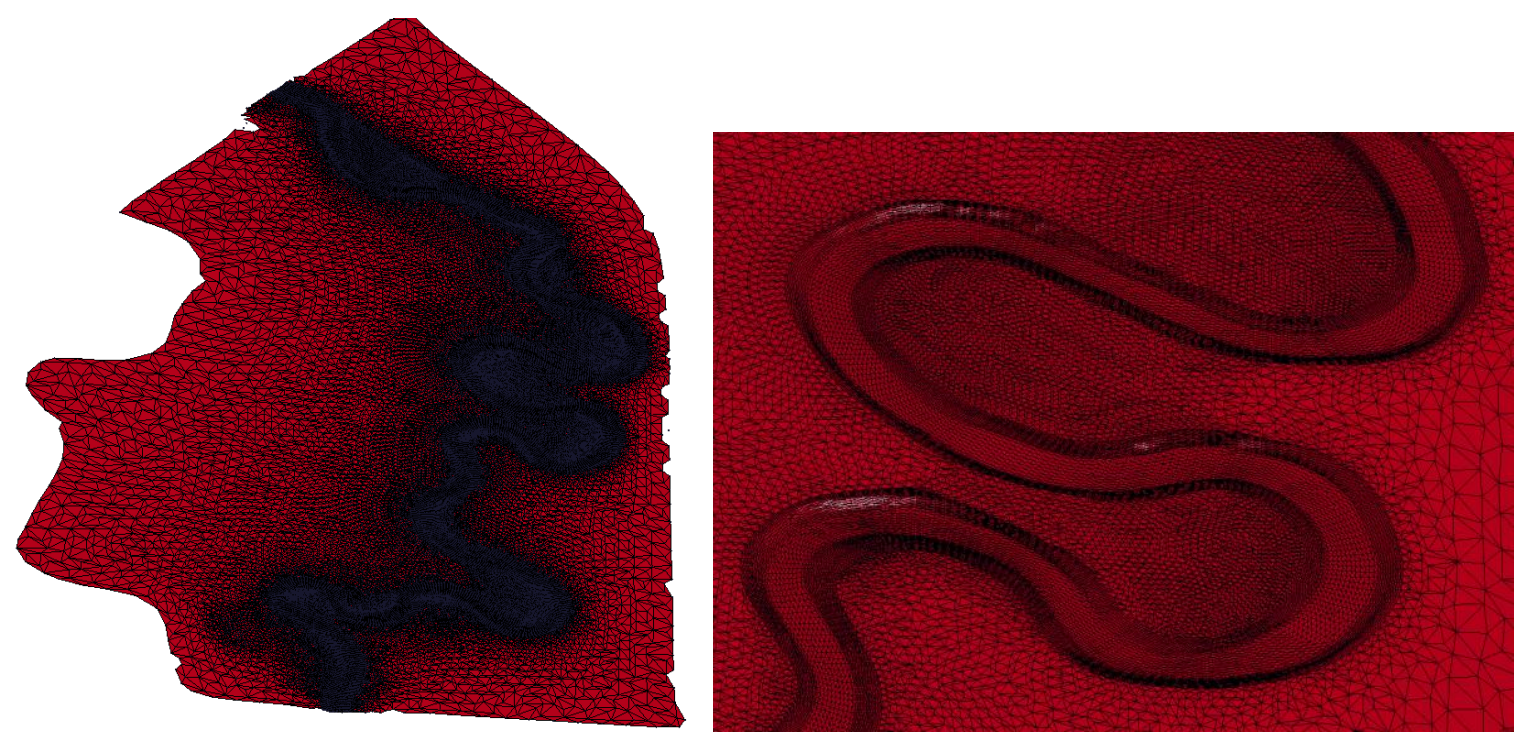

Figure 3-2. A screenshot of a triangulated surface of the stream and surroundings. A general view on the left and a close-up view of two horseshoe bends on the right of the modeled stream reach

Three-Dimensional Flow Analysis Methodology for Assessing Stream Stability and Channel Migration 


\subsection{Mesh Generation}

Extrusion and trimming meshing techniques were used in the mesh generation. A polyhedral mesh was generated at the riverbed and was used as a base mesh. A thin mesher was used to extrude the polyhedral grid upwards in computational cell layers to the top of the domain, maintaining a specified cell maximum thickness, and to generate a prismatic type volume mesh in the process. The number of grid points in the vertical direction varied in each case. In cases with low water depth, 25 to 30 cell layers were used, while in cases with deep water, the number of cell layers ranged between 40 and 50.

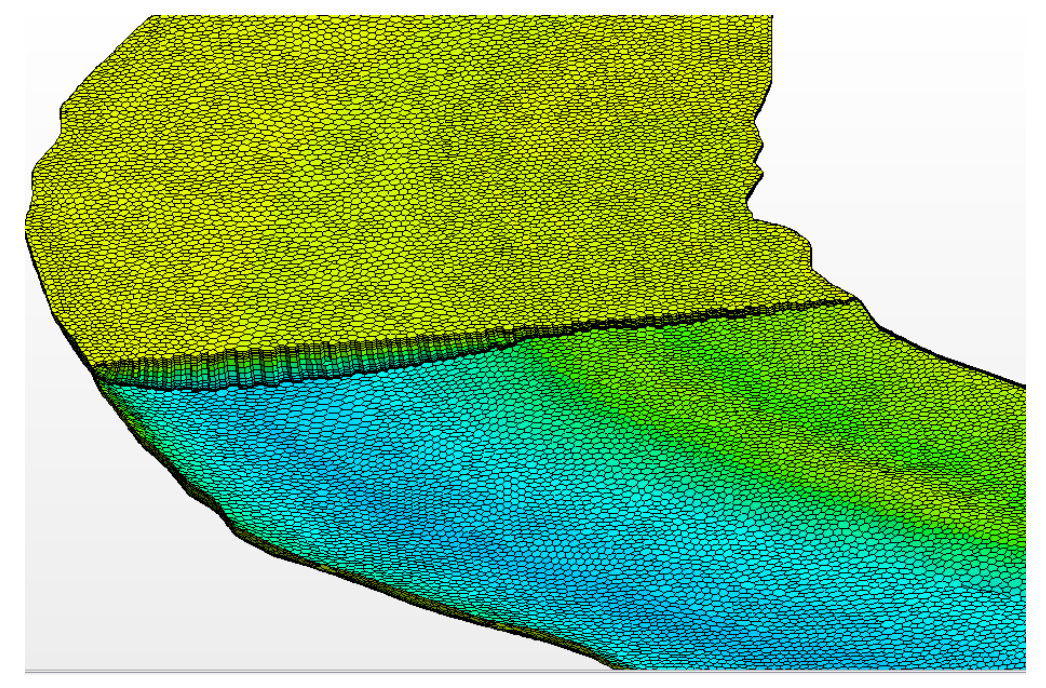

Figure 3-3. An example mesh cut through in the domain showing vertical layers of cells

\subsection{Model Setup Considerations}

As noted in Section 3.1, the Unsteady Reynolds Averaged Navier-Stokes equations solved in this study with a k-epsilon turbulence model to obtain the flow field and shear stress distribution on stream banks. The k-epsilon turbulence model in combination with wall functions was assumed to be sufficient for computing river bed and bank shear stress for further engineering analysis in this application. Eddies, periodically shed from structures or irregularities in the bed, passing over the bed, cause fluctuations in the bed shear stress as they pass by. When bed shear is below that needed for onset of sediment entrainment, the passage of an eddy can raise it above that threshold. Large eddy simulation (LES) or detached eddy simulation (DES) can identify areas where fluctuating bed shear stress oscillates above and below that needed for onset of sediment entrainment. Those areas may be missed using a k-epsilon model when the mean bed shear is less than but near critical shear stress, over most of the bed. In the cases analyzed in this study, however, the bed shear under nearly all flow conditions was well above critical for the bed particle size range at the site of interest. This condition is likely also the case in most streams that may have elevated migration risk due to extreme weather events when evaluating the impact of those events on erosion risk. Therefore, any underestimation of entrainment rates would be at most a small secondary effect. The cost of running either LES or DES simulations would be expensive and the time needed to complete all the cases that were analyzed would far exceed the time Three-Dimensional Flow Analysis Methodology for Assessing Stream Stability and Channel Migration 
available to complete the study. Therefore, use of the k-epsilon turbulence model was deemed to be good enough to obtain the engineering data needed to achieve the goals of the study within the time and budget of the project.

The site contains trees, bushes, and grass that are not part of the geometry of the model. Additional flow resistance could have been included in the analysis by: adding tree trunks and meshing them, including bushes as small volumes of porous media, and grass in a variety of ways. These additions would have been very time consuming to incorporate and would have added complexity to the model physics that would have also increased the required work by an amount that would not have been acceptable within the time constraints of the project. Exclusion of the modeling of vegetation is not expected to have a major impact on the results, and it makes the results conservative by eliminating a complexity that would reduce erosion. The high shear zones in areas with grass are less at risk for significant scour because grass would offer more resistance to scour than loose bed material. Grassy and crop areas are also of less interest because they are on the flood plains. The influence of grass and other plants on the bed surface roughness was taken care of with the use of a roughness height calculated from a given Manning coefficient distribution according to Equation (8).

The boundary layer near the bed boundary was not resolved in the grid. Doing so would have made the model far too large and expensive to run. Instead, a variation of standard wall functions was used to compute the shear stress at the bed and banks of the channel. Uncertainty in this model was around ten percent, and was close to being as good as other more sophisticated and computationally intensive techniques. That level of uncertainty is sufficient for most engineering applications in hydraulics.

In the VOF multiphase model with free surface, the free surface water level in the river was resolved to about $\pm 1 / 2$ foot due to grid cell size and density smearing that occurs in cell layers above and below the free surface at many locations where the free surface does not align with the grid. The VOF model averages material properties in computational cells that contain the free surface weighted by the fraction of the cell occupied by water and air respectively. Advection of this averaged mixture into the downstream can produce density smearing where the free surface appears to be distributed over several vertical cells. Although the sharp resolution of the location of the free surface is not preserved, the mass flow of water is conserved to several significant figures. The location of the free surface is taken to be the height where the volume fraction of water is equal to 0.5. This is the location of the free surface when that surface is finely resolved and it is the best engineering estimate of the location when some density smearing at the air-water interface has occurred. 


\section{Simulation Results}

A wide range of inlet flow rates was analyzed: 1,000 cfs, 2,000 cfs, 5,000 cfs, 7,000 cfs, 9,000 cfs, $12,000 \mathrm{cfs}, 15,000 \mathrm{cfs}$, and $20,000 \mathrm{cfs}$. At the lowest rate, the flow is contained in the river channel. For the highest rates the flow is spread out onto the surrounding area, forming large flood plains. In all cases above 1,000 cfs, a VOF simulation was run because it could better capture the three-dimensional flow character when the flow depth varies from relatively shallow to fairly deep over cross sections in the bends as well as along the river reach. For the 1,000 cfs case, a rigid lid simulation was run with only the single phase of water and the water surface modeled as a free slip boundary.

\subsection{Velocities}

Figure 4-1 shows a color plot of velocity magnitude of the river surface velocity through the horseshoe bends for flow rates from 1,000 cfs through 20,000 cfs. The legends have different color scales with the value of the maximum velocity shown in red increasing as the discharge increases to maintain the detail of a nearly full range of colors as the discharge and maximum velocity increase. The river is a narrow stream within the channel banks at flow rates from 1,000 cfs up to 9,000 cfs, and then spreads over large portions of the flood plains at flow rates of 12,000 cfs and greater. The higher velocities occur primarily in the stream channel, and lower velocities occur in the flood plains for the higher discharges.
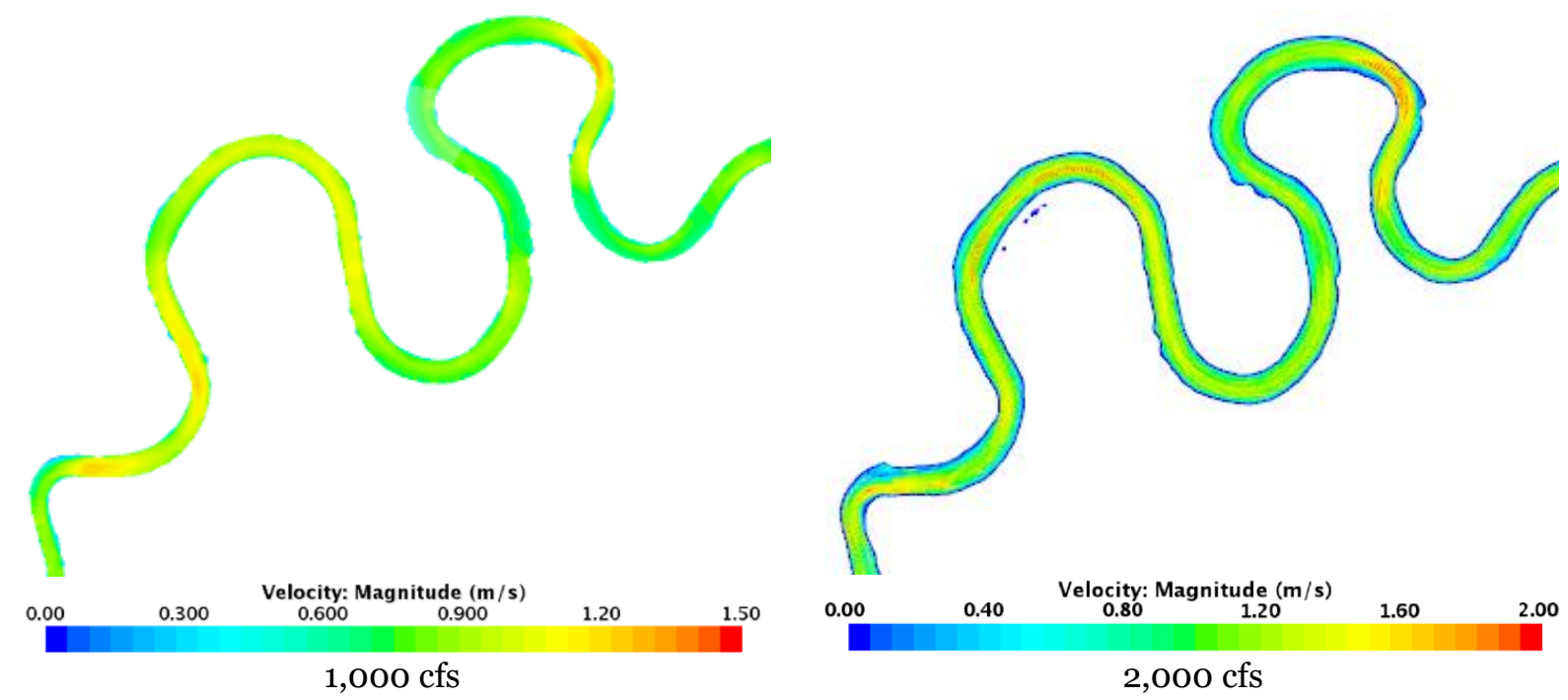

Three-Dimensional Flow Analysis Methodology for Assessing Stream Stability and Channel Migration 

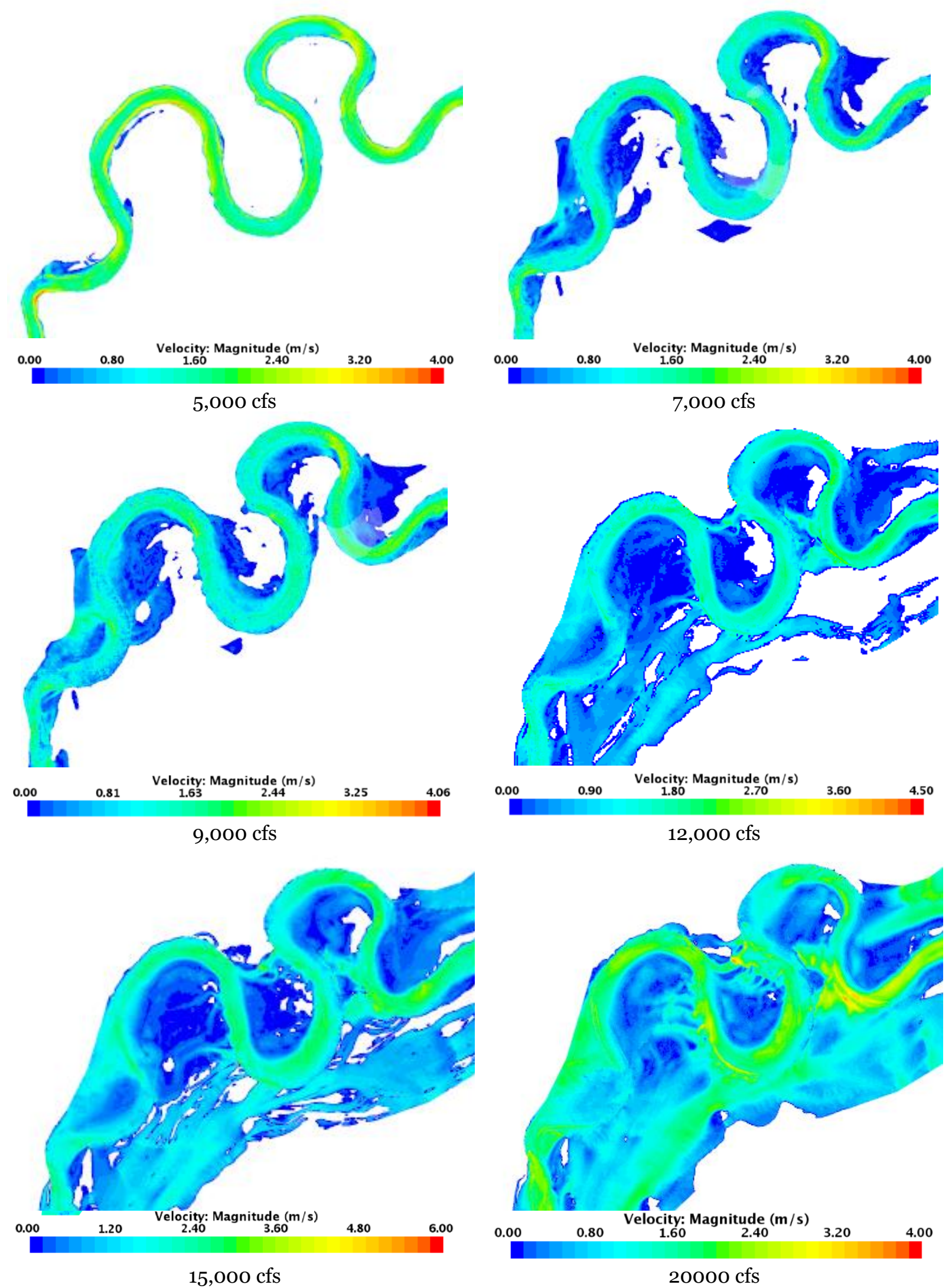

Figure 4-1: Surface velocity distributions for discharges from 1,000 to 20,000 cfs Three-Dimensional Flow Analysis Methodology for Assessing Stream Stability and Channel Migration 
The flow in the stream, especially through the bends is three-dimensional with secondary flow vortices forming in the cross section. These vortex structures can be seen in the cross-section water velocity vector plots of Figure 4-3. The vector plots are shown for one of the bends for flow rates of 2,000, 9,000, and 12,000 cfs at an instant of time. While these plots may depend to some degree on the flow time at which the data is plotted, they do show the complex nature of the secondary flows arising from flow through the bend and the varied nature of bathymetry in the river. In general, there is a cross stream flow at the surface from the inner bank toward the outer cut bank and from the outer cut bank back toward the inner shallower bank near the river bed. This characteristic pattern, depending on the flow and bend bathymetry, however, may be broken up in to several vortices covering a cross section as seen in Figure 4-2 (b) for a 9,000 cfs flow.
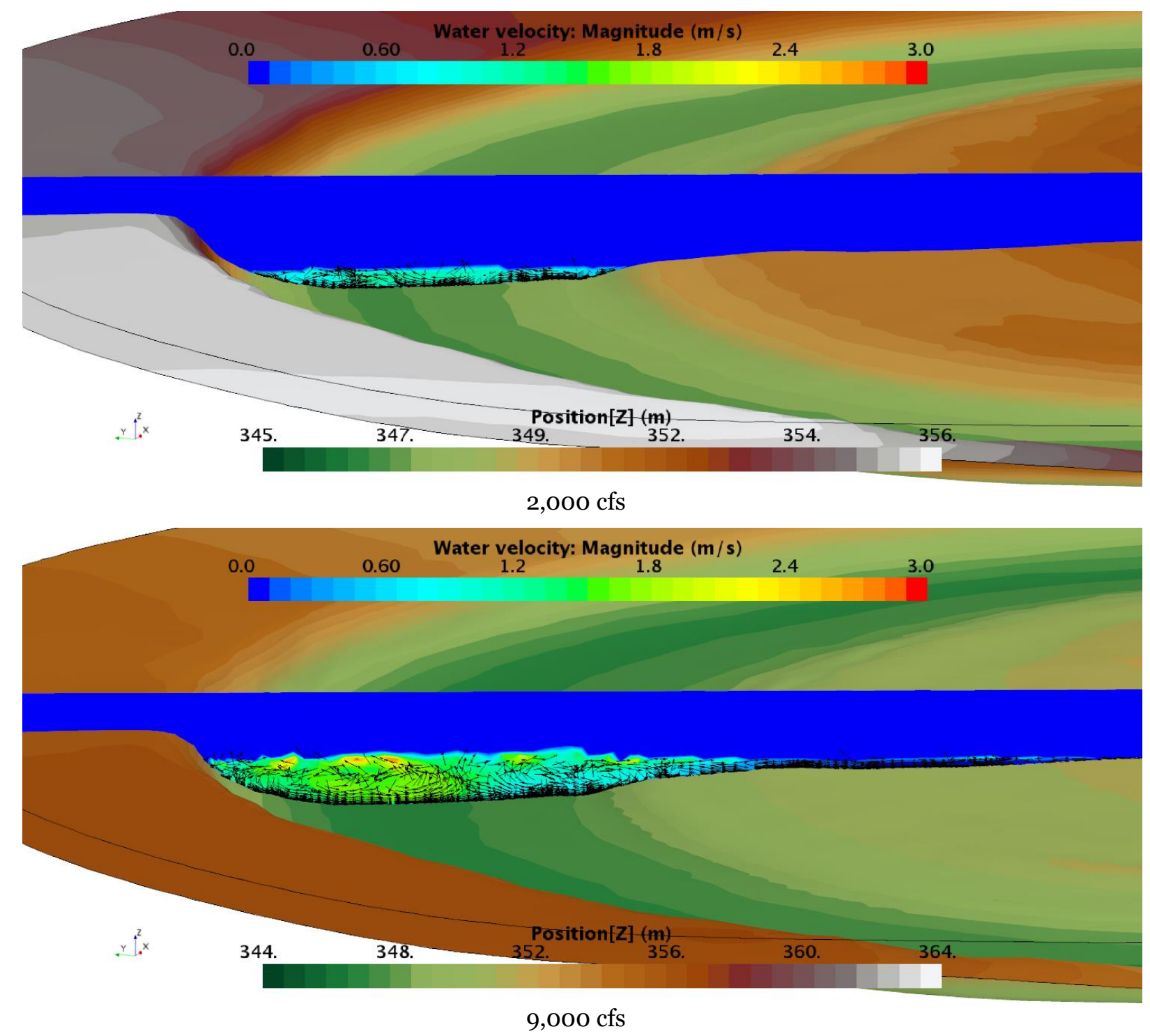

Three-Dimensional Flow Analysis Methodology for Assessing Stream Stability and Channel Migration 


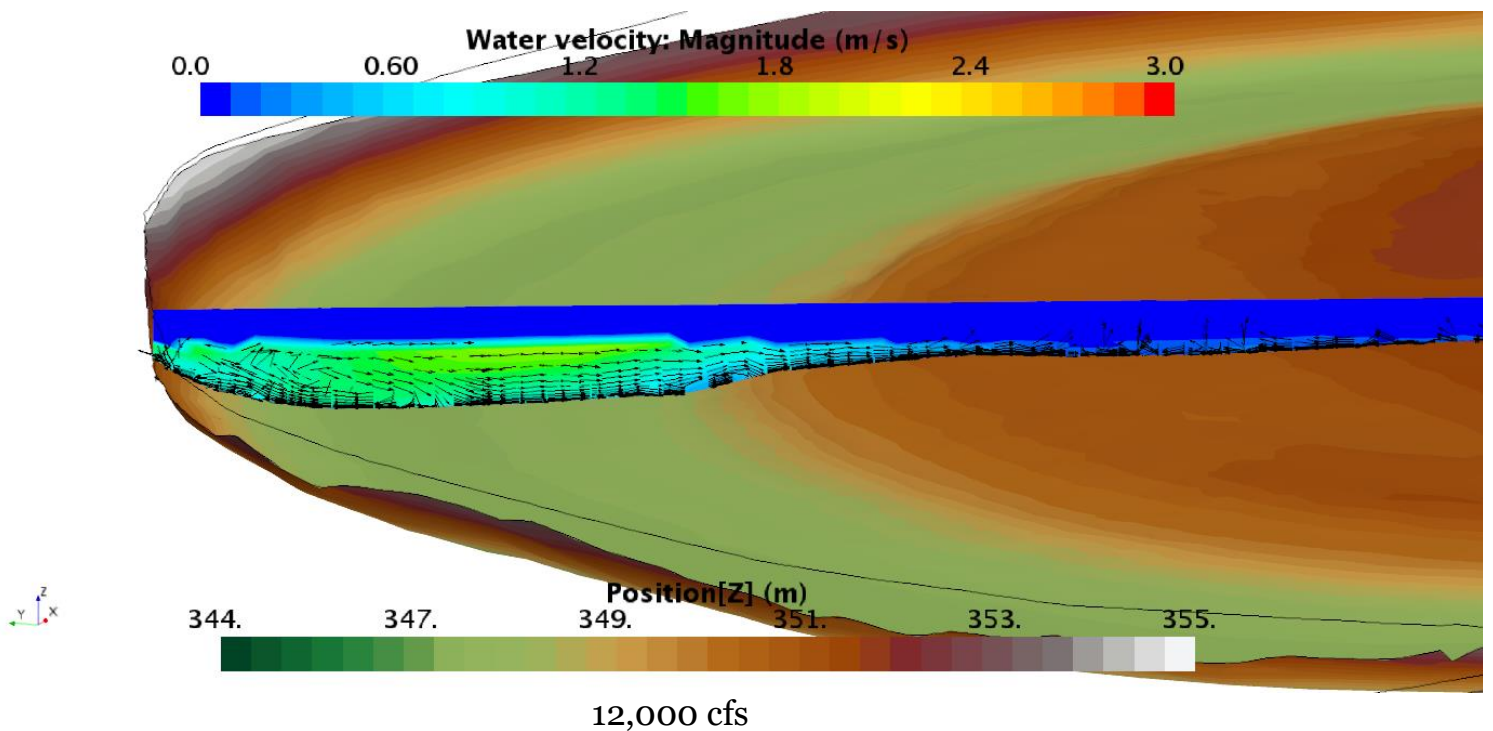

Figure 4-2: Velocity vector plots in a bend cross section for flow rates of 2,000, 9,000 and $12,000 \mathrm{cfs}$, showing vortex structures.

The three-dimensional nature of the flow through a bend is also visible in the streamline plot shown in Figure 4-3. A large number of the streamlines form a spiral around an axis as they proceed through the bend.

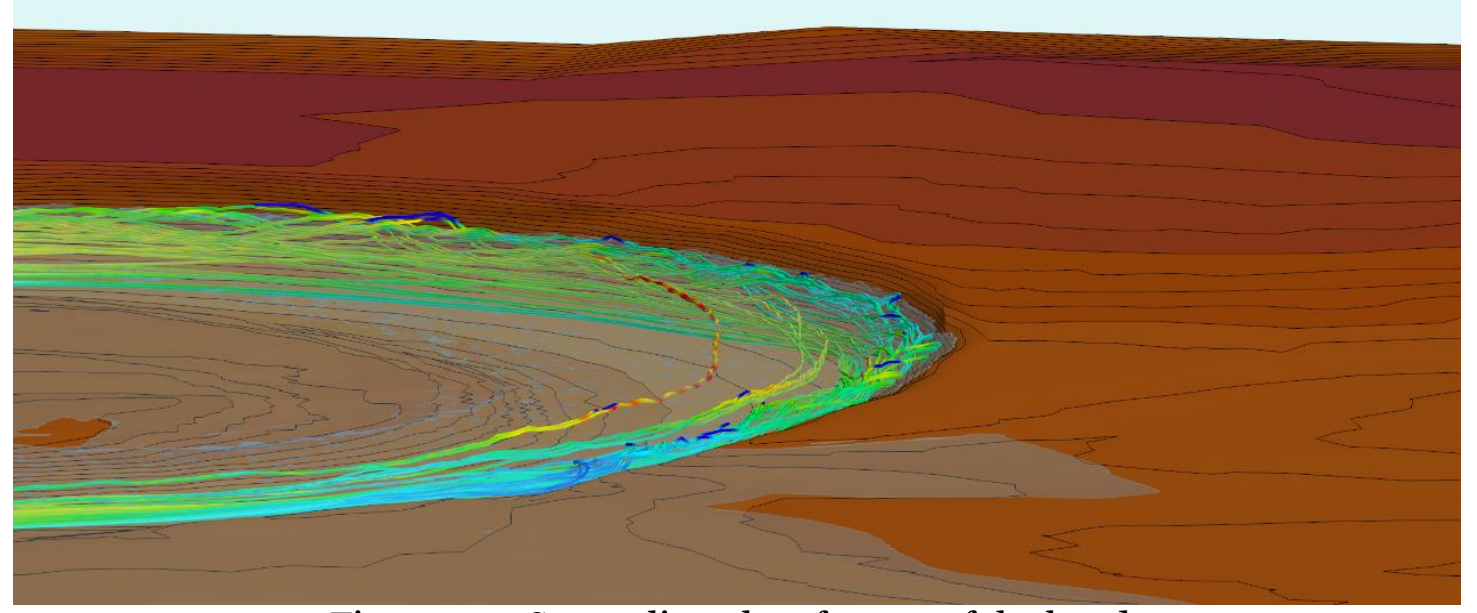

Figure 4-3: Streamline plots for one of the bends

Three-Dimensional Flow Analysis Methodology for Assessing Stream Stability and Channel Migration 


\subsection{Bed and Bank Shear Stress}

The river bed and bank shear stress distributions are presented in this section for flow rates from $1,000 \mathrm{cfs}$ and $20,000 \mathrm{cfs}$. The shear stress on the river bed and banks is a product of the detailed three-dimensional CFD flow solution through the river reach. As noted in Section 4.2, the shear stress on the river bed and banks is computed using the k-epsilon turbulence model wall functions in an all $y^{+}$treatment. In this turbulence model the wall shear stress is a function of the velocity and turbulent kinetic energy, $k$, at the cell centroid in a computational cell adjacent to a river bed or bank boundary cell face. As previously noted, the case of 1,000 cfs was run as a rigid lid single phase model that included only the channel, and consequently the river bed and bank shear stress color plotted in Figure 4-4 for the 1,000 cfs case shows only the channel. The other cases from 2,000 cfs and greater where modeled as two phase flows with water and air above using a VOF model and included the flood plains. Most of the area of the flood plains had only air or slow moving water in the flood plains, and consequently, the shear stress is near zero of dark blue in color. At the higher flow rates, 7,000 cfs and higher, parts of the flood plains have light blue color, indicating a shear stress that is still relatively low, but at least high enough to show on the color scale. Note also that the shear stress value corresponding to the maximum red color increases dramatically from $5 \mathrm{~Pa}$ in the plot for 1,000 cfs to $120 \mathrm{~Pa}$ in the plot for the 20,000 cfs flow. Adjusting the value of the stress corresponding to the red color allows the shear distribution to be visible in a nearly full range of colors for all of the widely varying case flow rates.

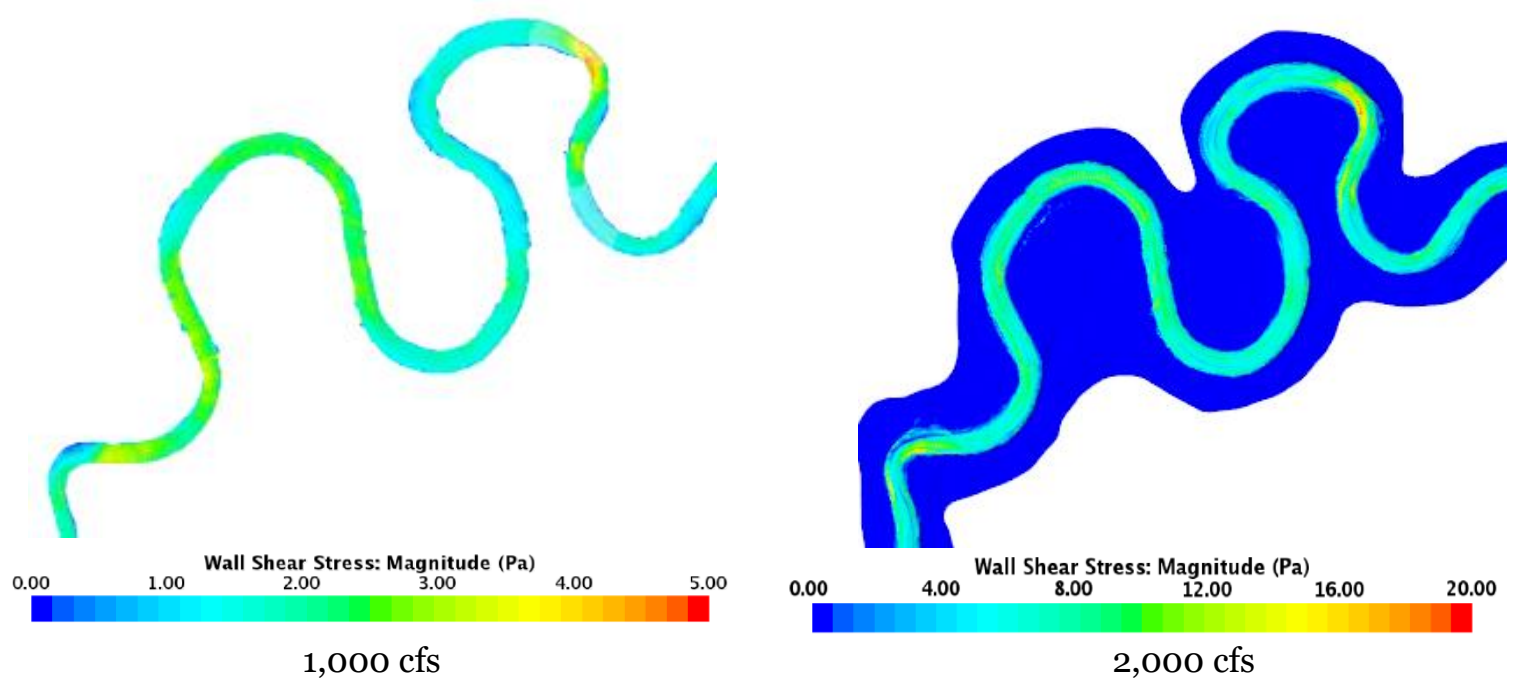

Three-Dimensional Flow Analysis Methodology for Assessing Stream Stability and Channel Migration 

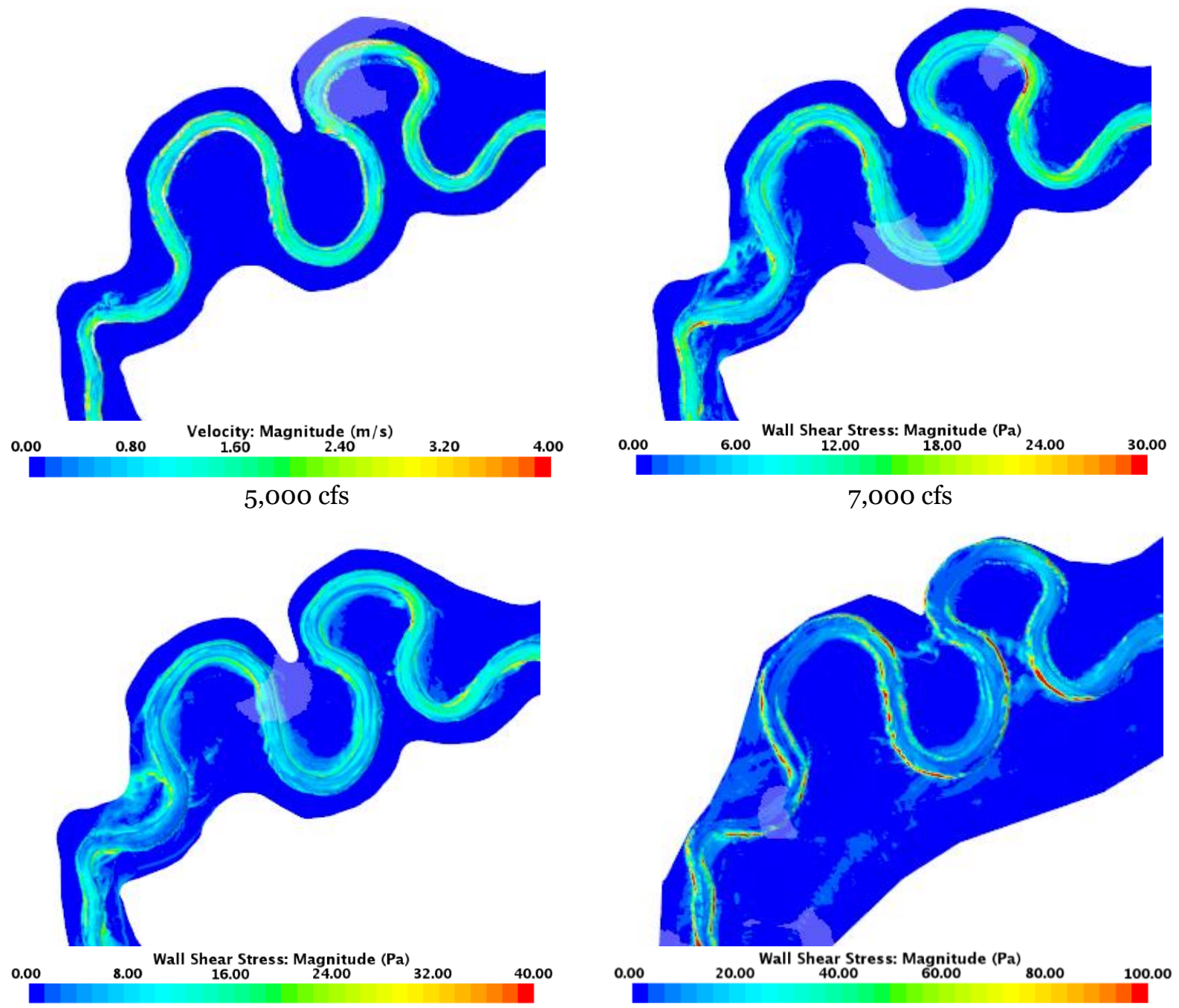

$9,000 \mathrm{cfs}$

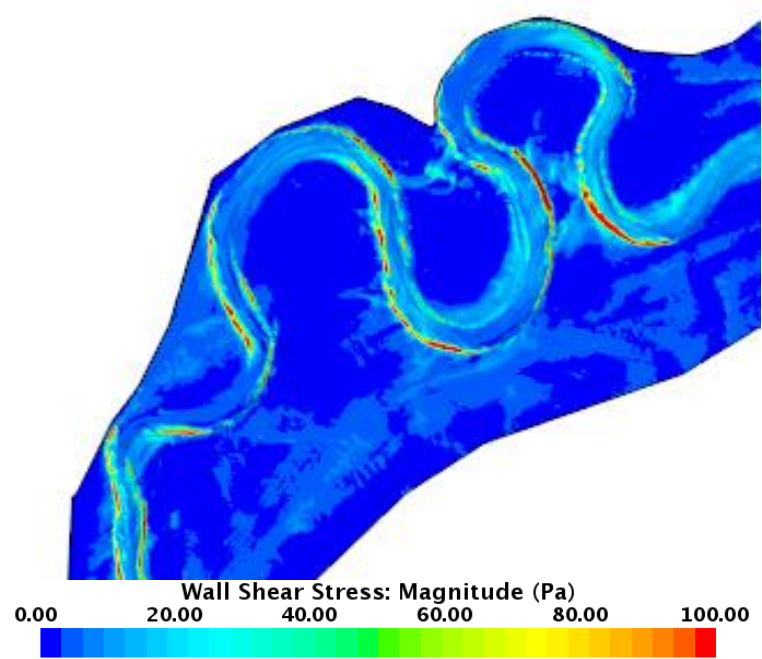

$15,000 \mathrm{cfs}$

$12,000 \mathrm{cfs}$

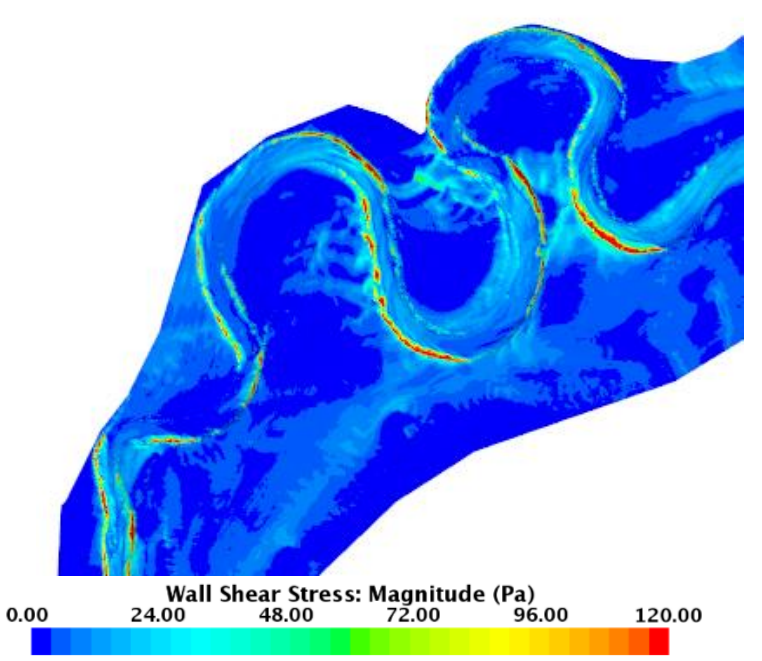

$20000 \mathrm{cfs}$

Figure 4-4: Shear stress distribution on the bed surface for discharges 1,000 to 20,000 cfs.

Three-Dimensional Flow Analysis Methodology for Assessing Stream Stability and Channel Migration 


\section{Estimation of the Stream Bank Erosion Rate and Migration Distance}

There are two primary causes of stream bank migration: surface erosion and collapse of a steep channel bank. Surface erosion is caused by hydrodynamic shear forces acting on the banks during high velocity flows, while bank failure can be attributed to the seepage forces and freeze-thaw cycle, which weaken the internal shear strength of the soil mass. Furthermore, surface erosion changes the geometry of the bank. Bank erosion when the stream is not bank full leads to stream bank overhangs, which are prone to collapse.

Bank erosion is one of the main factors that influence changes in a river bathymetry, and many rivers have the potential to undergo significant bank migration. Three-dimensional CFD analysis provides a way to compute the detailed forces of water on stream bank that are a primary driver of erosion. This type of analysis combined with a bank failure model due to gravity on steep and overhanging slopes and a method to move the stream banks and bed in a large computational domain promises to provide very accurate predictions of stream bank migration. While such capabilities are emerging in $3 \mathrm{D}$ CFD scour models, the scale of the model for even a few bends with a potential to migrate several hundred feet is currently beyond the computer resource capacity of even relatively large computer clusters, and not currently feasible.

An alternative modeling approach for stream bank migration that captures most of the benefits to the $3 \mathrm{D}$ CFD analysis of the stream flow through bends treats the stream bathymetry and surrounding land topology as static, but obtains detailed shear stress and water level maps for flow through the bends for a set of discharges. The results of the analysis can be used to obtain a quasi-steady bank migration rate and distance for the flow conditions on any given day. Using a hydrograph to provide daily discharges through the river reach with bends provides a discrete set of up to thousands of small daily bank migration increments that may be summed to obtain a total migration over a long period of time and assess the time frame of potential risk to roads and other structures due to active stream migration.

The following chapters present a new methodology for assessing bank erosion rates and distances that combines the use of: hydrographs, historical scans of the river topology, and geotechnical surveys with computational modeling. The proposed methodology for assessing river bank migration consists of the following steps, and it is illustrated in Figure 5-1:

1. Obtain at least one scan of the river bathymetry with the geometry as detailed as possible. Use the bathymetry data to build a $3 \mathrm{D}$ geometry model of the river reach that serves as a basis for a series of CFD simulations of the river flow under varying flow rates. Shear stresses on the river banks and bank full fractions are derived from the computations.

2. Obtain a daily hydrograph from a measurement station that is as close as possible to the river reach being analyzed and provides a good measure of the flow in the reach.

3. Obtain the soil conditions in the area of interest, including material properties that are needed in the bank erosion rate formula. If the material characteristics are not available, then other methods should be considered. An alternative methodology proposed and demonstrated in this work requires a set of historic images of the river bends of interest (source: google maps or USGS). The more images of the changing topology are available, the more detailed the forecast of the stream migration will be. The historic migration obtained from these images is then used to fit bank soil erosion rate material property parameters in a bank erosion rate function of shear stress.

Three-Dimensional Flow Analysis Methodology for Assessing Stream Stability

and Channel Migration 
4. Perform an interpolation procedure that yields daily average eroding bank shear stress and bank full fraction on a section of the bank subject to rapid erosion from the daily discharge and the shear stress computed in CFD simulations of bounding discharges.

5. Calculate the daily erosion rates to get the daily erosion distance and sum them up to get total erosion distance for sections of river bank for a chosen time period.

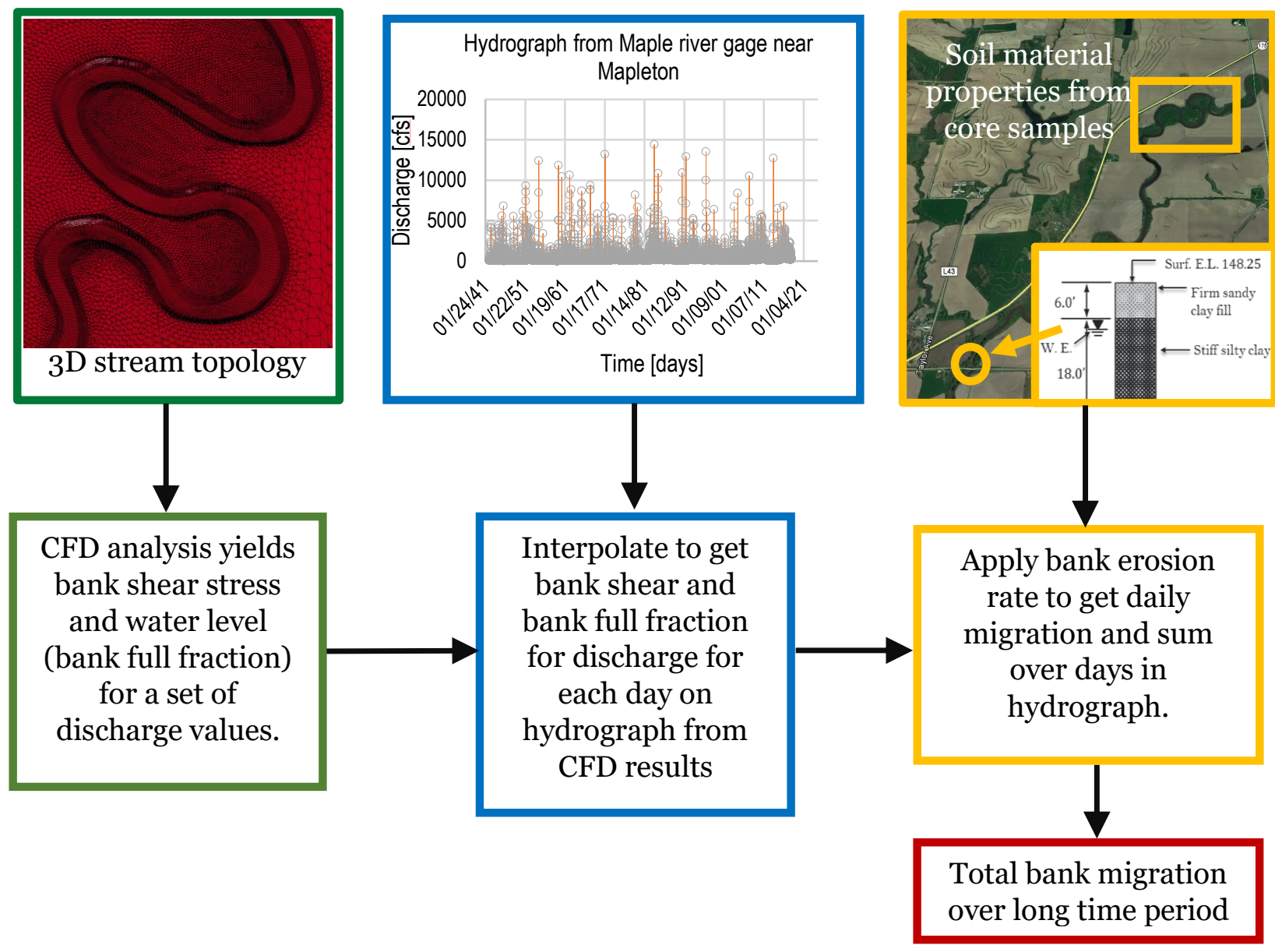

Figure 5-1. Schematic of stream bank migration estimation methodology for long time periods.

This methodology of analysis was applied to four meanders of the Maple River, located in the vicinity of Highway 175, as shown in Figure 5-2. One of them (number 1) migrated several hundred feet in recent decades towards the road, and is currently within approximately 100 feet of the Highway 175 Right-of-Way. The forecasting of its migration is important for determining when intervention to protect the road will be needed. The other area of interest is located near bend number 3, where the banks of the river in a horseshoe bend are only approximately 106 feet away from each other (as of 2016). Any future erosion at this location may result in a cutoff event which may significantly affect the flow at bend number 1 . The goal of the analysis is to show when, and under what conditions: (1) bend number 1 reaches the road, as well as (2) when the horseshoe bend between bend number 2 and 3 may be cut off. 
(a)

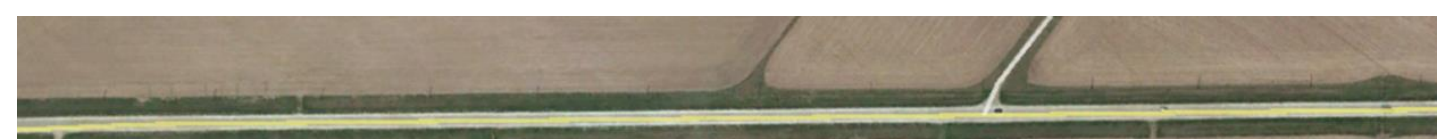

(b)
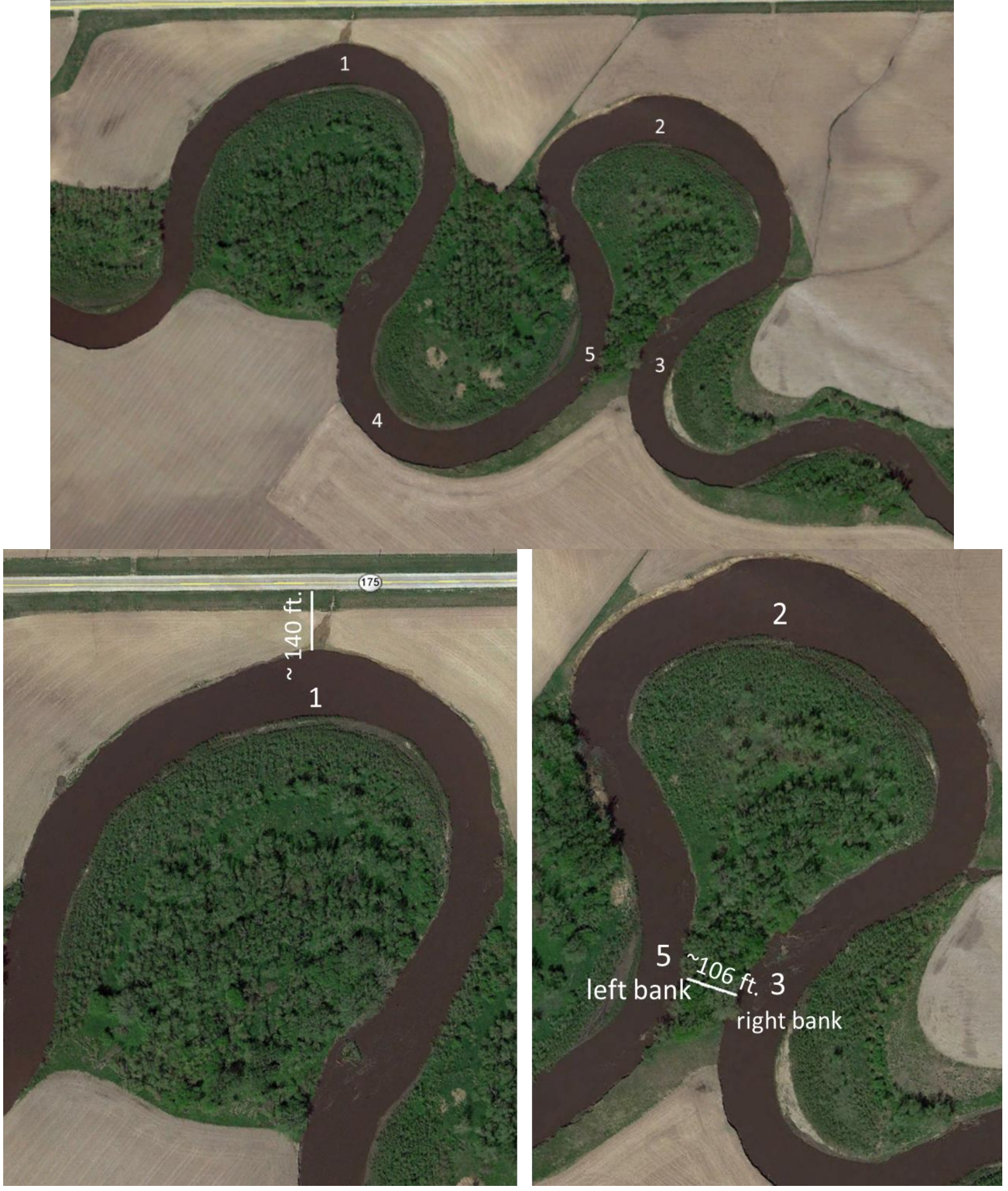

Three-Dimensional Flow Analysis Methodology for Assessing Stream Stability and Channel Migration 
(c)

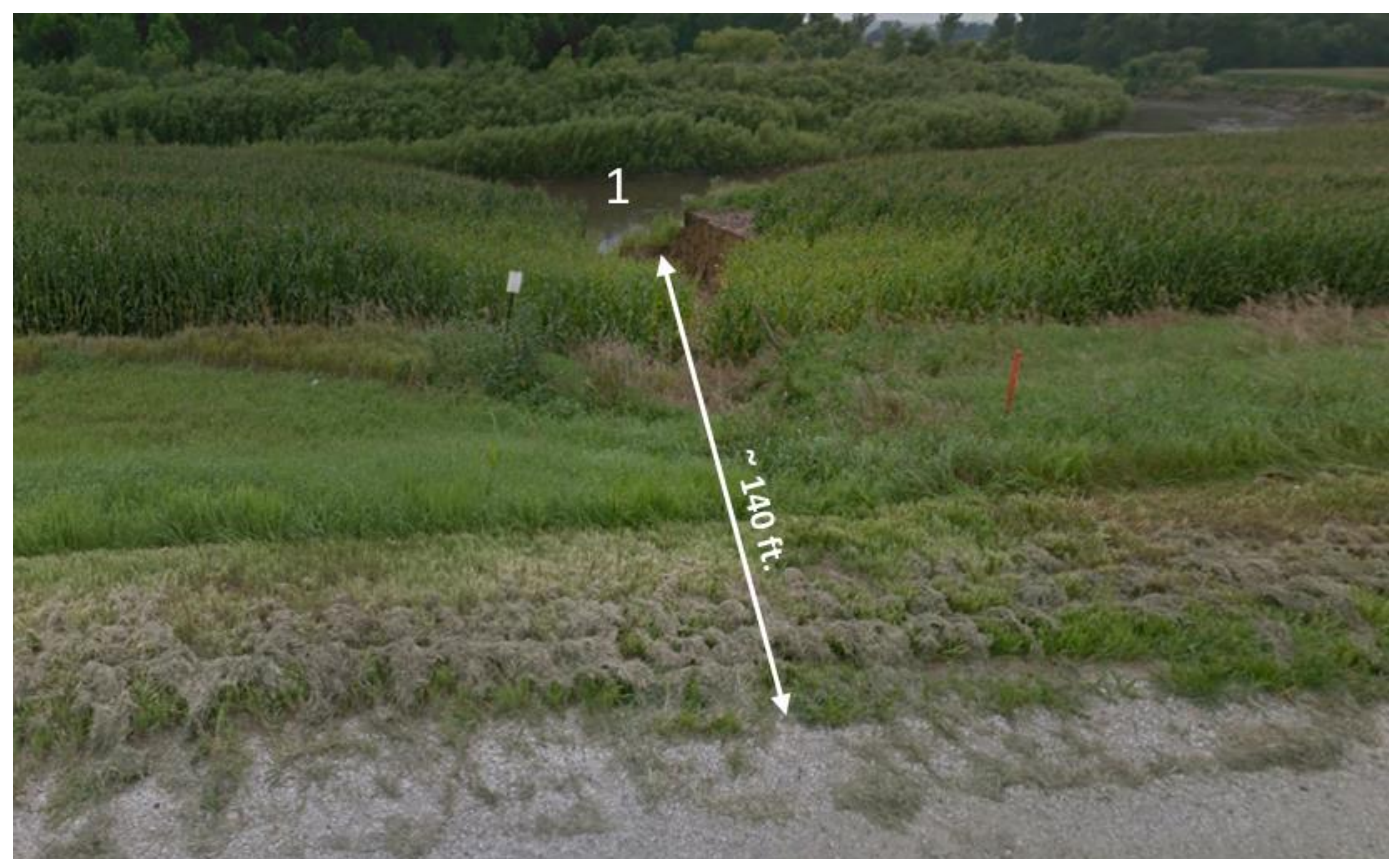

Figure 5-2: Images of the meanders of the Maple River closest to Highway 175 in (a) and (b). A snapshot of river from highway 175 in (c). In 2016 the riverbank near bend-1 was less than $140 \mathrm{ft}$ away from pavement and $80 \mathrm{ft}$ from the highway shoulder. Source: Maple River at $\left[42^{\circ} 15^{\prime} 57 \cdot 51^{\prime \prime} \mathrm{N}, 95^{\circ} 40^{\prime} 42.17^{\prime \prime} \mathrm{W}\right.$, Google Earth.
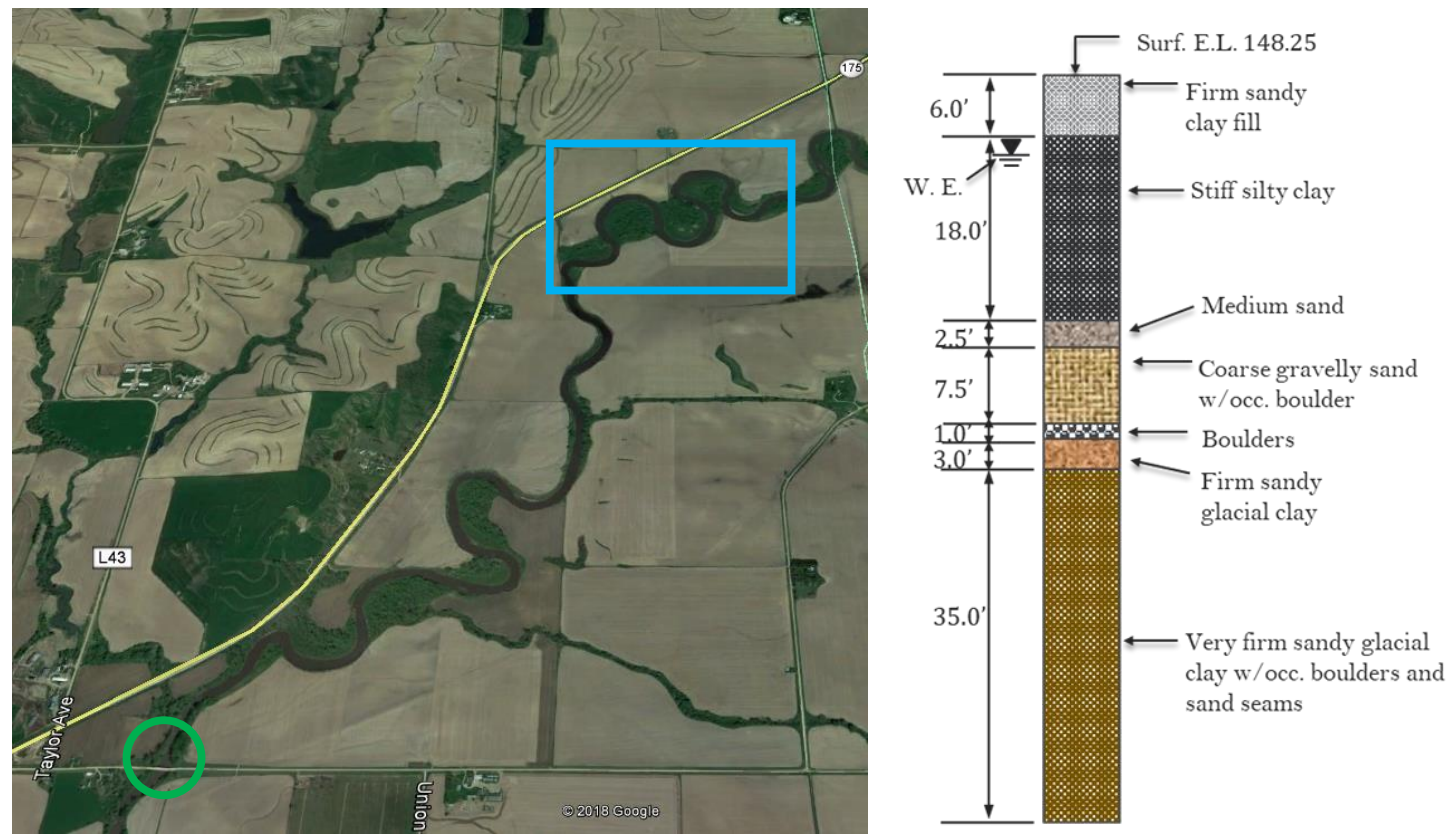

Figure 5-3: The boring location (in green circle) on left [image source: google earth] and the boring log data analysis on right from Iowa DOT Project HR-292 (1989) [11]

Three-Dimensional Flow Analysis Methodology for Assessing Stream Stability and Channel Migration 


\subsection{Assessment of the Soil Type}

Information on soil conditions in the area of interest was not available to the researchers. Soil material data was available from a boring log done 3 miles downstream of the point of interest [11]. The boring location and the results of the boring log data analysis are shown in Figure 5-3. The boring log data show the type of soil found on site and the water table. The top 6 feet of soil was classified as firm sandy clay. Below, stiff silty clay was found, up to the depth of 24 feet. This suggests that the stream banks are formed by sandy clay, while the river bed consists of silty clay. Both types of soil contain about $40 \%$ to $50 \%$ of clay, with sediment particle size less than 2 microns. Furthermore, the riverbed soil is more cohesive as it contains more silt (particle size less than 50 micron) than the bank soil. The content of clay in the bank soil determines the erosion resistance of the bank soil, with a higher clay content usually meaning a lower erosion rate.

\subsection{Near-bank Shear Stress Distribution Obtained from CFD Models}

Shear stress distributions along the stream banks obtained in the CFD simulations are shown inFigure 4-4. The bank shear was averaged for each of the four banks over small patches shown in Figure 5-4. These patches follow the bank lines, covering an approximately 80 to 120 -degree sector of the arch length. Their thickness is small, to include only the stream bank surface. An area weighted averaging of shear stress was performed over non-zero values, omitting the locations where shear stress was equal zero. The average bank height and water depth were also recorded for these sections of river bank at the bends.

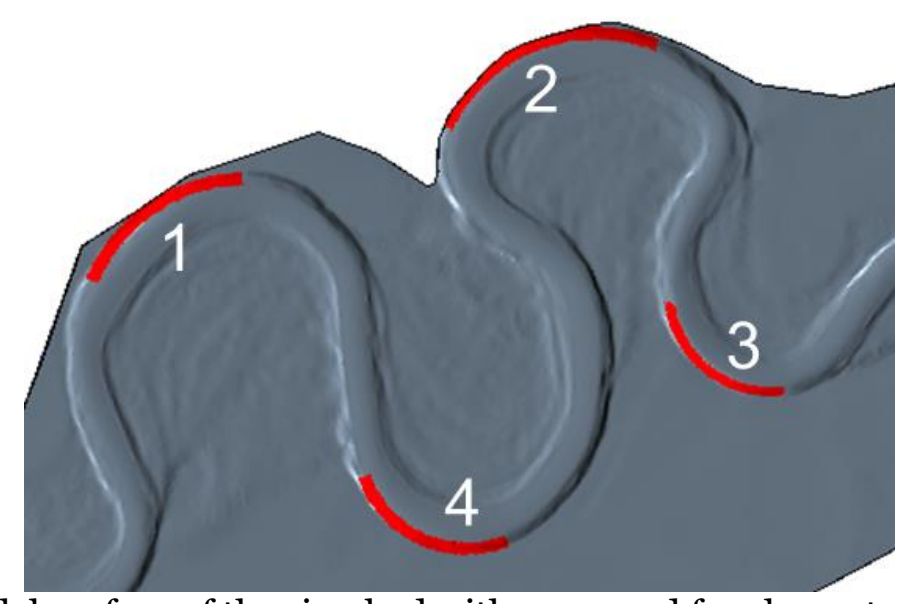

Figure 5-4: The model surface of the riverbed with area used for shear stress averaging (in red)

\subsection{Stream Bank Lateral Erosion Rate and Distance}

The fluvial erosion rate is quantified using an excess shear stress formula [9] and expressed as:

$$
\dot{x}_{\perp}= \begin{cases}k_{d}\left(\frac{\tau}{\tau_{c}}-1\right)^{m} & \text { if } \tau>\tau_{c} \\ 0 & \text { otherwise }\end{cases}
$$

Three-Dimensional Flow Analysis Methodology for Assessing Stream Stability and Channel Migration 
where $\dot{x}_{\perp}$ is lateral erosion rate $(\mathrm{mm} / \mathrm{hr}), k_{d}$ is the erodibility coefficient $(\mathrm{mm} / \mathrm{hr}), \tau$ is the average hydraulic bank shear stress $(\mathrm{Pa}), \tau_{c}$ is the critical shear stress $(\mathrm{Pa})$, and $m$ is an empirical exponent. When the shear stress exerted by water exceeds $\tau_{c}$ of the soil, erosion process begins at a rate that is proportional to the erodibility coefficient. The three erosion parameters in Equation (9) depend on the soil type. They may be determined by testing soil from samples taken from the site in a laboratory. In this study the material properties of the soil relating to erodibility were not available from laboratory testing. Approximate values were known [11] based on the soil type described in Section 5.1. These values did not yield a good match with historical bank migration when tested, and therefore, they were used only as a starting point in tuning the soil erosion rate parameters as described below in Section 5.5. Once an effective bank erosion rate is known for a given flow condition in the channel, lateral bank erosion can be estimated for time period where the same flow conditions exist in the channel.

The lateral erosion distance, $L E$, can be calculated as:

$$
L E=\dot{x}_{\perp} \Delta t h_{f}=\left\{\begin{array}{cc}
k_{d}\left(\tau / \tau_{c}-1\right)^{m} \Delta t h_{f} & \text { for } \tau>\tau_{c}, \\
0 & \text { otherwise }
\end{array}\right.
$$

where $\Delta t$ is the duration of discharge, and $h_{f}$ is the bank full fraction of the stream bank, which is equal to the water depth divided by the bank height. The assumption here for the lateral erosion distance is that when the water depth is less than the bank height, erosion into the bank proceeds with soil collapsing from above the water depth into the water settling onto the submerged bank, and that this material must then also be eroded and carried away. The assumption is that the erosion rate of collapsed material above the water line is the same as that of the undisturbed bank. This should be a conservative assumption because at least some of the collapsed soil should be looser and therefore easier to entrain than the original undisturbed bank. Note that the bank may collapse in chunks and that the interior of a chunk may be as resistant to entrainment as the undisturbed bank.

\subsection{Hydrograph Data}

Hydrograph data provides the daily discharge through the reach of a stream of interest. The nearest USGS stream gage in the area of interest is gage number 06607200 in Mapleton, IA, which is located 14.5 miles downstream of the study area, positioned on the right bank on the downstream side of Highway 175 bridge (Front Street). This gage has been active since 1941, and collects daily discharge data along with monthly and annual peak flows. The daily recorded peak flows over the past 25-year period varied from $282 \mathrm{cfs}$ in year 2000 to $13500 \mathrm{cfs}$ in year 1996, while the all-time high peak flow was 20,800 cfs, and happened in 1978. Data from this stream gage was assumed to be sufficiently close to the study area to be used to provide the daily discharge in the stream reach of interest.

CFD simulation could be used to obtain the effective shear stress for bank migration and the bank full fraction for the discharge conditions on any particular day, and these values could be used to estimate lateral bank migration for that day. Doing this to estimate bank migration for any long period of time, however, would be impractical due to the very large number of CFD simulations that would have to be run. In this study a set of CFD simulations was run for discharges spanning the range of historical discharges, giving the bank full fractions and effective bank shear stress for discharges in the set. The effective bank shear stress and bank full fraction for a particular bank

Three-Dimensional Flow Analysis Methodology for Assessing Stream Stability and Channel Migration 
and discharge on a given day are obtained by interpolating between the CFD results for the next lower and higher discharge in the CFD computation results as described in Section 3

$$
\text { Interpolation }\left(V^{-}, V^{+}, \tau^{-}, \tau^{+}, h_{f}^{-}, h_{f}^{+}\right) \stackrel{\text { yields }}{\longrightarrow}\left(\tau_{i}, h_{f, i}\right) \text { for a given day } i
$$

where $V$ is a discharge and superscripts '-' and '+' refer to the CFD simulation results for the next lower and higher discharges. Once the bank shear and bank full fraction are estimated for a given day, then the bank migration distance for that day may be estimated from Equation (11) and the total bank migration distance, $L E_{\text {total }}$, for a given hydrograph may be calculated as:

$$
L E_{\text {total }}=\sum_{i}^{n} \dot{x}_{\perp, i} h_{f, i}=\left\{\begin{array}{cc}
k_{d}\left(\tau_{i} / \tau_{c}-1\right)^{m} h_{f, i} & \text { for } \tau_{i}>\tau_{c} \\
0 & \text { otherwise }
\end{array},\right.
$$

where subscript $i$ indicates a quantity obtained from the discharge for day $i$ in the hydrograph, $n$ is the number of days in the hydrograph, and the time period for incremental bank migration, $\Delta t=1$ day, is implicit and therefore not shown.

Figure 5-5 shows the hydrograph data for the entire gage operation period, from 1990 to 2018. The information obtained from the daily discharge plot was used to do estimations of the past migration with the methodology reported here to obtain soil erosion model constants, and to predict the future erosion. The hydrograph was used to assess future migration potential in an unchanged form, assuming the hydrograph of the future would repeat that of the past, and in a modified form to create hypothetical weather scenarios to explore the effect of various variations of more extreme weather conditions on stream migration rates.

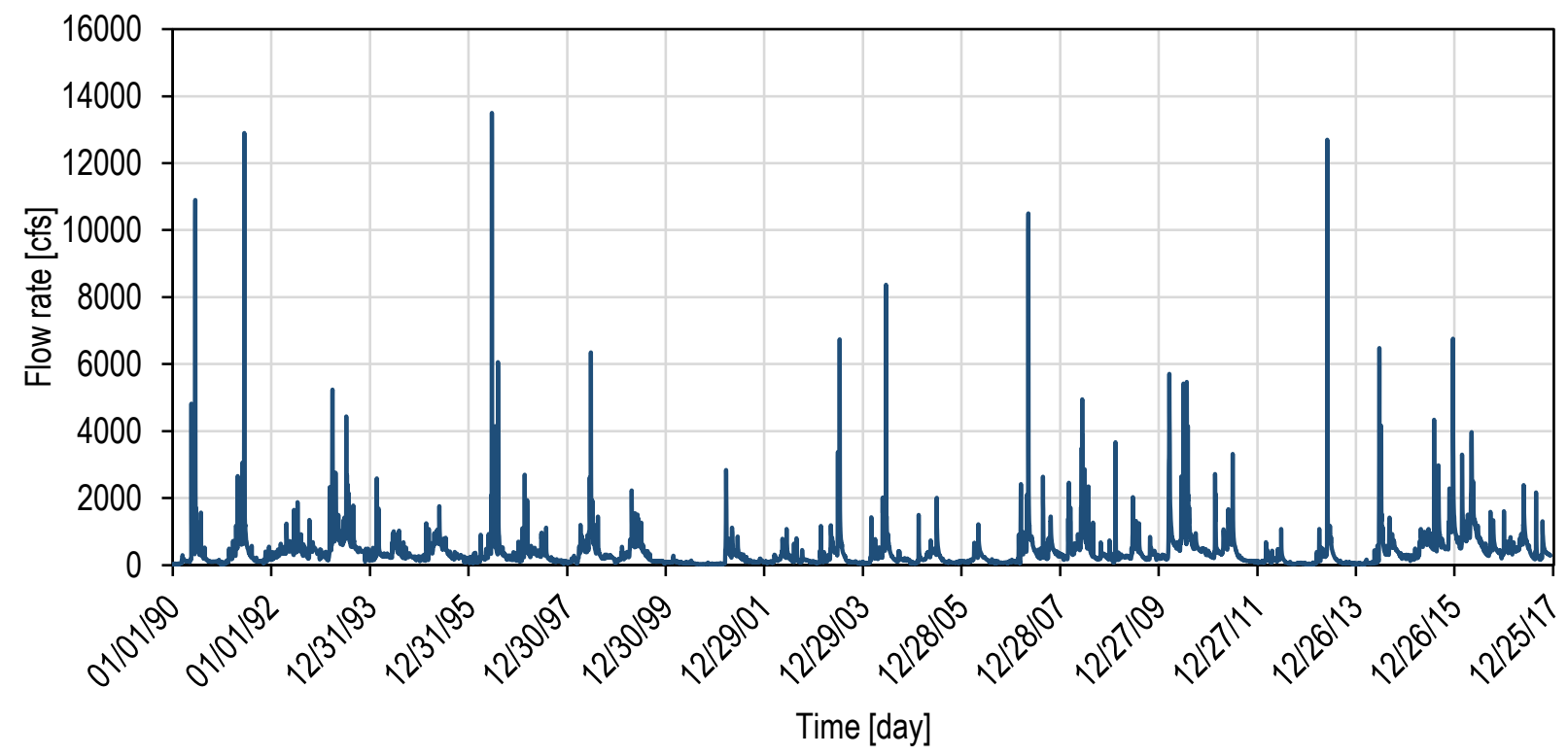

Figure 5-5: Hydrograph for the Maple River from a gage located near Mapleton (USGS gage number 06607200) U.S. Geological Survey, 2018, National Water Information System data [12]

\subsection{Using Historic Channel Imagery to Tune the Erosion Rate Function}

Historic satellite images of the studied section of Maple River from years from 1990 to 2016 were combined in Figure 5-6. They show the lateral bank migration over the years.

Three-Dimensional Flow Analysis Methodology for Assessing Stream Stability and Channel Migration 

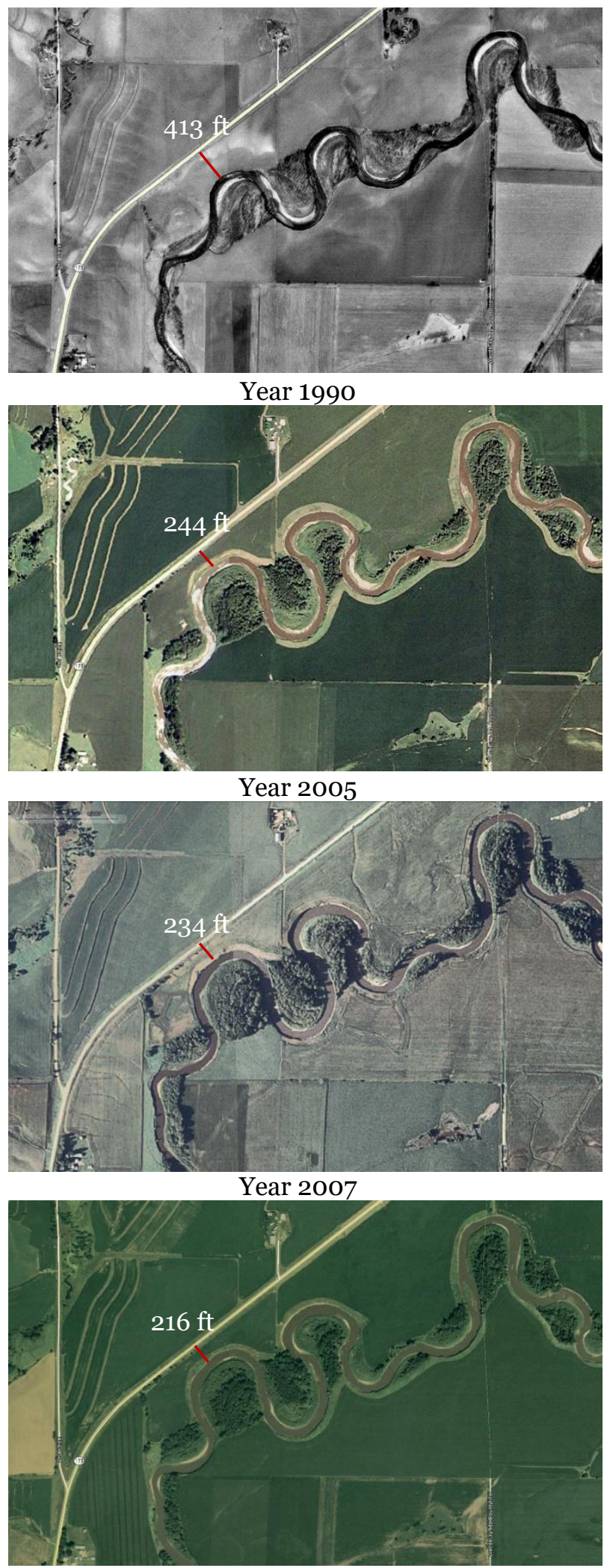

Year 2009

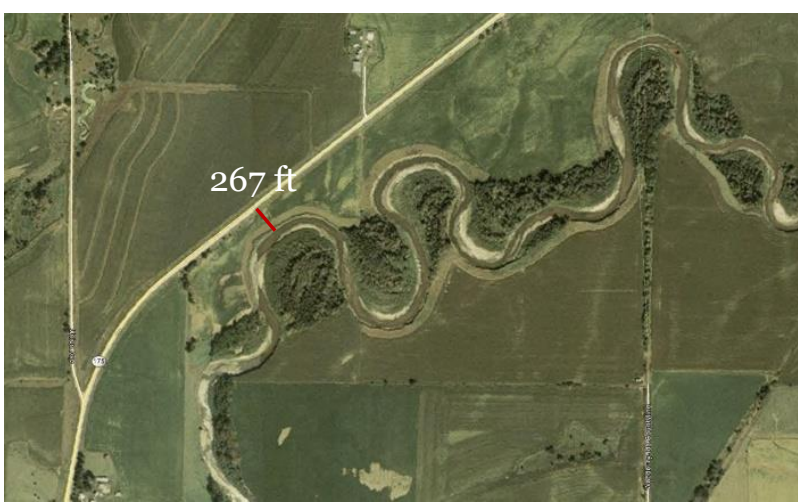

Year 2004

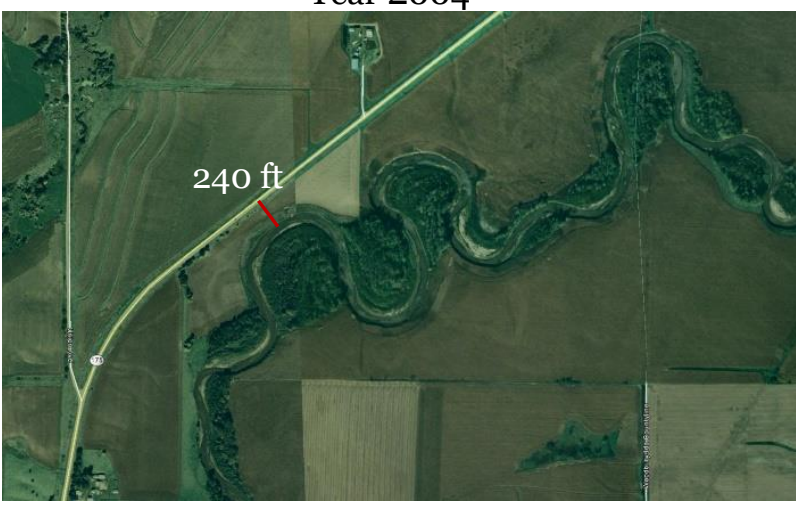

Year 2006

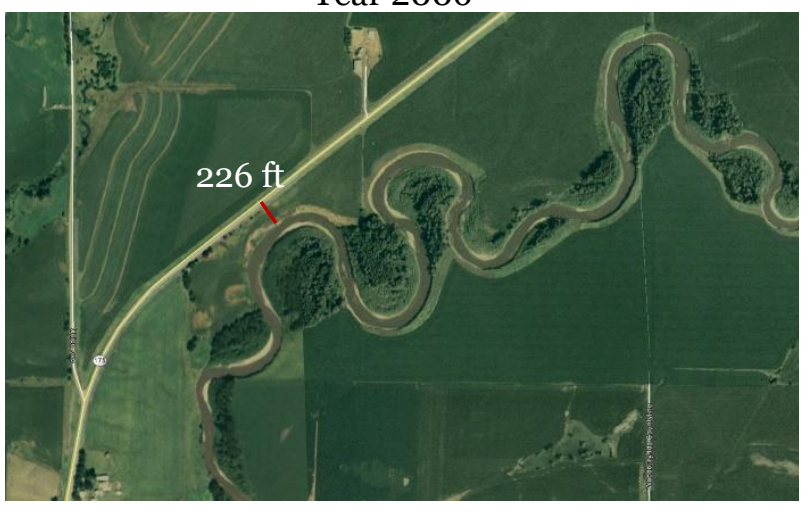

Year 2008

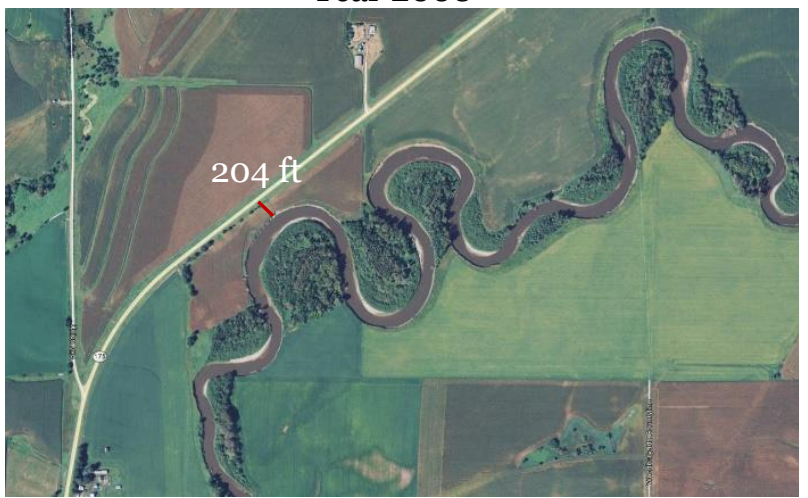

Year 2010

Three-Dimensional Flow Analysis Methodology for Assessing Stream Stability and Channel Migration 


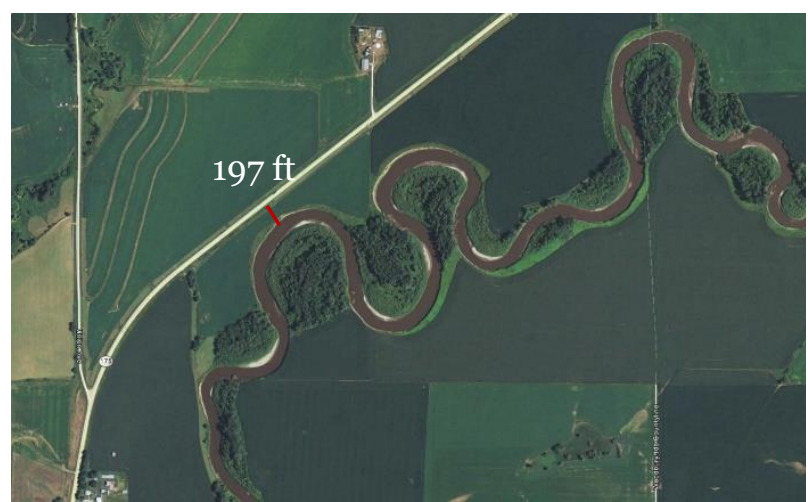

Year 2011

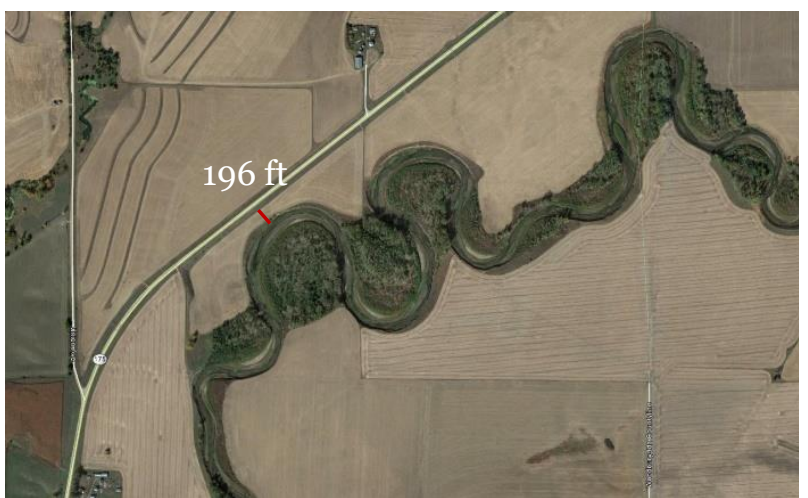

Year 2012

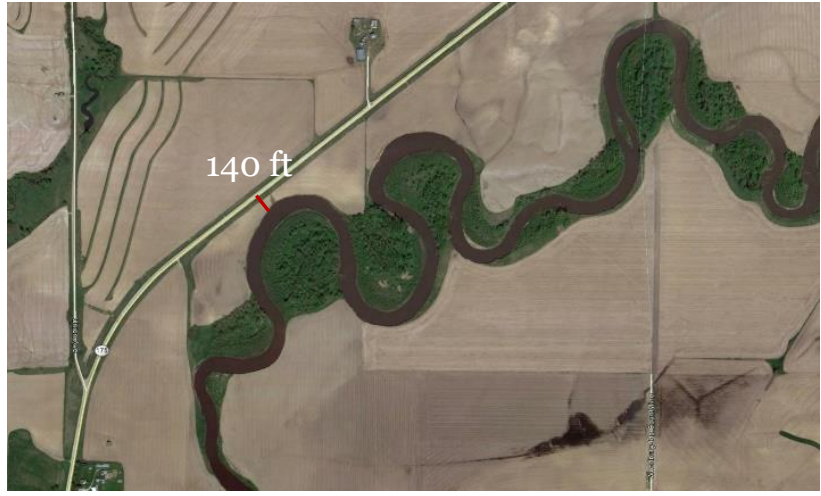

Year 2016

Figure 5-6: Historic imagery for Maple River at [ $\left.42^{\circ} 15^{\prime} 57.51^{\prime \prime} \mathrm{N}, 95^{\circ} 40^{\prime} 42.17^{\prime \prime} \mathrm{W}\right]$ from 1990 to 2016. Accessed via Google Earth historic imagery from google earth V7.1.8.3036 (February 2, 2018)

\subsubsection{Determination of the Bank Migration Direction from Imagery}

Channel meanders migrate laterally due to the erosion of the outside banks. On the inside of the bend in turn, the lower velocity results in the deposition of the sediment. A comparison of the historic position of the bank-lines, and of the movement of the centroids of the arcs covering the bank-lines, can be used to predict the potential future position of a bend based on the past channel migration characteristics [4]. Meandering direction estimation for years 1990-2016 is shown in Figure 5-7. The arrows, marked in red and yellow, connecting the centroids of the arcs covering bank-lines of successive years, show the historic migration direction and indicate the most probable future migration direction of the bend. The red arrow shows the bank migration direction during the period 1990 - 2005, while the arrow in yellow shows the change in migration direction for years 2005 - 2016. 


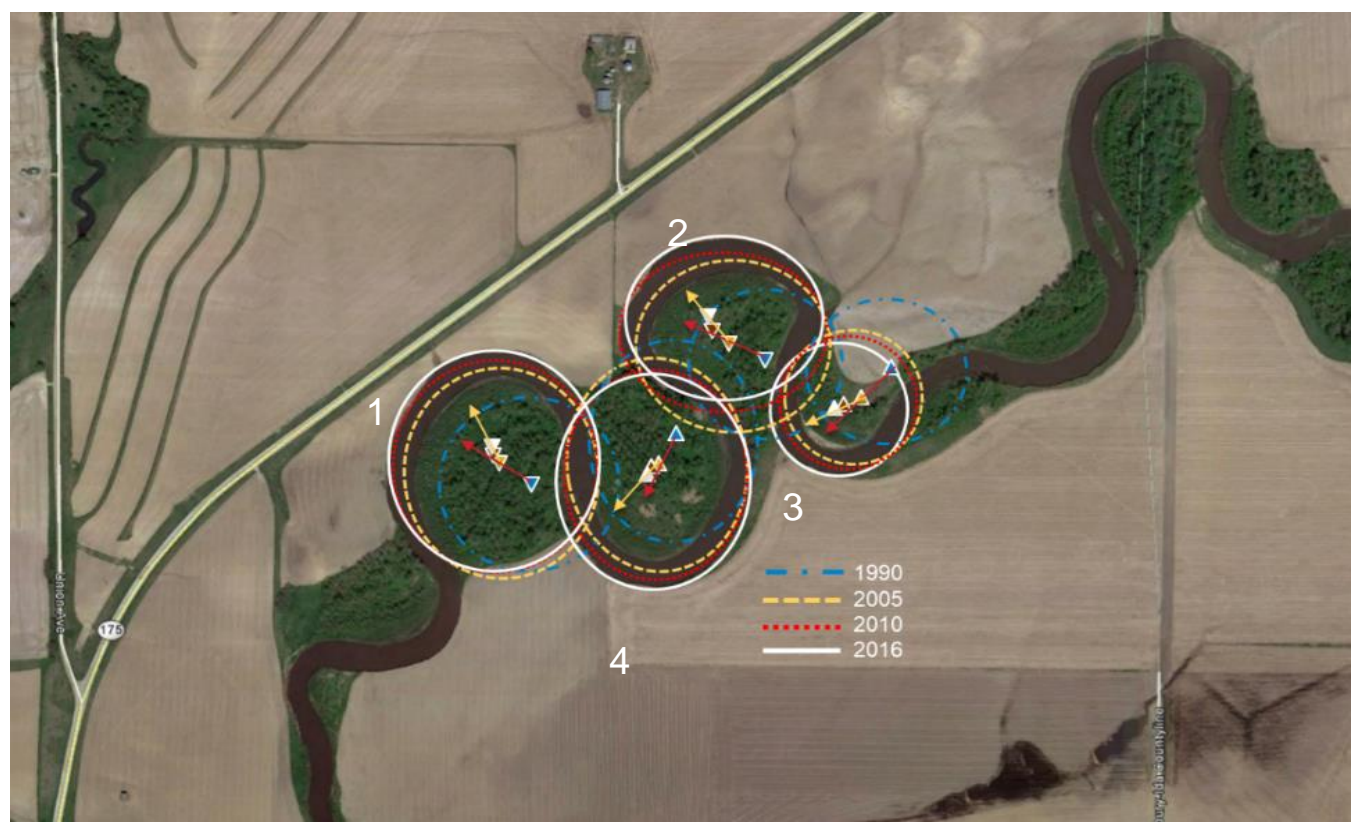

Figure 5-7: Determination of the migration direction of meander loops based on the movement of the centroids of the circumscribed arcs [4]

\subsubsection{Determination of the Bank Migration Distance from Imagery}

The historical outer bank migration was measured by overlaying the available images of the stream topography from years 1990-2016, establishing the direction of the movement, and measuring the distances between them. The measured bank migration distance was plotted in Figure 5-8 for bends number 1 to 4 for two time periods: from 1990 to 2016 and from 2005 to 2016. The bank migration for the 25-year period between 1990 and 2016 is shown in Figure 5-8 (a). The 1990 channel bank line is used as a baseline for the long-term channel movement estimation in this study. There is large gap between the data points between 1990 and 2005 because no reliable topological data was available for this period. The maximum migration of $\sim 370 \mathrm{ft}$ occurred at bend number 2 , followed by a $\sim 280 \mathrm{ft}$ migration at bend number 1 .

Figure 5-8 (b) displays a plot, with the topology from 2005 adopted as an initial state, showing the total migration for the last 10 years of the analyzed time period. This plot shows the variability of the bends' movements for same flow discharge for a given year.

Three-Dimensional Flow Analysis Methodology for Assessing Stream Stability and Channel Migration 
(a)

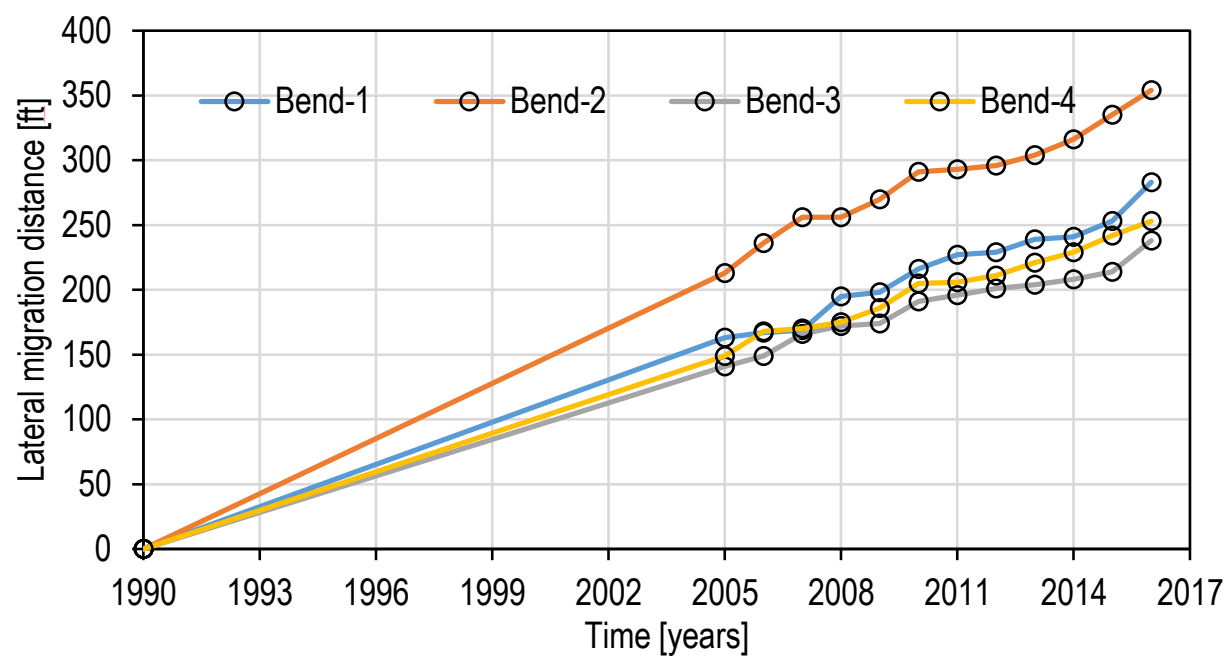

(b)

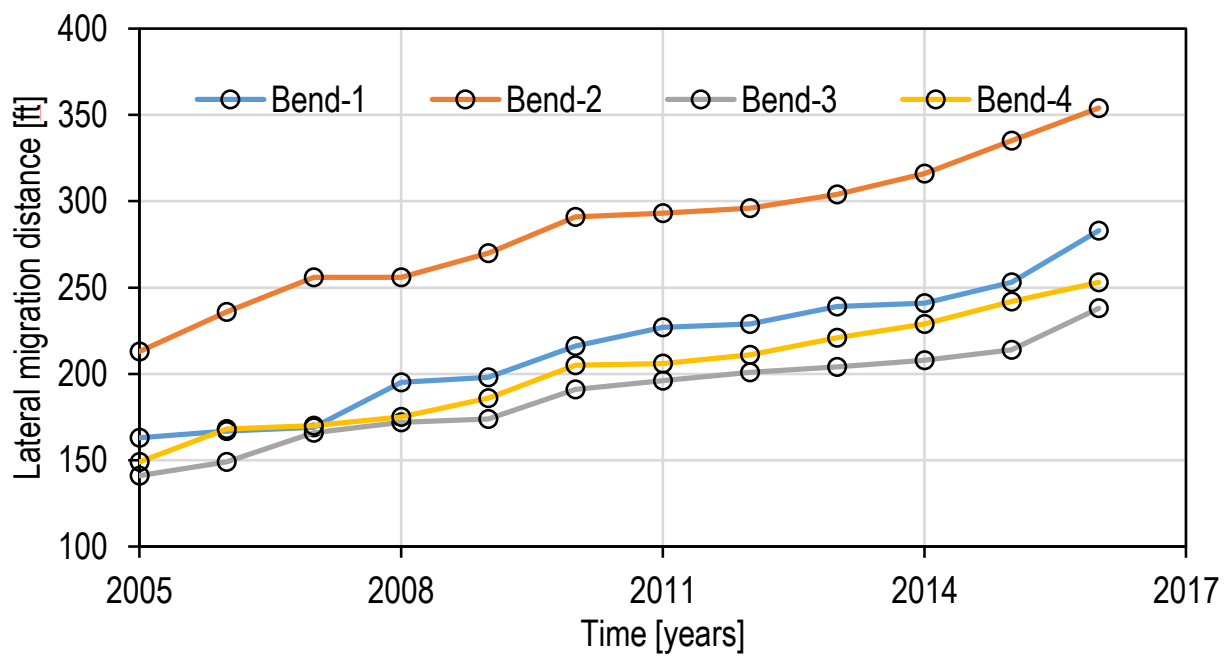

Figure 5-8: Historic migration of the banks during (a) a 25-year period (1990-2015), and (b) a 10-year period between 2006 and 2015.

The migration of the banks across the neck section between bend- 3 and bend- 5 shows some interesting aspects. The distance between the river bends i.e. the width of neck section in 1990 was equal approximately $440 \mathrm{ft}$ and it decreased to about $106 \mathrm{ft}$ by 2015 , as shown in Figure 5-9 (a). The plot in Figure 5-9 (b) shows the migration of the bends over the 25-year period. The right bank, bend 3 outer bank, experienced an almost constant annual average bank erosion. The left bank, bend 5 outer bank, in the first 15 years experienced a very small migration of 14 feet, as compared to 150-foot migration of the right bank. In the following 10-year period the erosion rate increased to the level of the right bank erosion rate. Overall, the left bank moved by a $100 \mathrm{ft}$ and the right bank moved by $238 \mathrm{ft}$.

Three-Dimensional Flow Analysis Methodology for Assessing Stream Stability and Channel Migration 
(a)
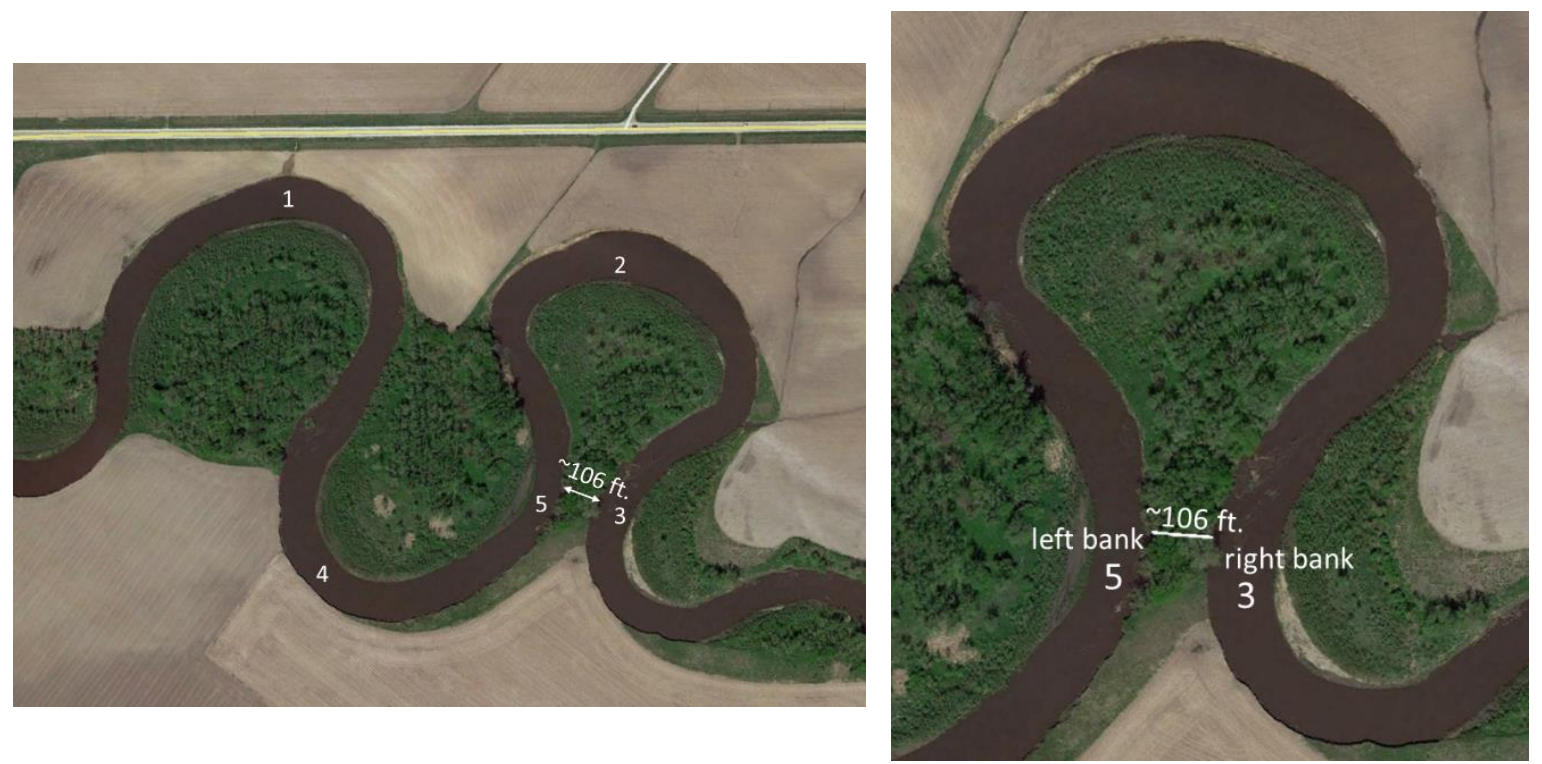

(b)

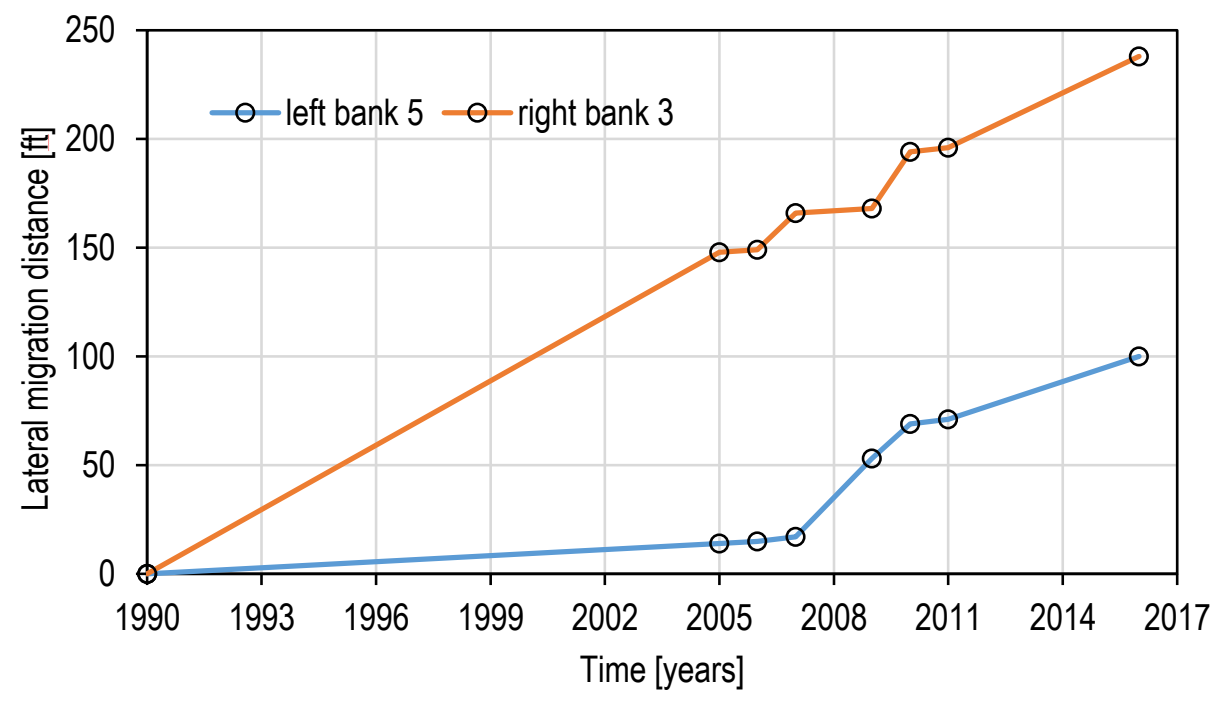

Figure 5-9: Migration distance analysis of the river banks at location 3; (a) image of the area in 2016 , (b) lateral migration of the banks during a 25-year period (1990-2015).

\subsubsection{Tuned Erosion Rate Parameters}

Equation (9) used to calculate the erosion rate of the river banks, contains three parameters, which need to be established for each site. The critical shear stress for the type of soil, $\tau_{c}$, was set to 2.0 Pa in this study based on the value for a similar soil in the FHWA report "Scour in Cohesive Soils," [9]. The historical data set from years 1990-2015 was partitioned into three sections consisting of data sets for years: 1990-2005, 2006-2015, and 2009-2015. The erodibility coefficient, $k_{d}$, and exponent $m$, are established through a minimization of the error between the historical and computationally estimated lateral erosion distances for the three time periods, with a special focus on the 2005-2016 date range. The 2005-2016 range was chosen for matching because more recent data was assumed to be more likely to be characteristic of future conditions. An ad-hoc minimization method was used with no special tool or algorithm employed for this purpose. It was setup in a spreadsheet and the minimum was found by iteratively entering refined Three-Dimensional Flow Analysis Methodology for Assessing Stream Stability and Channel Migration 
estimates of parameters until further refinement produced no further improvement. A part of the spreadsheet with the calculations was shown in Table 1. The CFD simulations provided information about the fraction of the bank height covered with water and averaged bank shear stresses on four bends of interest for a set of discharge levels, from $500 \mathrm{cfs}$ to $12,000 \mathrm{cfs}$.

Linear interpolation was used to compute water depths and shear stresses yielding erosion rates and distances corresponding to the daily hydrograph data. A third-party add-on to Microsoft Excel, XonGrid $\AA$, was used [10] to interpolate between CFD results. An ordinary kriging interpolation method from the XonGrid $囚$ library was used, with beta value of 1.5 and all reference points. This interpolation technique uses a weighted average of neighboring samples to estimate the unknown value at a given point. Use of kriging interpolation helps avoid over-estimation of values compared to simple mean, piecewise linear, and polynomial interpolations.

The daily migration distances were calculated with the use of formula (10) and then summed up, to obtain the total bank migration distances for each bend for a time period of interest. The overall relative difference of these erosion distances with respect to historical data for the three selected date ranges is presented in Table 4. The fitted values were chosen to minimize the relative difference for the years 2005-2016 while also maintaining close clustering of the percentage error among the four bends for all date ranges. Achieving this clustering helps to eliminate the influence of bank topology on the erosion rate parameters. The difference between predicted and historical migration is shown in Figure 5-10. A negative value in Table 4 indicates under-prediction of total erosion distance while a positive value corresponds to an over-prediction.

The fitted values of the erodibility coefficient and the exponent are: $k_{d}=1.583 \mathrm{~mm} / \mathrm{hr}$ and $m=1.4$. With $\tau_{c}=2.0 \mathrm{~Pa}$, the erosion rate relation for the soil at the river reach of interest is:

$$
\dot{x}_{\perp}= \begin{cases}1.583\left(\frac{\tau}{2.0}-1\right)^{1.4} & \text { if } \tau>2 \\ 0 & \text { otherwise }\end{cases}
$$


Table 1: Averaged CFD Results for Discharges up to 12,000 cfs

\begin{tabular}{|c|c|c|c|c|c|c|c|c|c|c|}
\hline & \multicolumn{5}{|c|}{ Bankfull fraction [-] } & \multicolumn{5}{|c|}{ Shear stress [Pa] } \\
\hline Discharge & Bend 1 & Bend 2 & Bend 3 & Bend 4 & Bend 5 & Bend 1 & Bend 2 & Bend 3 & Bend 4 & Bend 5 \\
\hline 0 & 0.00 & 0.00 & 0.00 & 0.00 & 0.00 & 0.00 & 0.00 & 0.00 & 0.00 & 0.00 \\
\hline 10 & 0.00 & 0.00 & 0.00 & 0.00 & 0.00 & 0.00 & 0.00 & 0.00 & 0.00 & 0.00 \\
\hline 500 & 0.24 & 0.21 & 0.20 & 0.19 & 0.20 & 3.19 & 3.18 & 2.81 & 3.05 & 2.68 \\
\hline 1,000 & 0.31 & 0.31 & 0.25 & 0.29 & 0.28 & 3.21 & 3.67 & 3.04 & 3.19 & 3.02 \\
\hline 2,000 & 0.40 & 0.35 & 0.36 & 0.37 & 0.36 & 5.20 & 5.83 & 5.41 & 5.13 & 5.07 \\
\hline 3,000 & 0.43 & 0.40 & 0.40 & 0.38 & 0.40 & 7.38 & 7.54 & 7.25 & 6.86 & 5.28 \\
\hline 5,000 & 0.49 & 0.47 & 0.45 & 0.48 & 0.46 & 7.57 & 8.31 & 9.29 & 8.76 & 6.06 \\
\hline 7,000 & 0.62 & 0.60 & 0.64 & 0.64 & 0.62 & 8.37 & 8.60 & 8.68 & 8.38 & 6.96 \\
\hline 9,000 & 0.76 & 0.70 & 0.70 & 0.76 & 0.70 & 8.85 & 9.63 & 11.90 & 11.97 & 11.61 \\
\hline 12,000 & 0.98 & 0.93 & 0.91 & 0.97 & 0.92 & 8.94 & 10.23 & 13.63 & $3 \quad 15.26$ & 15.35 \\
\hline
\end{tabular}

Three-Dimensional Flow Analysis Methodology for Assessing Stream Stability and Channel Migration 
Table 2: Bend Bank Shear Stress and Bankfull Fraction Interpolated from Table 1 with Discharge on Hydrograph Date

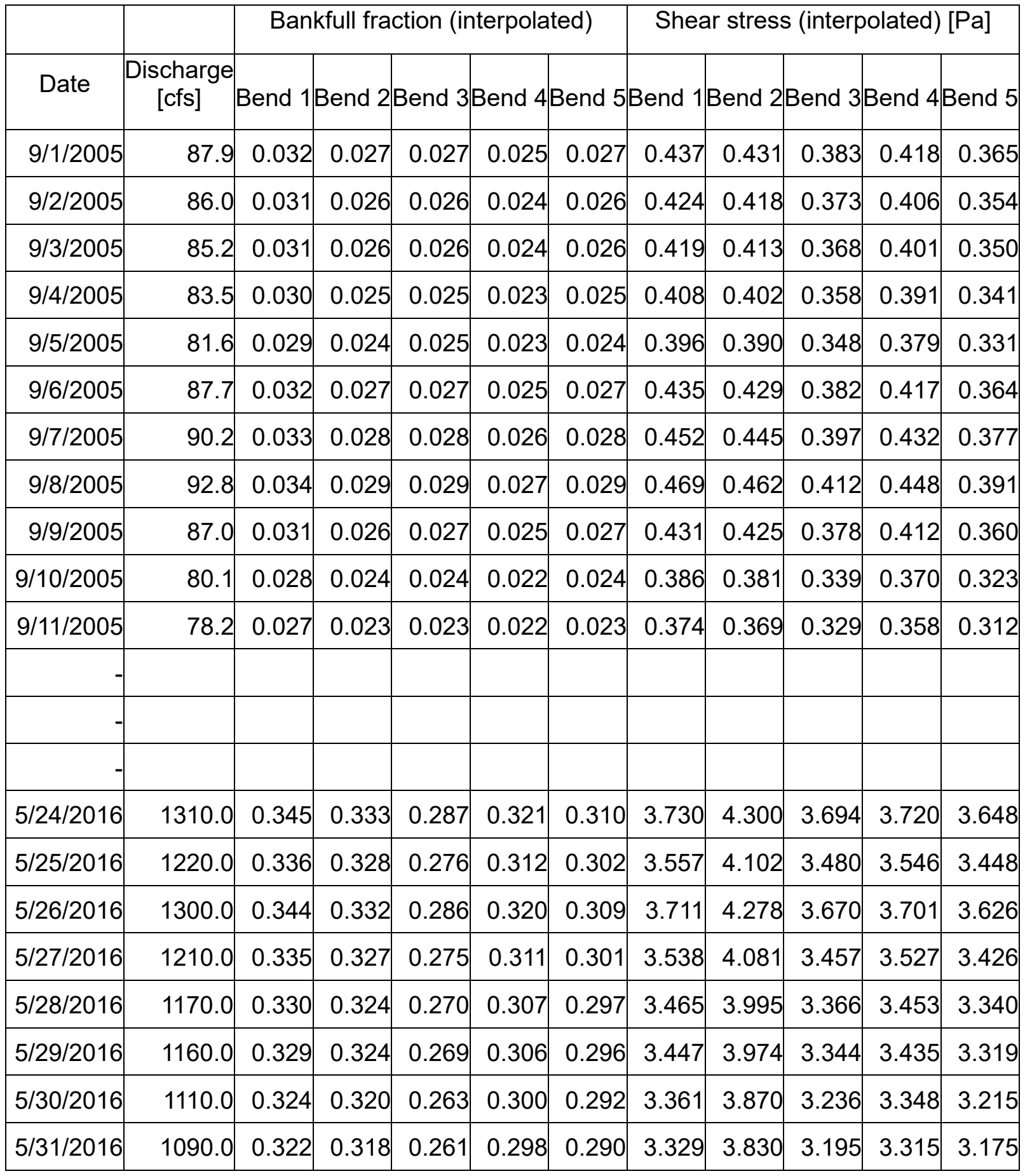

Three-Dimensional Flow Analysis Methodology for Assessing Stream Stability and Channel Migration 
Table 3: Daily Bank Migration Estimate Calculated from Table 2

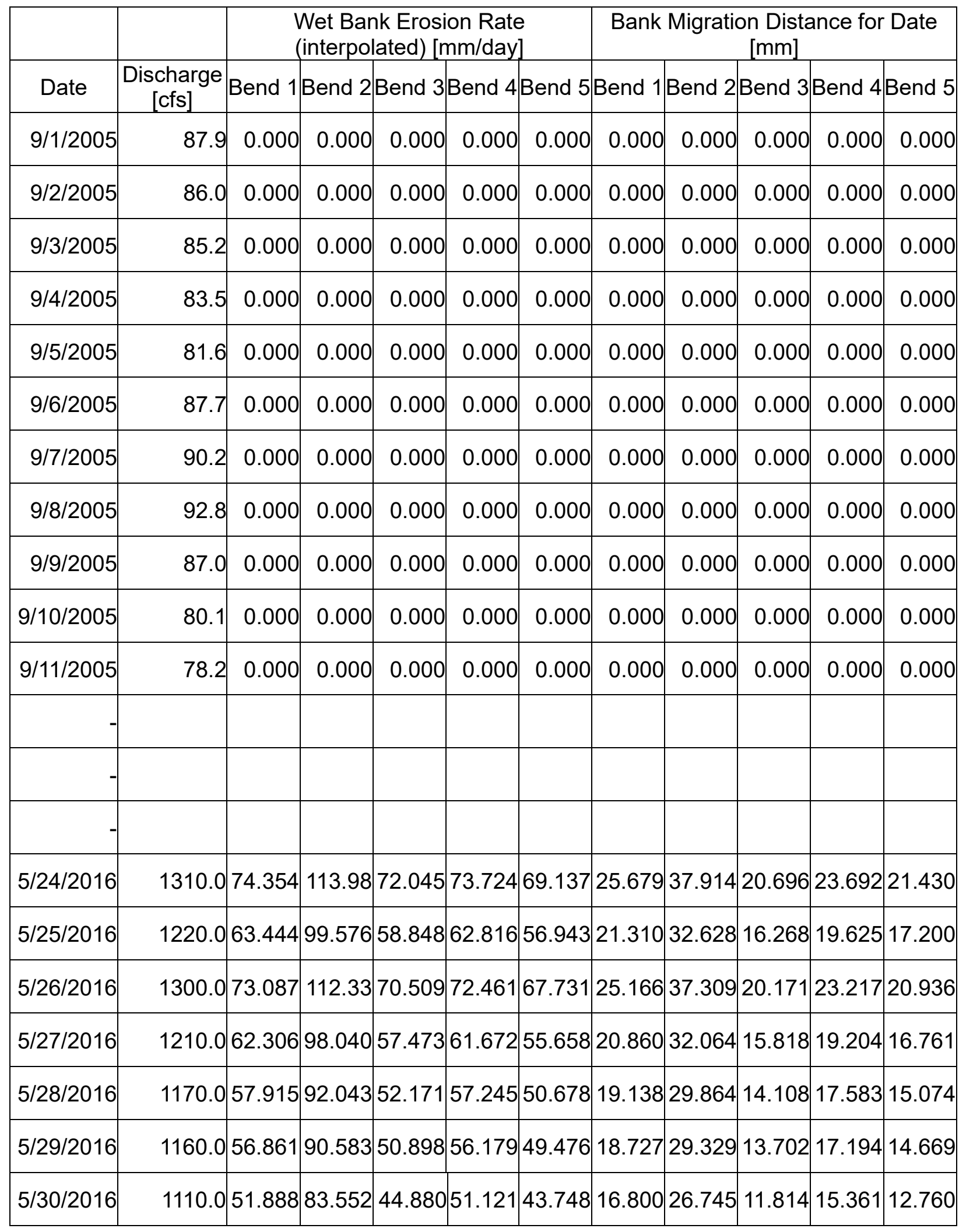

Three-Dimensional Flow Analysis Methodology for Assessing Stream Stability and Channel Migration 
Table 4: Percentage Difference Between the Estimated and Historical Migration of the Bends

\begin{tabular}{|c|c|c|c|c|}
\hline $\begin{array}{c}\text { Bend No. I } \\
\text { Time } \\
\text { Period }\end{array}$ & $1990-2016$ & $1990-2005$ & $2006-2015$ & $2009-2015$ \\
\hline bend 1 & $-17 \%$ & $-31 \%$ & $1 \%$ & $5 \%$ \\
\hline bend 2 & $-18 \%$ & $-30 \%$ & $-5 \%$ & $14 \%$ \\
\hline bend 3 & $-20 \%$ & $-32 \%$ & $2 \%$ & $13 \%$ \\
\hline bend 4 & $-11 \%$ & $-22 \%$ & $2 \%$ & $15 \%$ \\
\hline
\end{tabular}

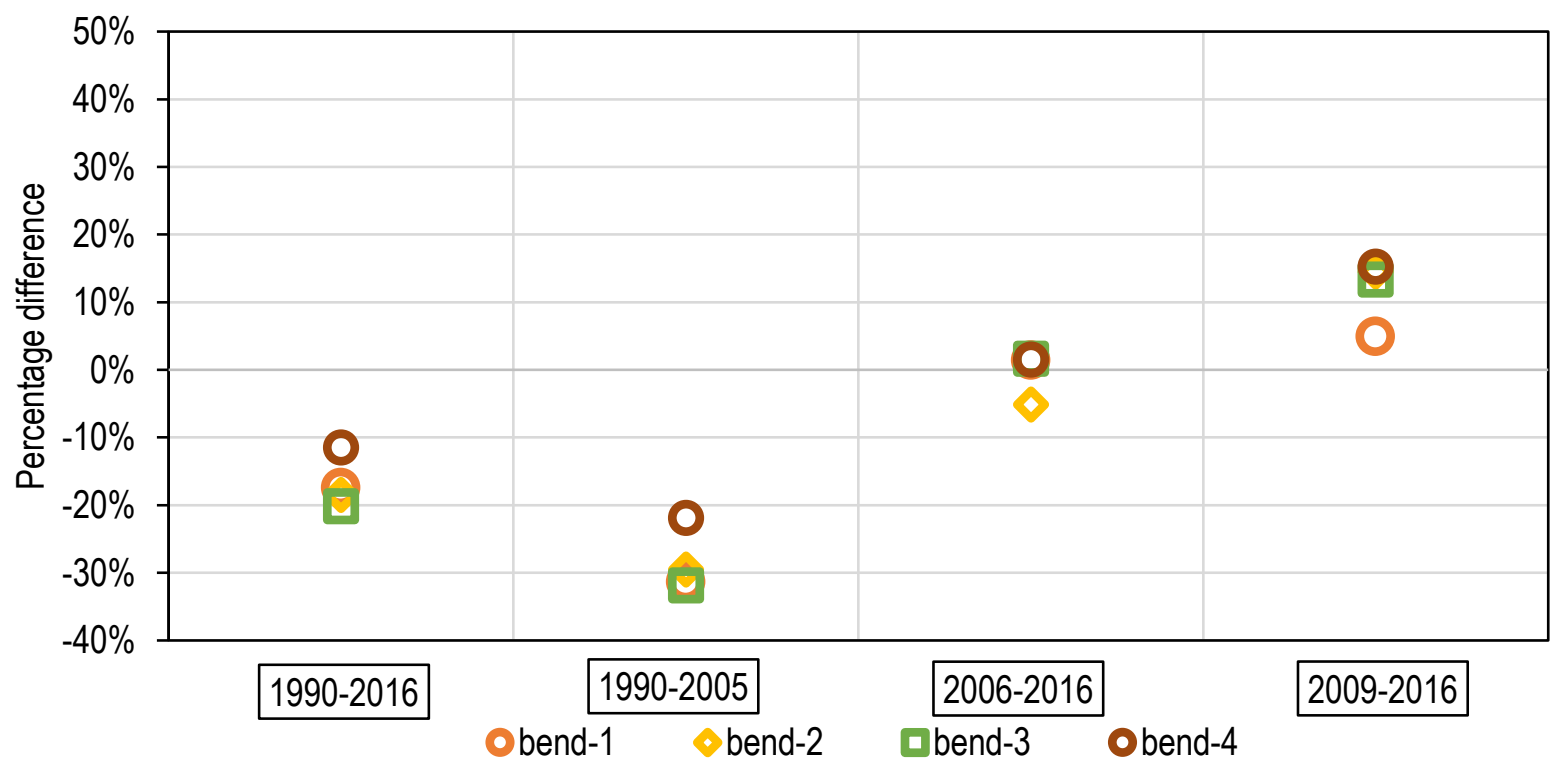

Figure 5-10: Percentage difference between the estimated and historical migration distance

\subsection{Calculated Bank Migration for the Period 2006-2015}

Figure 5-11 shows the hydrograph for the period between 2006 and 2016. For this period, two major flow events, with discharges above 10,000 cfs, were observed and most of the discharge values were below $2000 \mathrm{cfs}$. The estimated total erosion distance is very similar to the historic observation, as shown in Figure 5-12. Figure 5-13 shows an overlay of 2005 bank lines on the early 2016 aerial image of the river. The estimated migration distance over bend number 1 , which is located the closest to the highway, was $118 \mathrm{ft}$, as compared to historically measured $120 \mathrm{ft}$. The migration distances forecasted for the other bends were close to the historical values as well, and equal to $136 \mathrm{ft}$ for bend number 2, $104 \mathrm{ft}$ for bend number 3, and $101 \mathrm{ft}$ for bend number 4, with Three-Dimensional Flow Analysis Methodology for Assessing Stream Stability and Channel Migration 
the historical migration of: $141 \mathrm{ft}, 91 \mathrm{ft}$, and $104 \mathrm{ft}$ for bends 2 through 4 respectively. Furthermore, Figure 5-14 shows a yearly comparison of total lateral migration distance over each bend. The charts (a) to (d) show that not only does the total migration distance computed using CFD data closely match the accumulated migration distance, the calculated migration from CFD also matches the year by year lateral migration closely. Note that the parameters used in equation (12) were optimized to minimize the difference between the total, not partial (i.e. for each year), historical and calculated migration distance. This year by year match between measured migration and migration calculated from the model indicates that the model has captured some of the underlying physics driving the migration reasonably well.

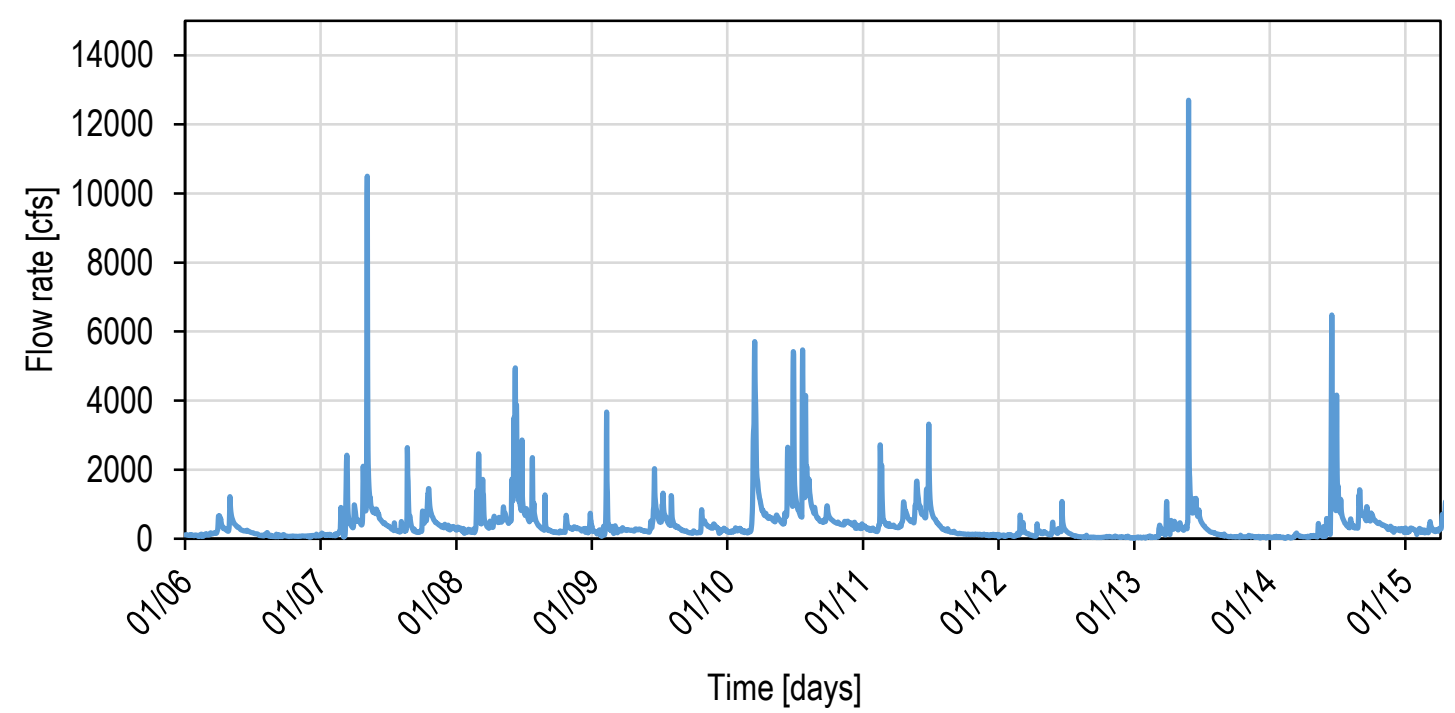

Figure 5-11: Hydrograph for years 2006-2016

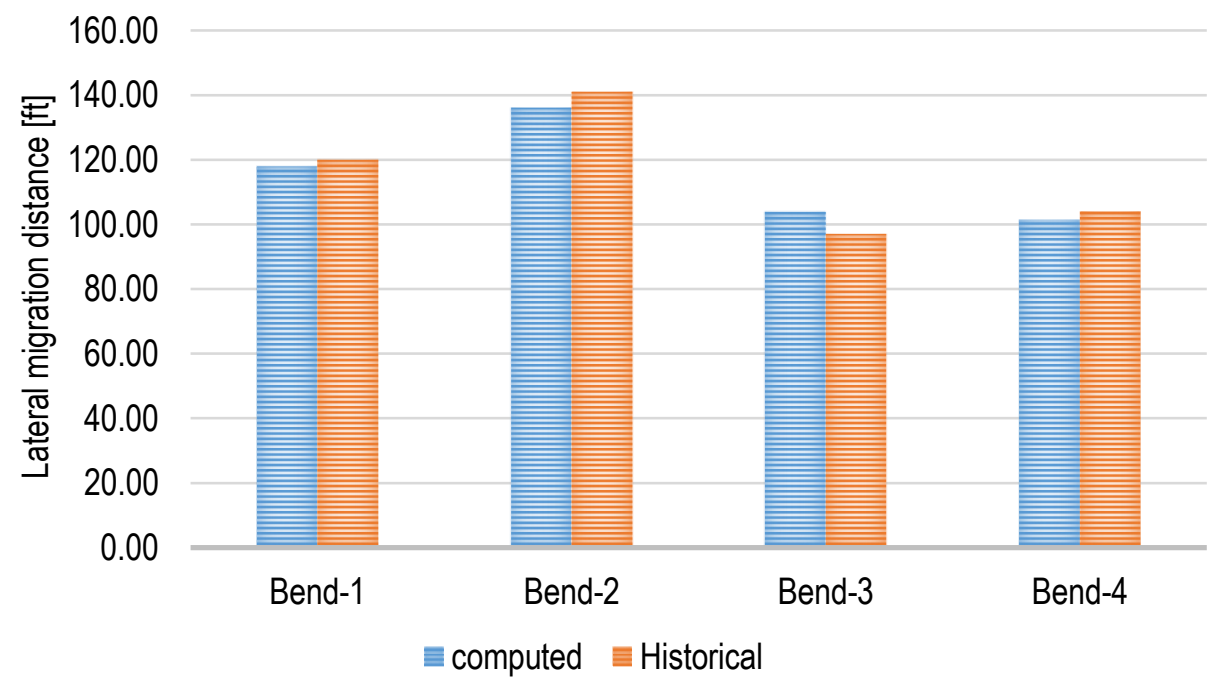

Figure 5-12: Historical and computed bank migration distance in years 2006-2016

Three-Dimensional Flow Analysis Methodology for Assessing Stream Stability and Channel Migration 


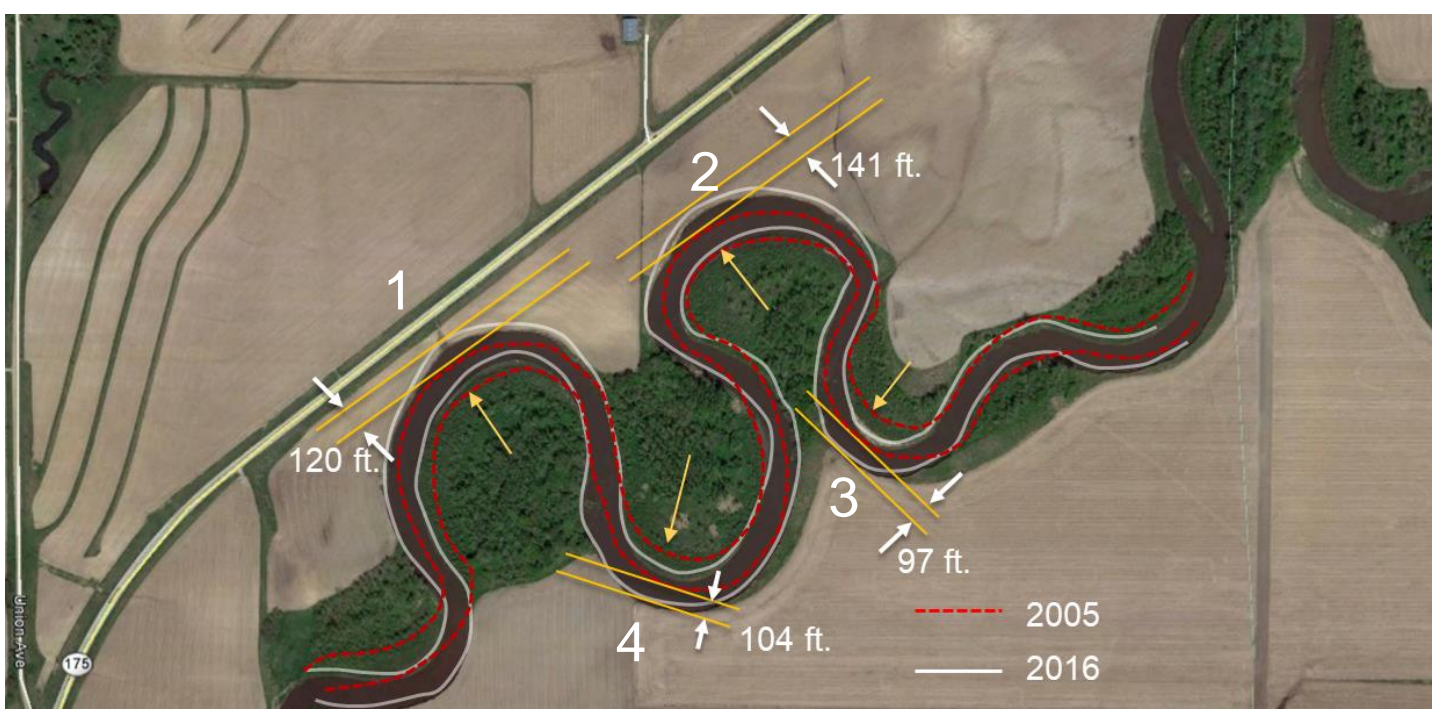

Figure 5-13: Migration distances between 2005 and 2016

(a)

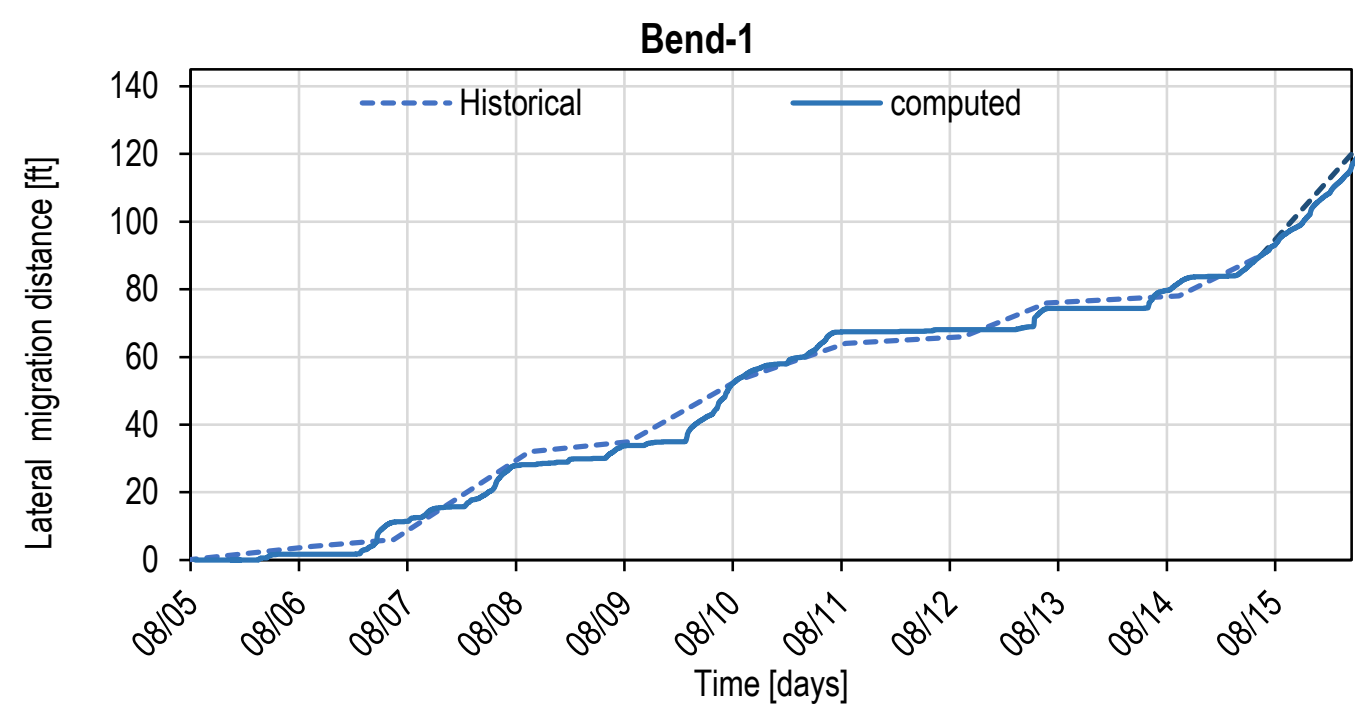

(b)

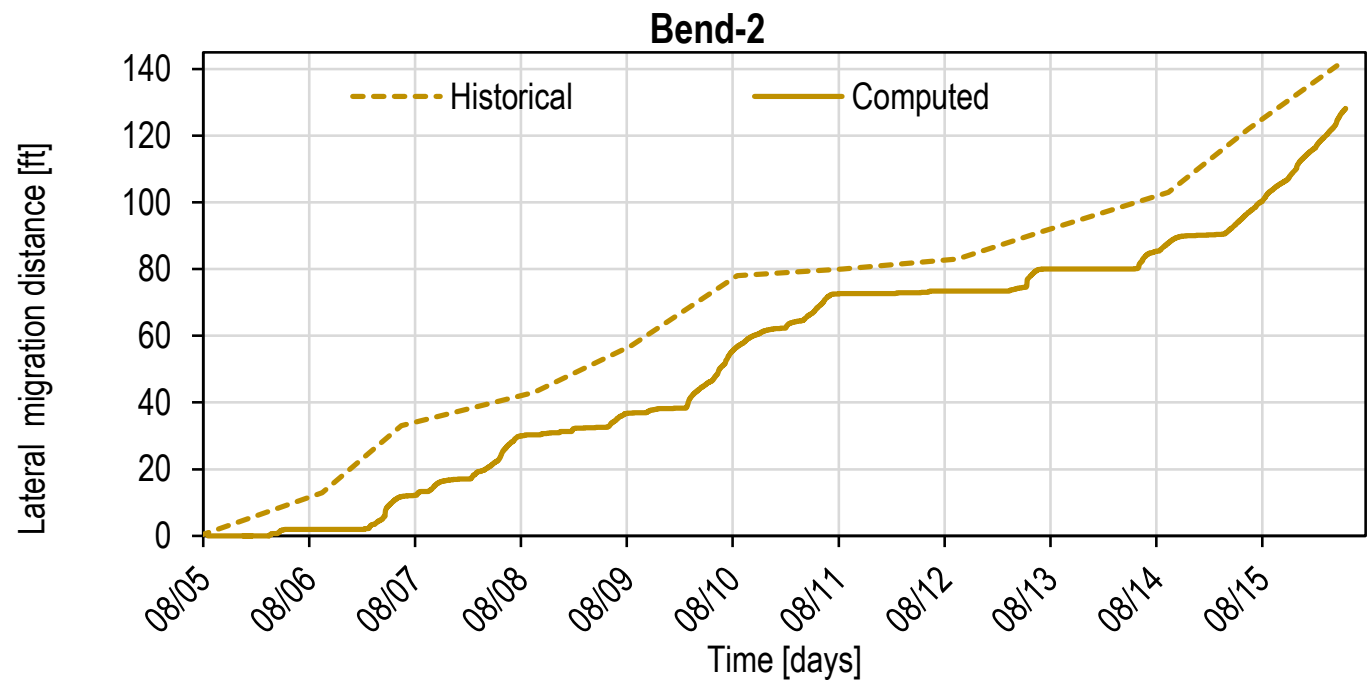

Three-Dimensional Flow Analysis Methodology for Assessing Stream Stability and Channel Migration 
(c)

Bend-3

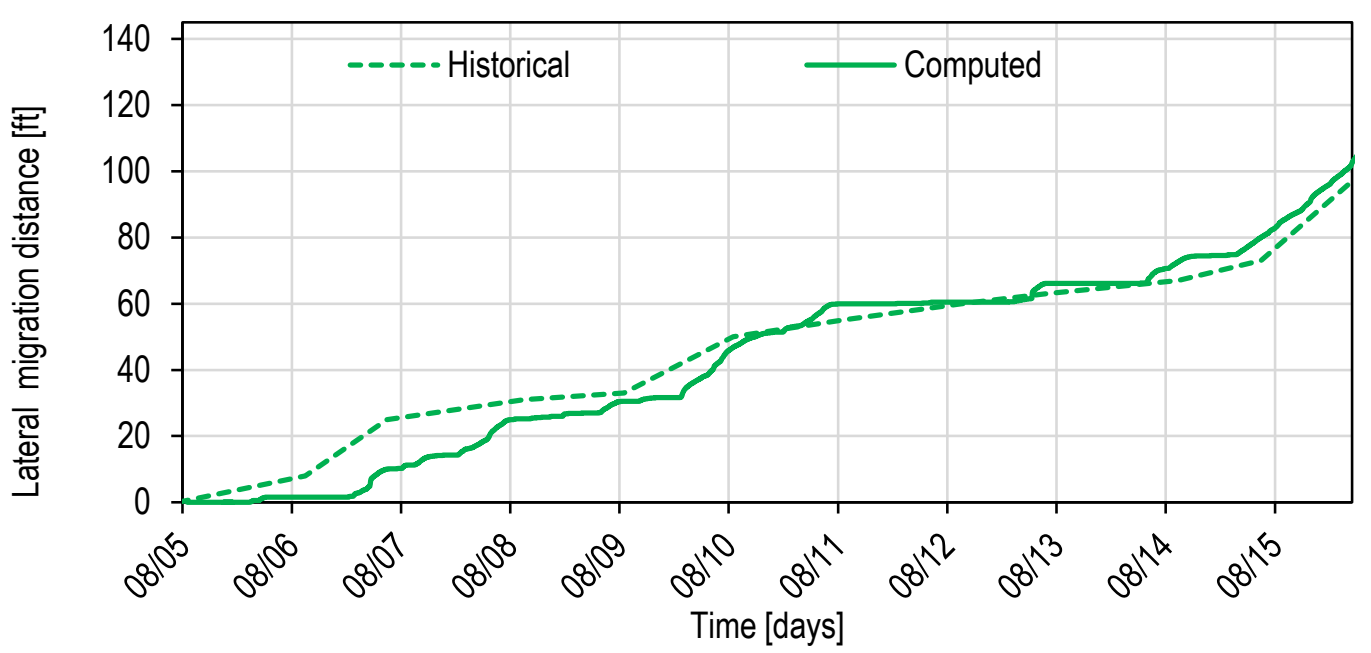

(d)

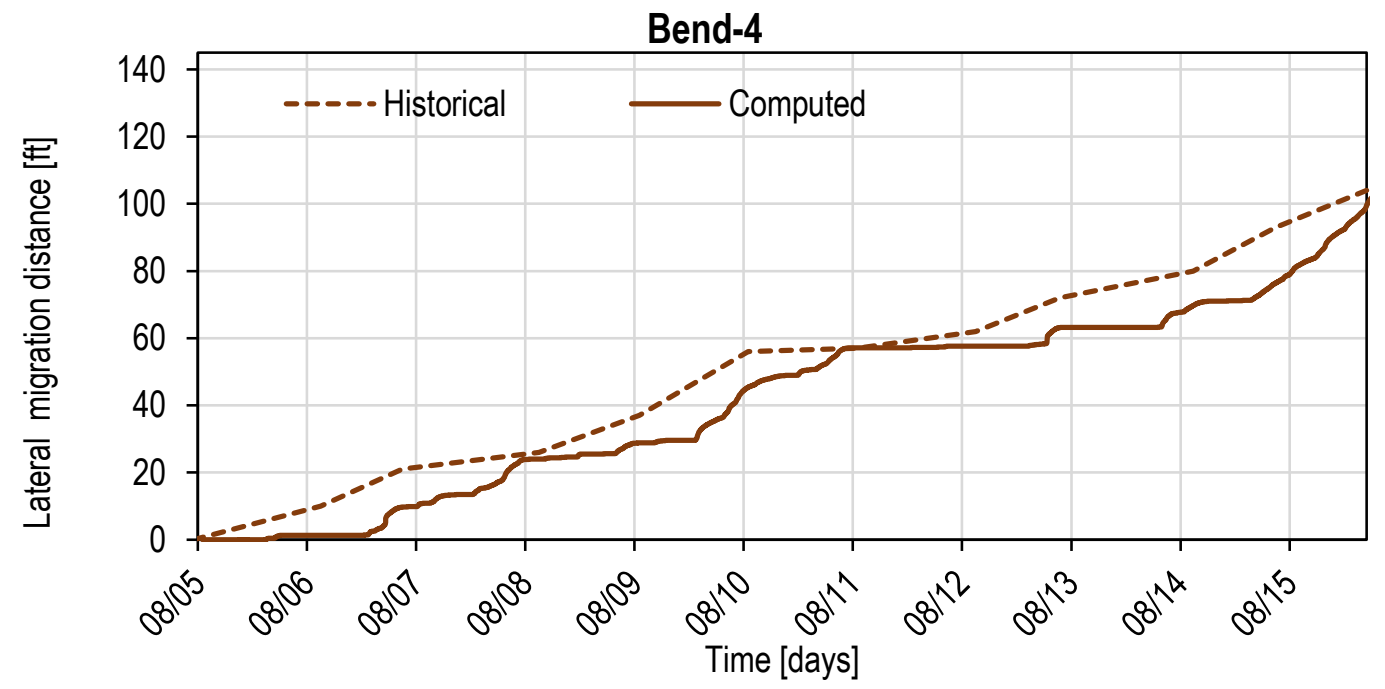

Figure 5-14: Comparison of historical vs. computed lateral migration distances for each bend for period 2005-2016, (a) bend 1, (b) bend 2, (c) bend 3, (d) bend 4

\subsection{Bank Migration in the Period 1990-2016}

The hydrograph for the period of 1990-2016 is presented in Figure 5-17. For this long time span, five major floods were observed with discharge higher than 10,000 cfs. The majority of time, 98.25\% of the days, discharge values were below 2,000 cfs. The total erosion distance estimation is shown in Figure 5-18 on a bar chart (in blue) and compared against historic measurements (in orange). It shows that the model underestimates the bank migration for the longer time span and earlier time. The error in bend 1 , the one closest to the road, is about $22 \%$, and that the largest error is in bend 2, about $28 \%$. A variety of things may have caused these differences. The stream geometry in 1990 is considerably different from that of 2016 used in the model, and therefore CFD analysis of flows through the bends would be somewhat different, and affect the shear stress results, and consequently the erosion and migration rates. Without having a sufficiently detailed 1990 stream bathymetry to build a mesh for the 1990 geometry the contribution of these differences to the underestimation difference cannot be assessed, but it seems likely that it could Three-Dimensional Flow Analysis Methodology for Assessing Stream Stability and Channel Migration 
account for a significant portion of the difference. Other causes over the long time span and large distances of the observed migration could include spatial variations in soil properties over the migration distance, variation of vegetation near and at the bank from year to year that affects how easily the bank collapses, anthropogenic disturbances caused by agricultural activities, or the level of bank moisture saturation due to off-stream sources. None of these things are accounted for in the model, and consequently a difference of 20 to 30 percent between the historical migration and model prediction for time spans and conditions that are far from those that were used to build the model is reasonably good.

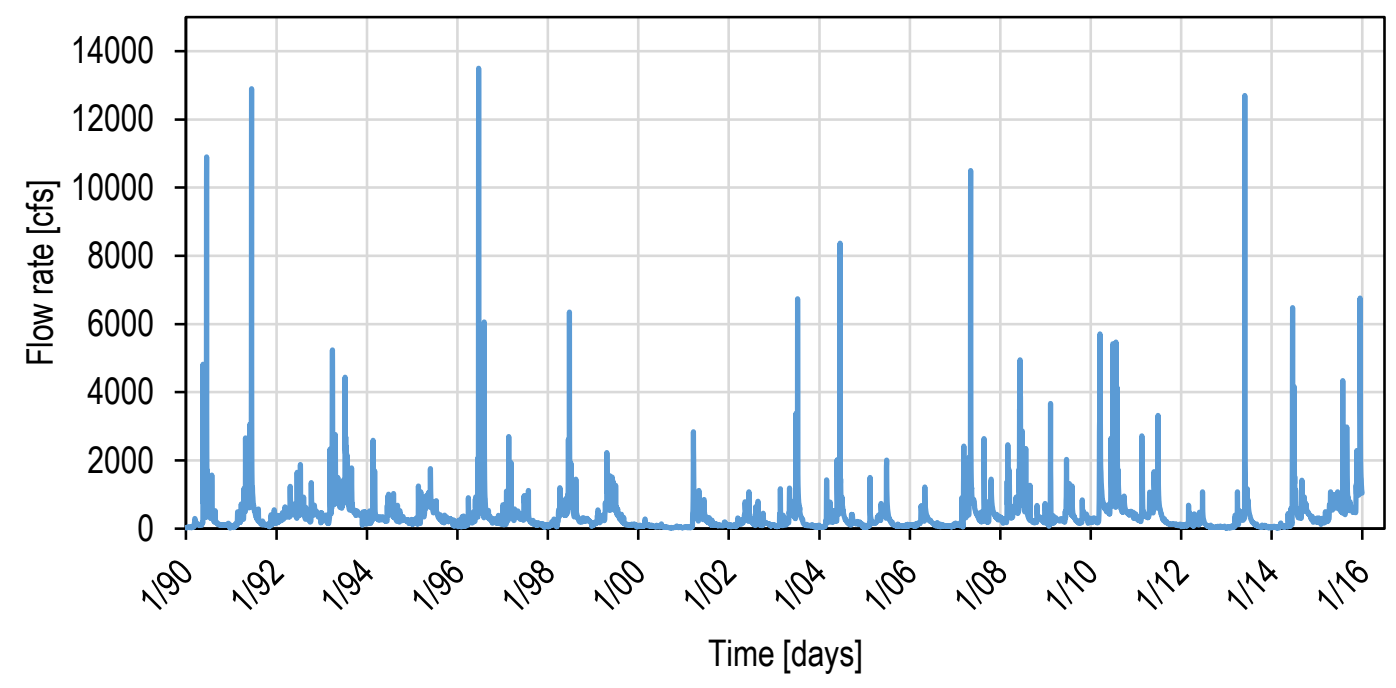

Figure 5-15: Hydrograph for the period from 1990-2016

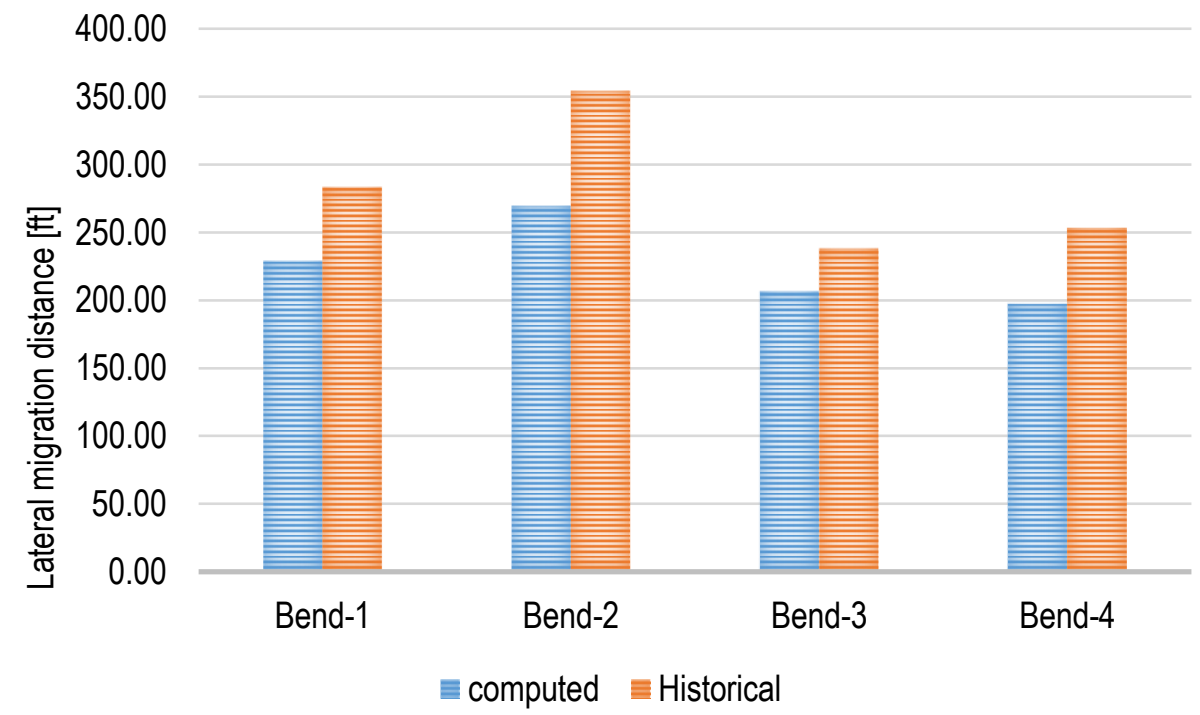

Figure 5-16: Historical and computed bank migration distance in years 1990-2015

Figure 5-19 shows an overlay of 2016 bank lines on the early 1990 aerial image of the river. The migration distances are marked for each of the bends. The historical lateral migration for bend number 1 was approximately equal to $283 \mathrm{ft}$. The highest migration distance of $\sim 351 \mathrm{ft}$ was observed at bend number 2 for this period. A comparison between observed historical values and Three-Dimensional Flow Analysis Methodology for Assessing Stream Stability and Channel Migration 
model predictions of accumulated migration distance for the $1990-2016$ period is presented in Figure 5-20. Note that only two data points at the ends of the period 1990-2005 could be determined from available aerial photographs. By 2005 most of the difference between the historical migration and model is present. After that the migration is very close between historical and model results, which makes sense partly because the erosion rate parameters were tuned based on migration in the latter part of the time period. The apparent close match between 1990 and 2000 is deceptive because there is no data point for year 2000, and the stream bank position in year 2000 is unknown. The model predictions show a distinct change in slope around 2000, where the rate of migration slows down considerably between 2000 and about 2007. In looking at the hydrograph, it shows only 3 events above $2000 \mathrm{cfs}$ and a very large number of points below $100 \mathrm{cfs}$ indicating a dry period from 2000 to 2007 where the bank migration due to flow in the stream would be expected to be very slow. It is likely that historical photographs would show the same trend if they were available. Conversely, the period from 1990 to 2000 has the highest two flow rate events, and a large number of low flow days where the flow exceeds $500 \mathrm{cfs}$, indicating a relatively wet period. The under prediction of the model is most likely to have occurred during this period.

To help ensure that the model does not under predict migration, a conservative correction can be added to migration distance. Let $\zeta$ be the maximum fraction of under-prediction of yearly lateral erosion distance for the set of historical data. Then $\zeta$ can be used as a correction factor for yearly stream migration calculated from the model for hydrograph variations to help ensure that the model does not under predict migration. With this safety factor, Equation (12) can be rewritten as

$$
L E=(1+\zeta) \dot{x}_{\perp} \Delta t h_{f}
$$

The additional factor increases the predicted erosion rate, and therefore gives a more conservative value.

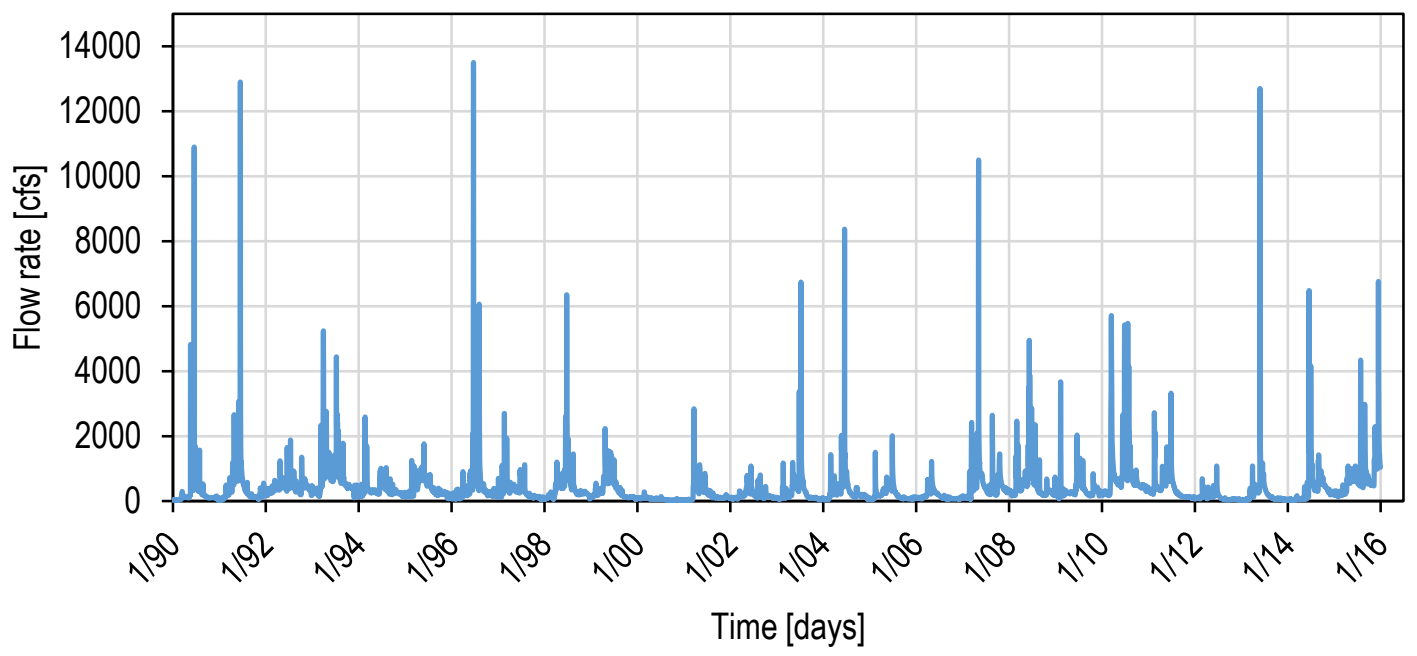

Figure 5-17: Hydrograph for the period from 1990-2016

Three-Dimensional Flow Analysis Methodology for Assessing Stream Stability and Channel Migration 


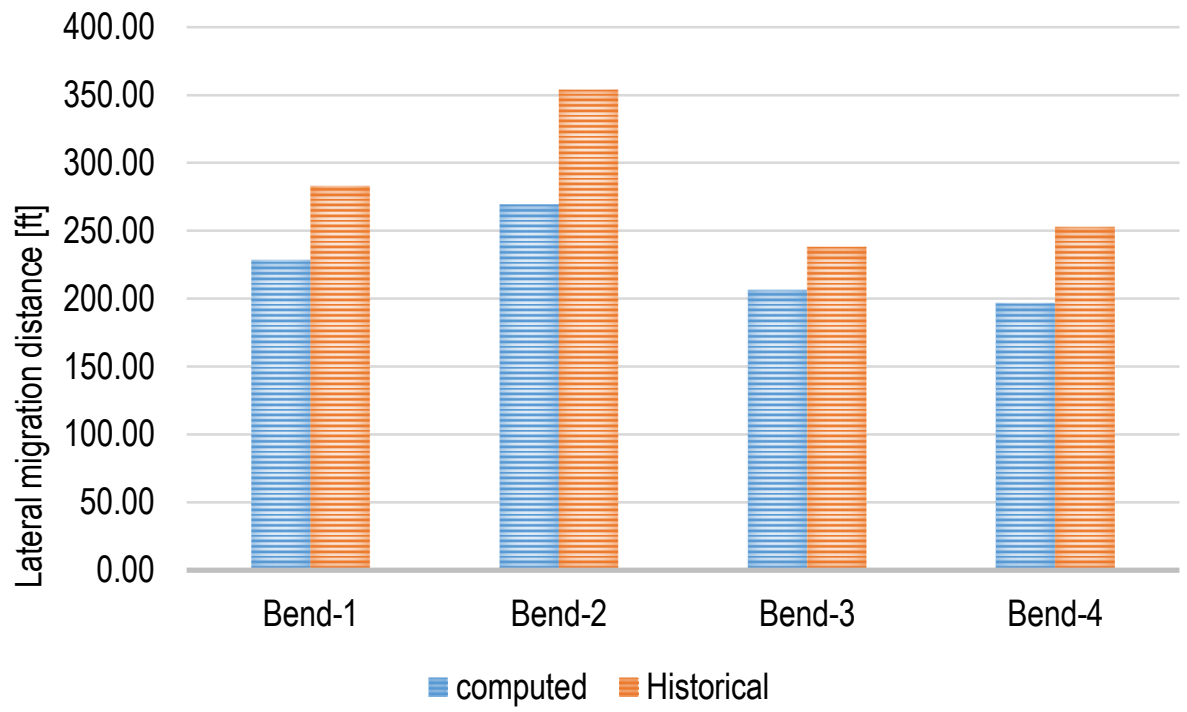

Figure 5-18: Historical and computed bank migration distance in years 1990-2015

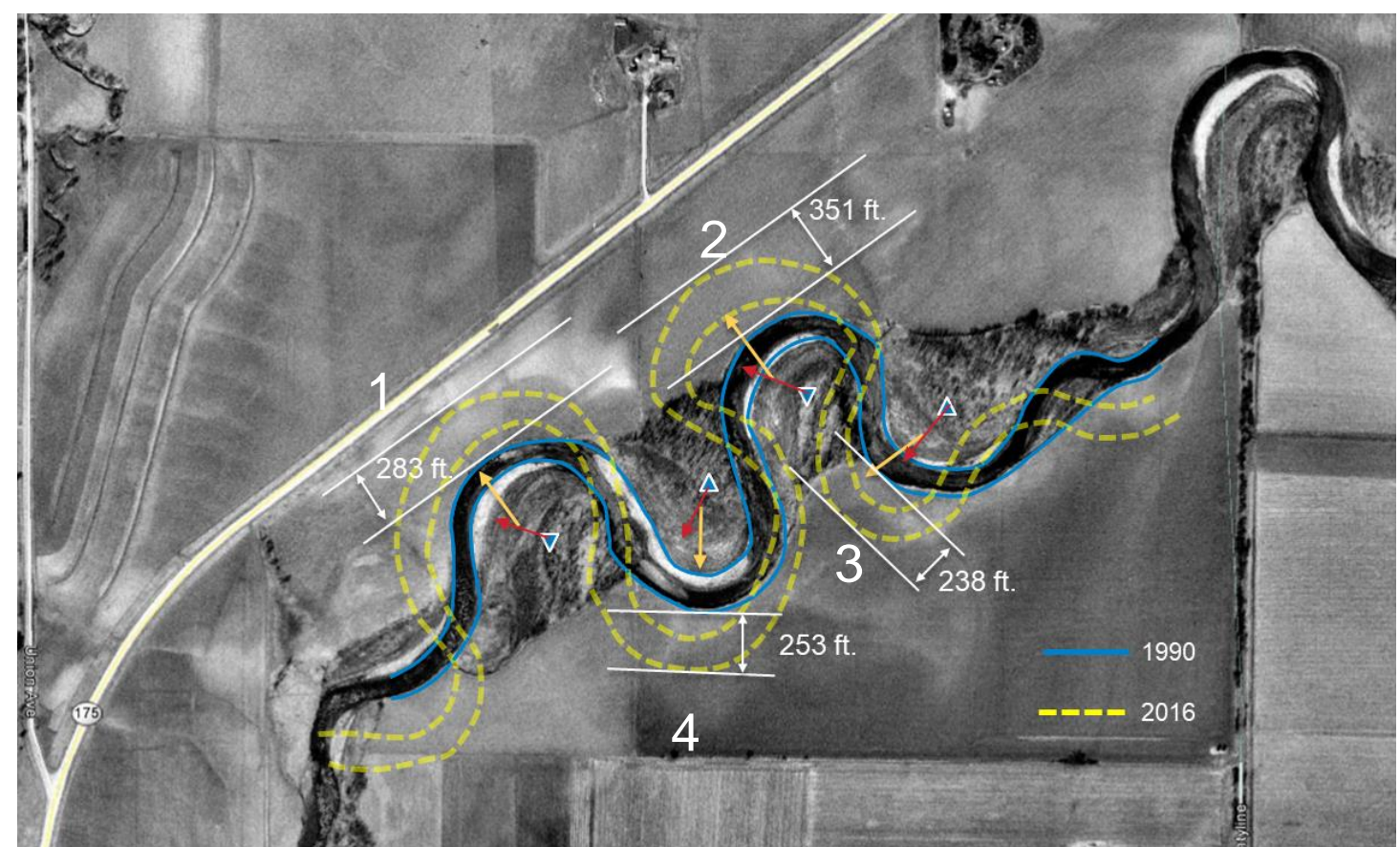

Figure 5-19: Aerial view of the 1990 stream with the shape of the 2016 stream (yellow dashed line). The distances between the bends are given.

Three-Dimensional Flow Analysis Methodology for Assessing Stream Stability and Channel Migration 
(a)

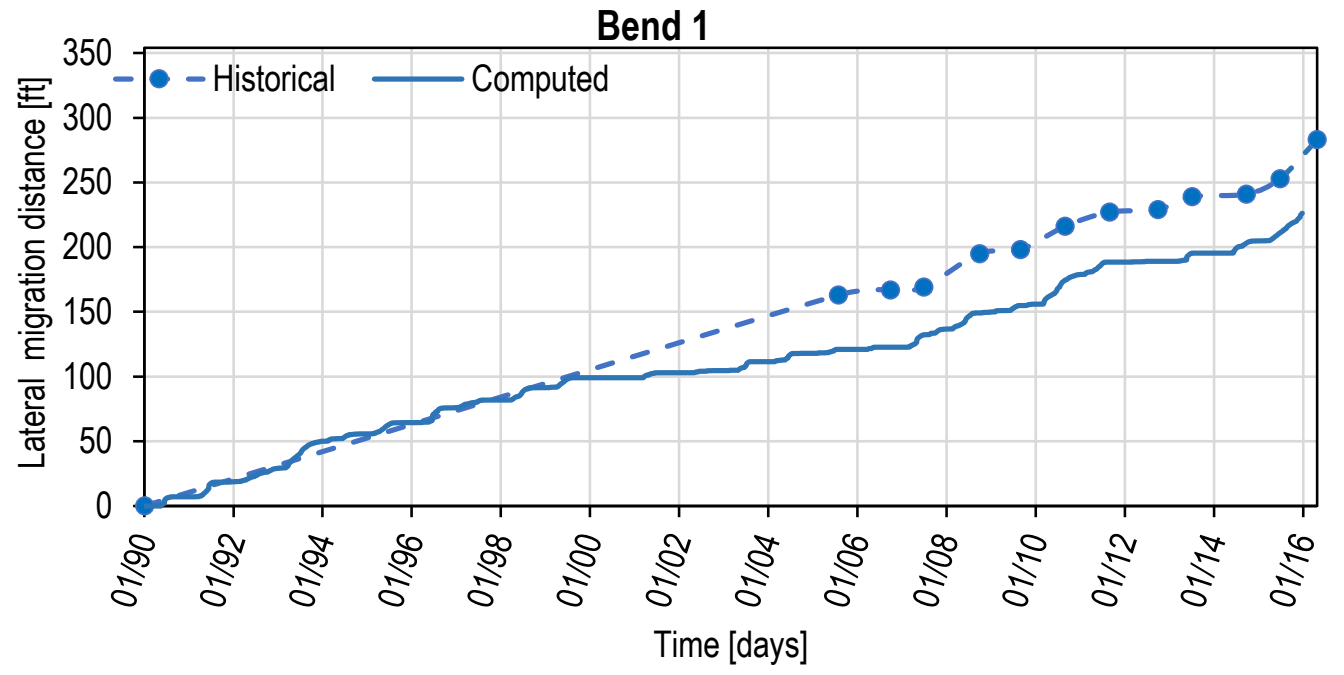

(b)

(c)
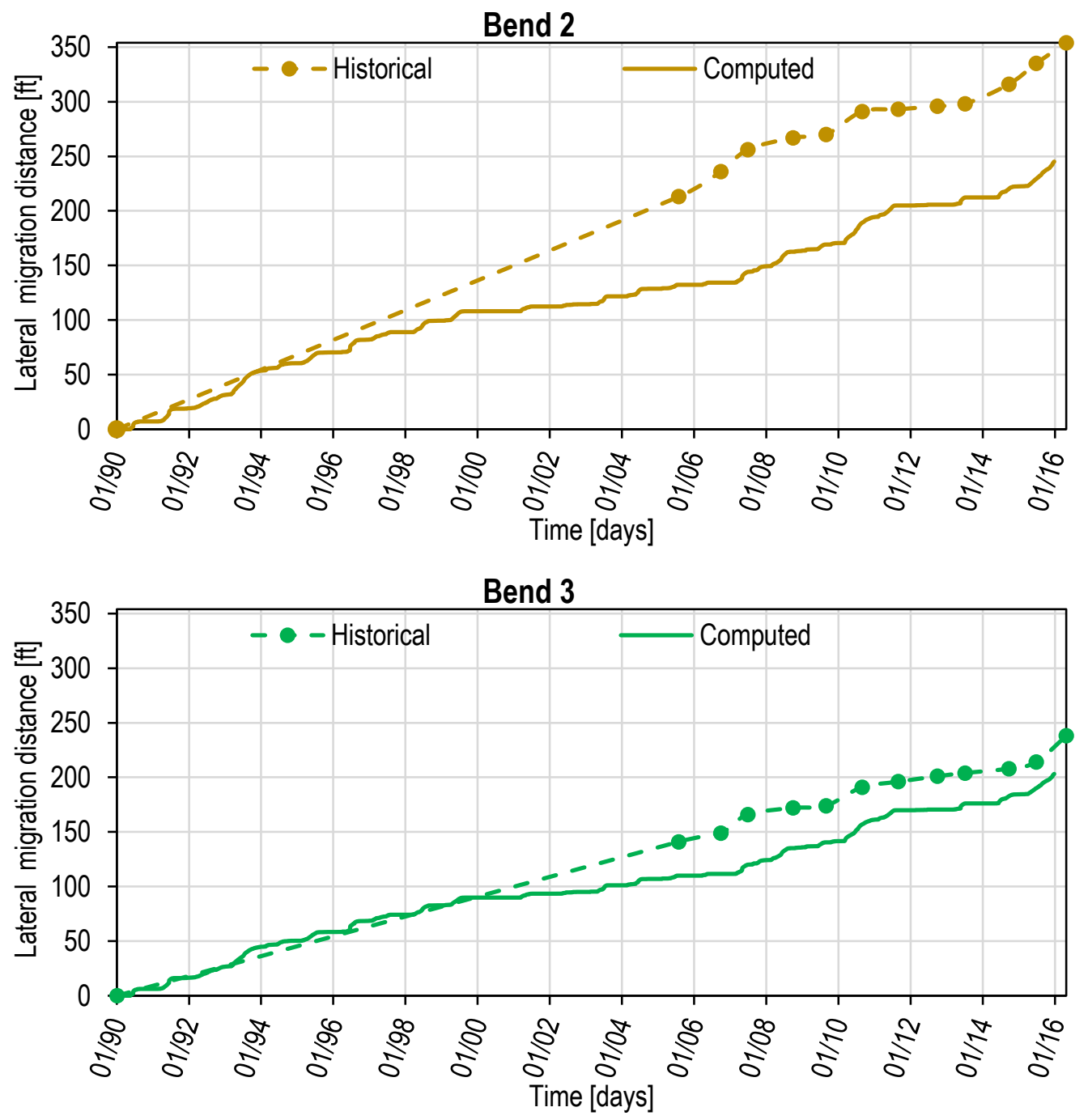

Three-Dimensional Flow Analysis Methodology for Assessing Stream Stability and Channel Migration 
(d)

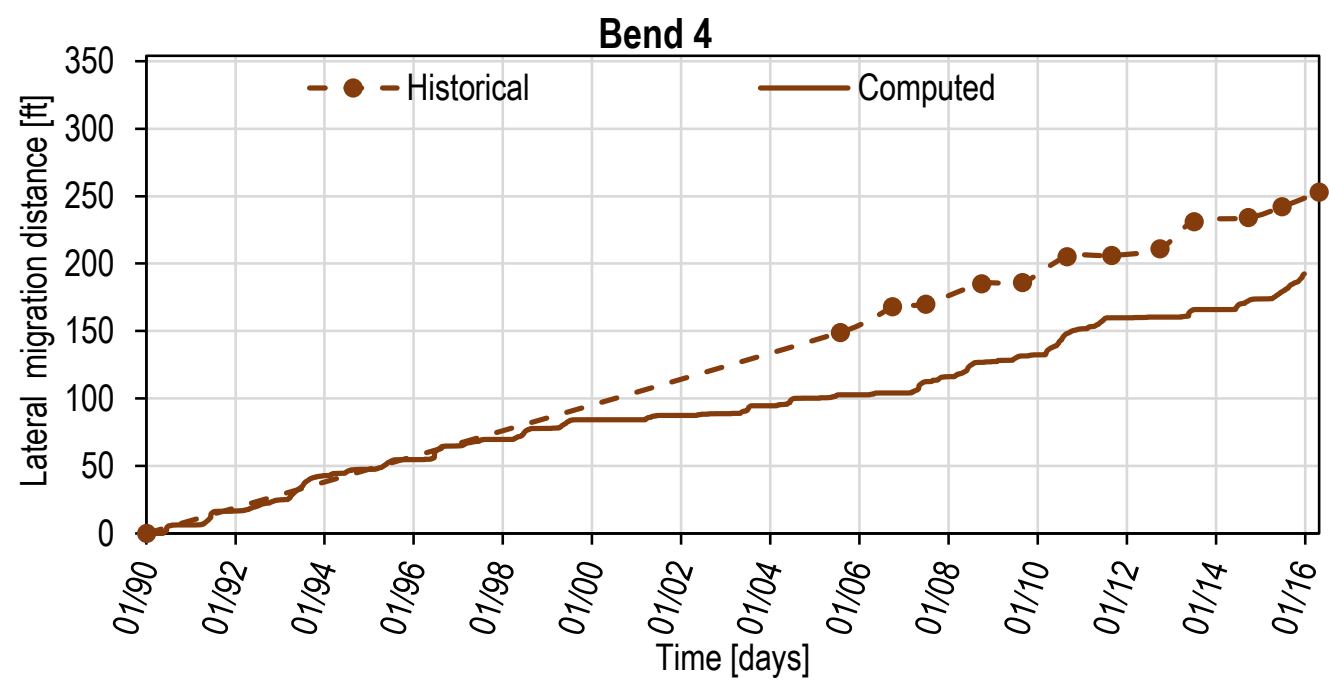

Figure 5-20: Comparison of historical vs. computed lateral migration distances for each bend for period 1990-2016, (a) bend 1, (b) bend 2, (c) bend 3, (d) bend 4

\section{Testing Scenarios for Future 10-Year Migration of the Stream Bends}

In this section, the methodology described in previous chapters is used to predict stream migration during the period from 2016-2026 under a set of four hypothetical rainfall conditions, characterized by four different hydrographs. The hypothetical hydrographs were based on the 2006-2016 hydrograph for the Maple River at the studied location and assumed that: (1) the discharge pattern was the same as the one observed in years 2006-2016, (2) the daily discharge was increased by $75 \mathrm{cfs}$ for all days, (3) the standard deviation of the daily discharges was doubled with no change to the mean of the daily discharges, and (4) an additional large peak flow of 10,000 $\mathrm{cfs}$ was added each year around the first week of May, the time of spring rains, including a ramp up and ramp down over a several day period.

\subsection{Scenario 1: Hydrograph Repeats Previous Ten Years}

In the first scenario, the hydrograph for the period 2016-2026 is assumed to be the same as for the period 2006-2016. When this hydrograph is used in the model to estimate bank migration for the next ten years, it yields the same lateral erosion distance as for the previous ten years. The anticipated lateral erosion for the bends is illustrated in Figure 6-1. The total migration of bend number 1 is expected to be equal to $95 \pm 24 \mathrm{ft}$. If the most conservative estimate is considered, the migration of the river bend over the next ten years would be $119 \mathrm{ft}$, which would place it within $21 \mathrm{ft}$ of Highway 175, and possibly require action over the following several years to avoid incursion from the river.

The neck between the bends at bend number 3 is predicted to have a major change in morphology based on the current migration rates. As shown in Figure 6-1, the right side of bank 5 intersects with the left side of bank 3 within 10 years. The banks moved by $176 \mathrm{ft}$ relative to each other $(\sim 88$

Three-Dimensional Flow Analysis Methodology for Assessing Stream Stability and Channel Migration 
$\mathrm{ft}$ each side) in the last 10 years. Figure 6-2 shows trendlines for the migration of bend 3 and 5 extending to 2023. A migration of $60 \mathrm{ft}$ on each side would cause the bends to merge and cutoff the horseshoe in between 6 and 7 years. The merging of the banks at bend 3 will have a complex effect on the flow in the other bends. The geometry of the model would need to be modified to follow the new path of the channel to assess the effect that the cutoff of one of horseshoe bends will have on the migration of the other bends.

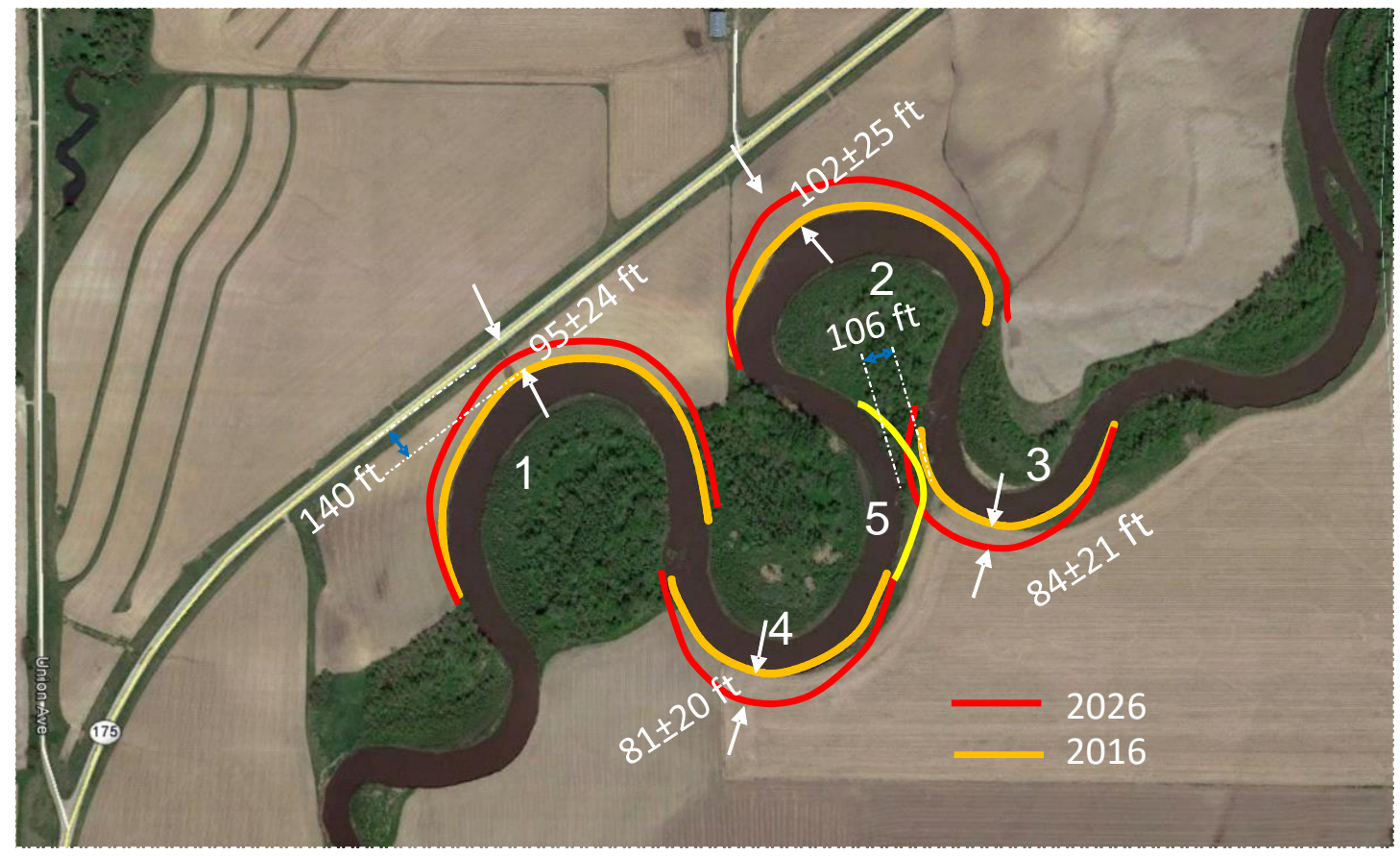

Figure 6-1: Lateral migration distances predicted for the bends in Scenario 1. Yellow line at bend-5 is estimated bank location based on current migration rate.

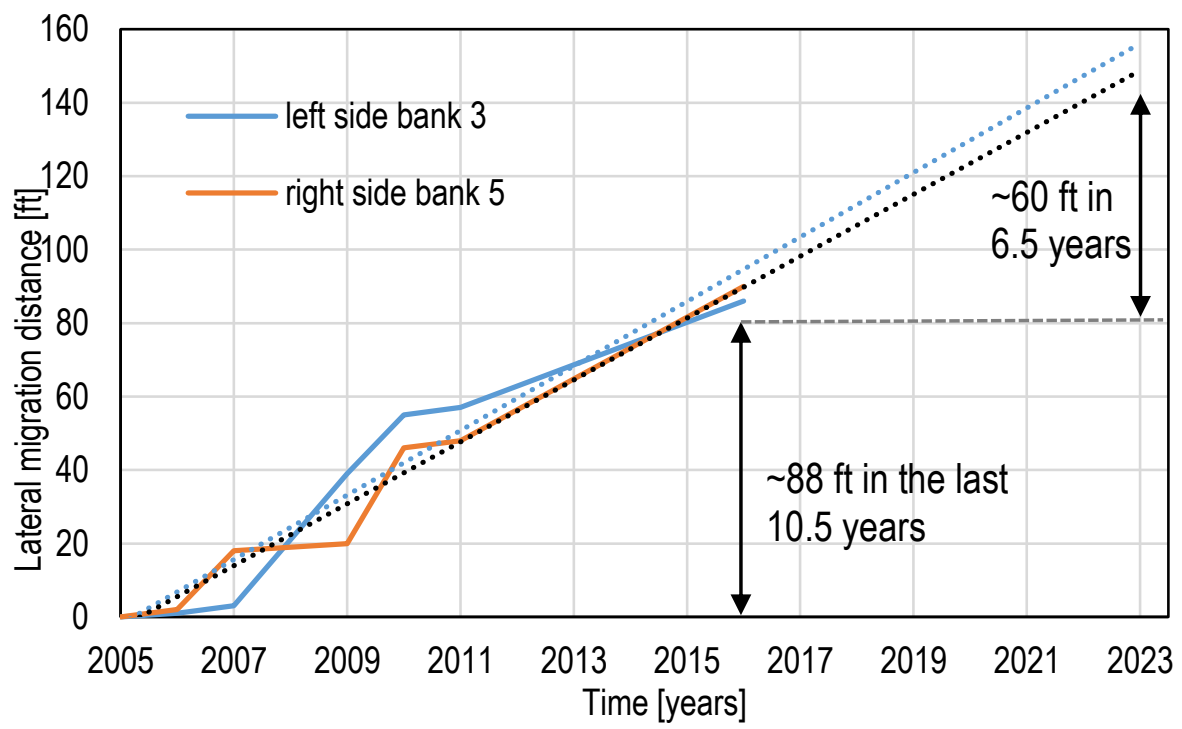

Figure 6-2: Lateral migration distance between the bends in location 3. Historical data for years 2005-2016 with a linear extrapolation until 2023

Three-Dimensional Flow Analysis Methodology for Assessing Stream Stability and Channel Migration 


\subsection{Scenario 2: Daily Discharge Increases by 75 Cubic Feet per Second}

In the second scenario, volume flow was increased by adding $75 \mathrm{cfs}$ to the flow rate of each day [1]. This change represents an increase of $18 \%$ in the total volume of flow over 10 years, from 129 billion cubic feet to 152 billion cubic feet. The increase in the future discharge was obtained by using a seasonally based regression of the 1941-2016 hydrograph in a Microsoft Excel spreadsheet to obtain the trendline in the hydrograph. The trend is shown in Figure 6-3. The anticipated lateral erosion for a hydrograph with an increase in discharge of $18 \%$ is shown in Figure 6-4. In this scenario, bend 1 migrates $115 \pm 29 \mathrm{ft}$ toward Highway 175, putting it, within the uncertainty range of encroaching on the highway within the next decade, which is $140 \mathrm{ft}$ away. In addition, the horseshoe bend made up of bends 2, 3, and 5 is predicted to cut itself off, changing the course of the channel, adding additional uncertainty to the migration of bend 1 near the highway.

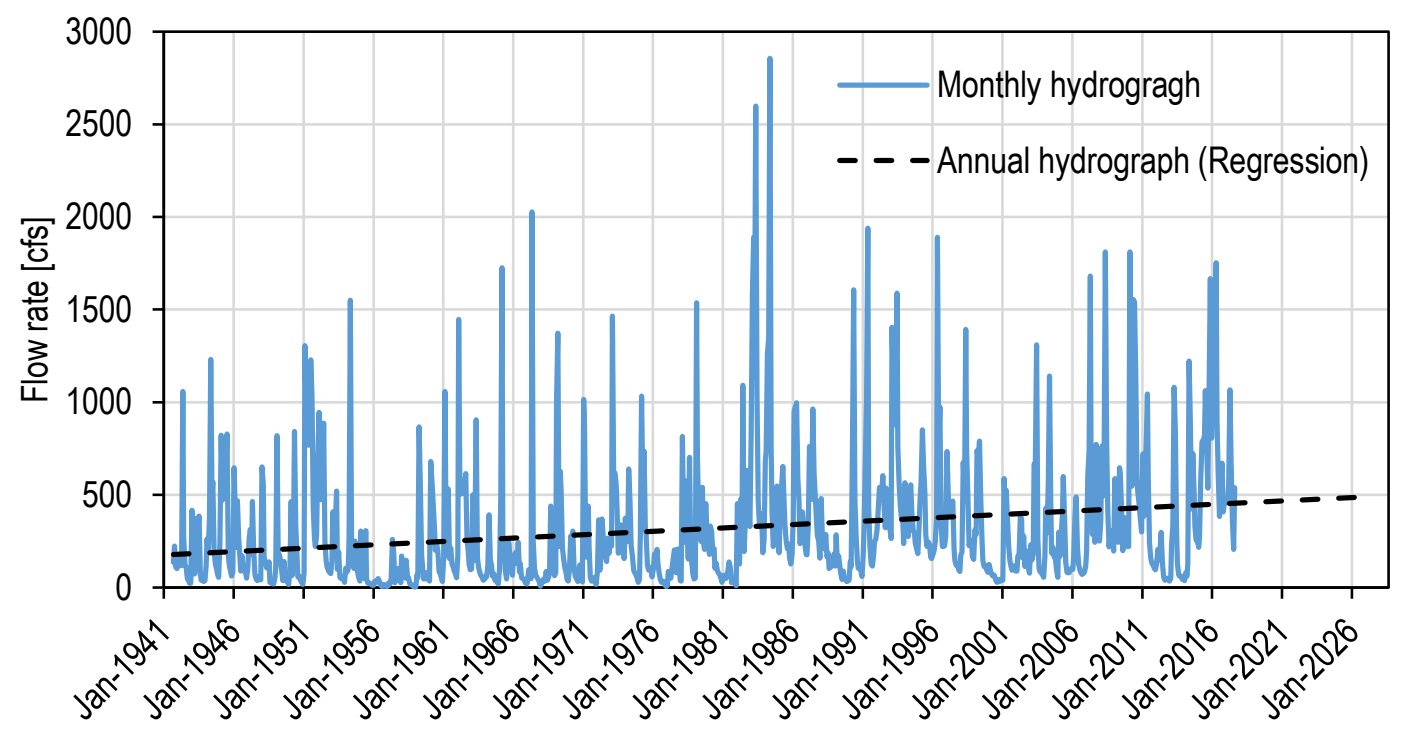

Figure 6-3: A hydrograph showing the monthly and annual discharge curves in the Maple River at the gage in Mapleton, IA between 1941 and 2016

Three-Dimensional Flow Analysis Methodology for Assessing Stream Stability and Channel Migration 


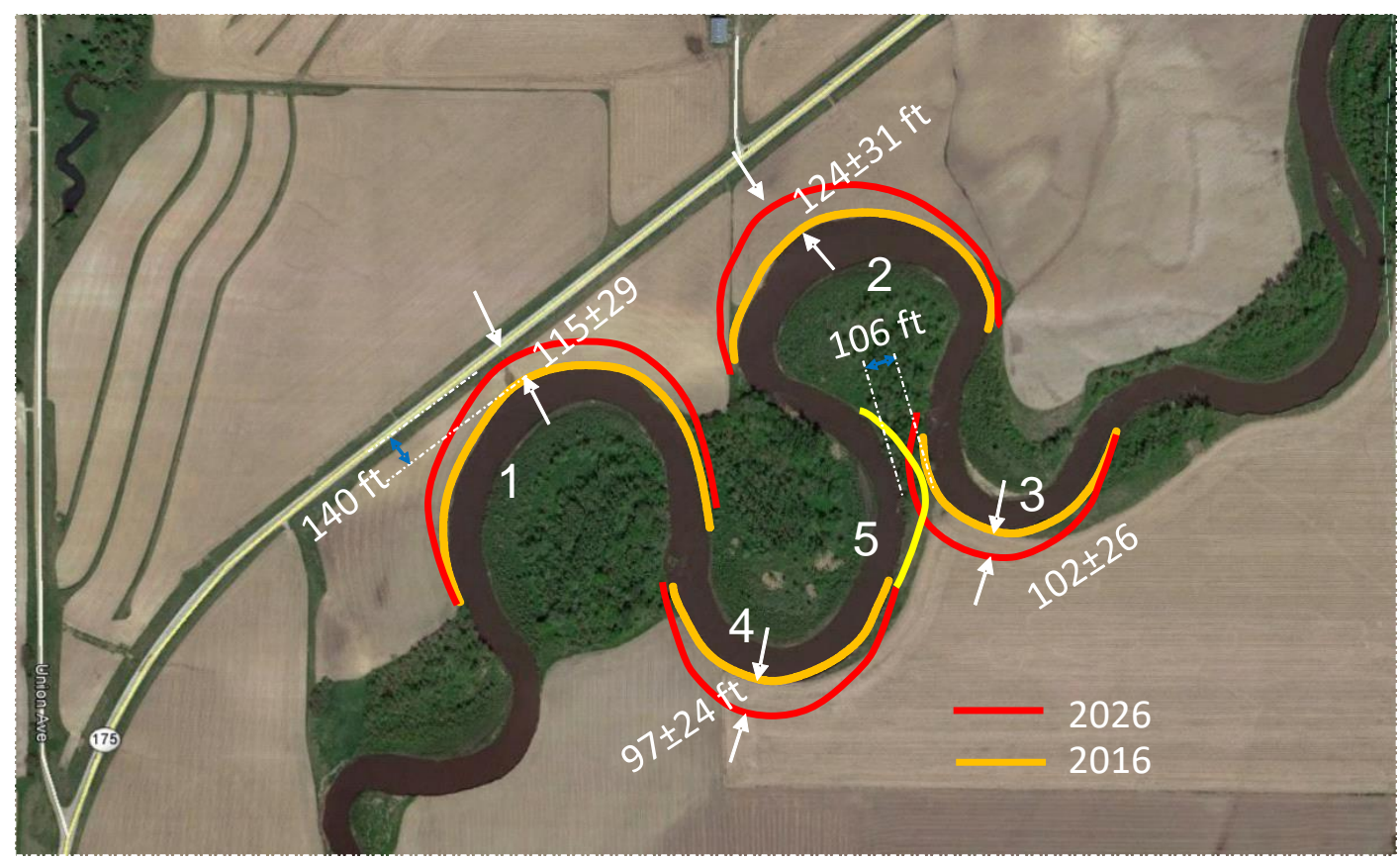

Figure 6-4: Aerial view of the Maple River from 2016. The forecasted bank lines for year 2026 according to the Scenario 2 were marked with red lines. Yellow line at bend- 5 is the estimated bank location based on the current migration rate.

\subsection{Scenario 3: Additional Extreme Events with Same Mean Daily Discharge}

Scenario 3 tests the effect of more extreme events in wet periods that average out with lower discharges during dry periods. The modified hydrograph contains more variation in the discharge values obtained by including days of higher and lower flows, without changing the mean discharge. The modified hydrograph was derived from the base case hydrograph by setting the daily discharge, $V_{e x}$, as follows:

$$
V_{e x, i}= \begin{cases}V_{B, i}+f_{h}\left(V_{\max }-V_{B, i}\right)+V_{a d j} & \text { if } V_{B, i}<V_{s p} \\ \max \left(V_{\min }, f_{l} V_{B, i}+V_{a d j}\right) & \text { otherwise }\end{cases}
$$

where $V_{B}$ is the base case daily discharge for a particular day, $V_{\max }=12,000 \mathrm{cfs}$ is a maximum daily discharge, $V_{a d j}=15.926 \mathrm{cfs}$ is an adjustment to the daily discharge to correct the mean value, $\mu_{e x}$, of the set $\left\{V_{e x}, i\right\}$ extreme events discharge values so that it is equal to the mean value, $\mu_{B}$, of the set $\left\{V_{B, i}\right\}$ of base case discharge values, $V_{s p}$ is the split point discharge above which discharges are increased and below which discharges are decreased in the modified hydrograph, $V_{\min }=17.44$ cfs is the minimum of the $V_{B}$ values, $f_{h}=0.3985$ is the high side factor, and $f_{l}=0.5$ is the low side factor. The constants $V_{s p}, V_{a d j}$, and $f_{h}$ were iteratively adjusted so that the standard deviation of the modified hydrograph values was twice that of the base case, $\sigma_{e x}=2 \sigma_{B}$ and the means of the two sets were equal, $\mu_{e x}=\mu_{B}$.

Figure 6-5 presents the original and modified hydrographs used in this scenario. Modifying the hydrograph in this way doubled the standard deviation of the discharge data points compared to Scenario 1 without changing the mean daily discharge. The formula given in Equation (15) is only one of an infinite number of ways to produce a hydrograph from the base case with the same mean Three-Dimensional Flow Analysis Methodology for Assessing Stream Stability and Channel Migration 
and double the standard deviation. However, it is reasonably plausible. The plot of the modified hydrograph in orange in Figure 6-5 shows that the peaks of high flow events have increased significantly yet they are all below the maximum discharge that occurred in the previous 10 years shown in blue. The orange line is also seen to be below the blue for the low flow periods corresponding to more extreme dry periods that lead to equal mean daily discharges for the two hydrographs.

Figure 6-6 shows the calculated lateral erosion distance at the four bends of interest. In this scenario, where only the severity of events increases while the total discharge remains the same, the bank migration distances of the banks decreased between 6 and $24 \mathrm{ft}$. This test case would appear to indicate that the bank migration is a strong function of the discharge and not a strong function of how extreme the events are with respect to mean conditions, as long as they are not severe enough to completely alter the course of the channel. It should be noted that the stream reach studied is traversing farmland, and that the characteristics of bank migration are also a function of the local topology and soil conditions.

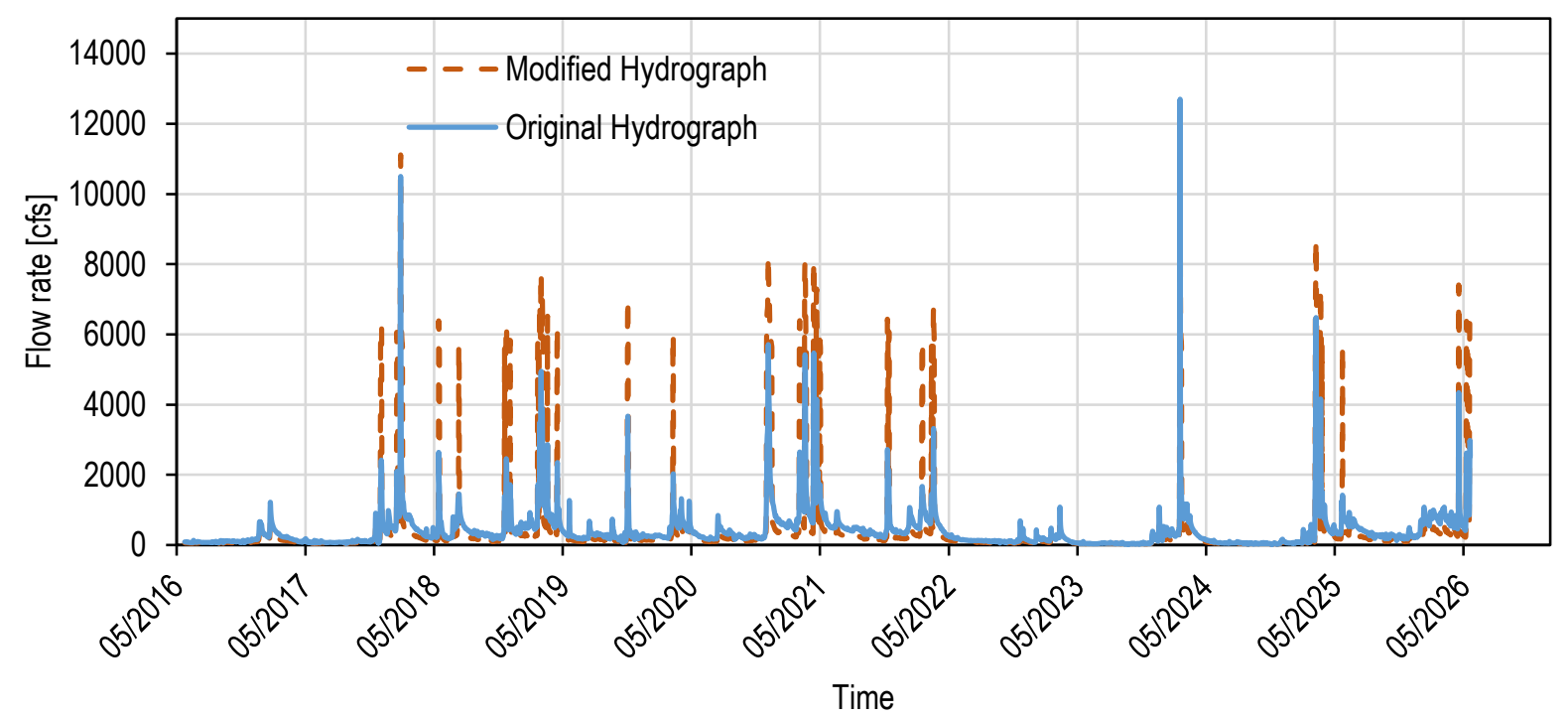

Figure 6-5: A comparison of the hypothetical hydrographs for the period 2016-2026 used in Scenario 1 (blue line) and used in Scenario 3 (orange line)

Three-Dimensional Flow Analysis Methodology for Assessing Stream Stability and Channel Migration 


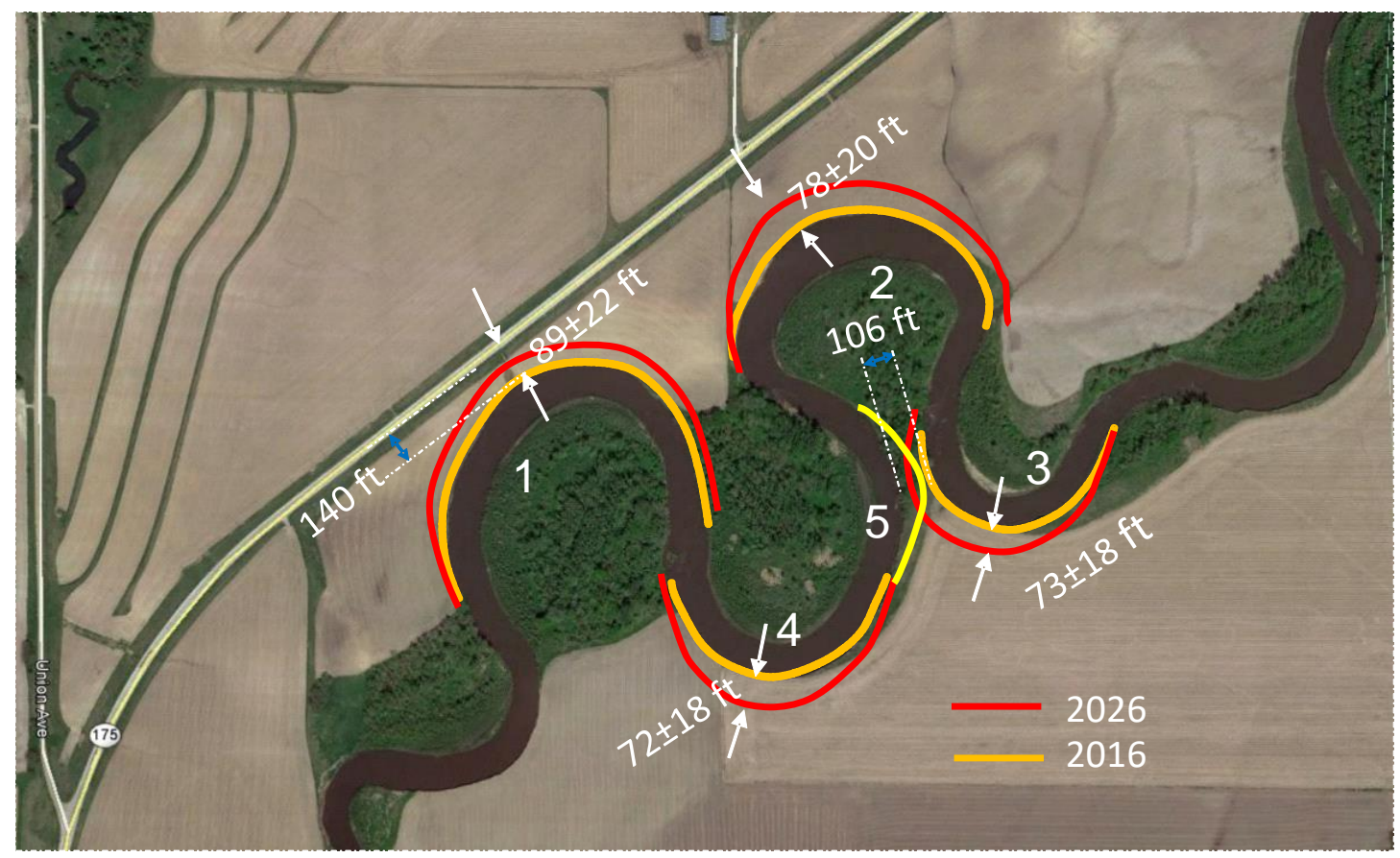

Figure 6-6: Aerial view of the Maple River from 2016. The forecasted bank lines for year 2026 according to the Scenario 3 were marked with red lines. Yellow line at bend- 5 is the estimated

bank location based on current migration rate.

\subsection{Scenario 4: One Additional 10,0oo cfs Discharge Event per Year}

The hypothetical hydrograph for scenario 4 represents an increase in extreme weather events that increases the total volume of discharge over 10 years by about 16 percent, going from 129 to 149 billion cubic feet. One event per year where the discharge reaches 10,000 cfs was added to the hydrograph in the early May time frame when there are usually spring rains. The peaks are reached by ramping up to the peak and back down over a period of about 9 days. The modified hydrograph is presented in Figure 6-7. This scenario tests the effects of a large increase in the frequency of very high flow events during the spring rains that add about 16 percent on average to the flow each year. Figure 6-8 shows the forecasted bank lines under the conditions of Scenario 4. In this case the migration distances are a little less than, but close to, those of scenario 2 where there were no additional high flow extreme events and simply $75 \mathrm{cfs}$ was added to the discharge each day. These results also indicate that the migration may be primarily a function of the volume of discharge over time that reaches erosive levels, and not a function of how extreme the flow variation is in terms of its standard deviation from the mean.

Three-Dimensional Flow Analysis Methodology for Assessing Stream Stability and Channel Migration 


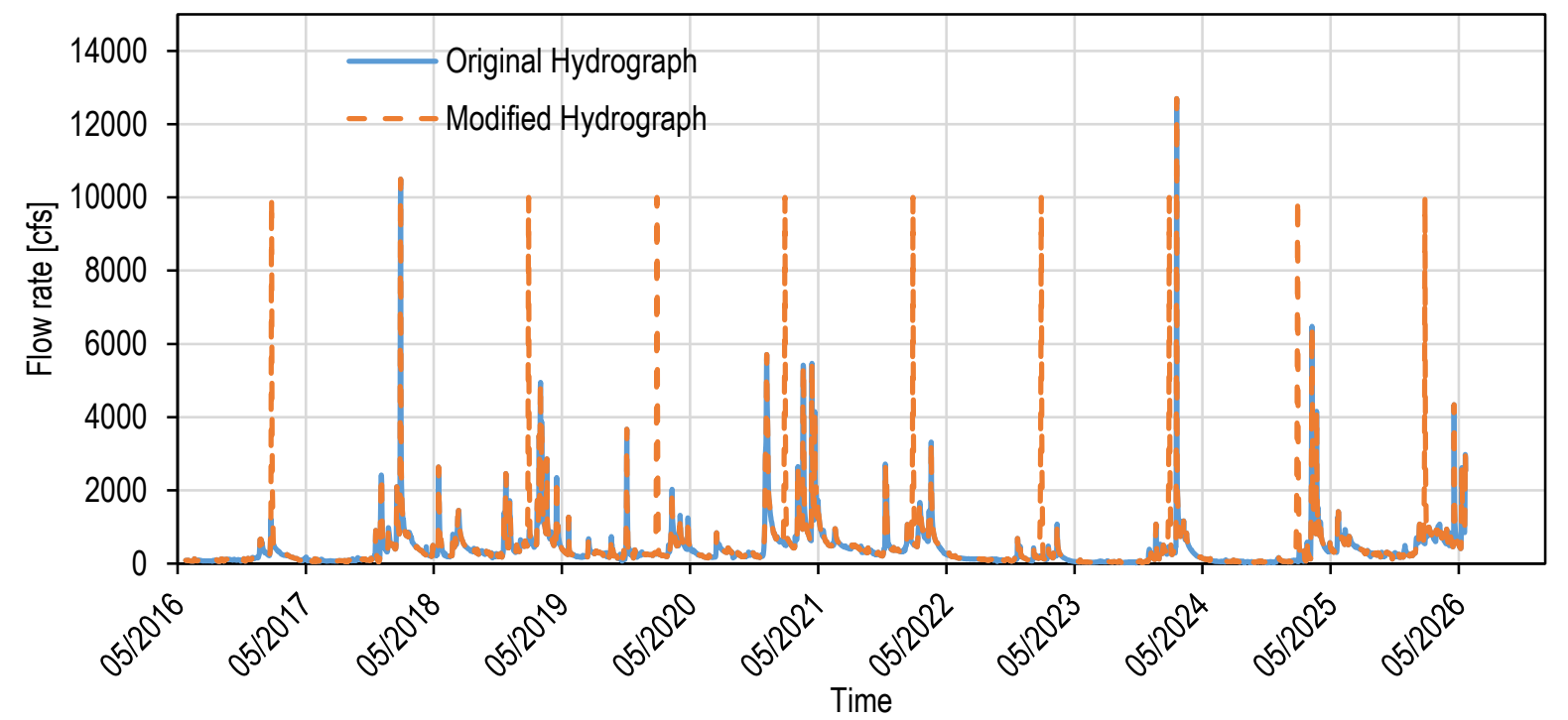

Figure 6-7: A comparison of the hypothetical hydrographs for the period 2016-2026 used in Scenario 1 (blue line) and used in Scenario 4 (orange line).

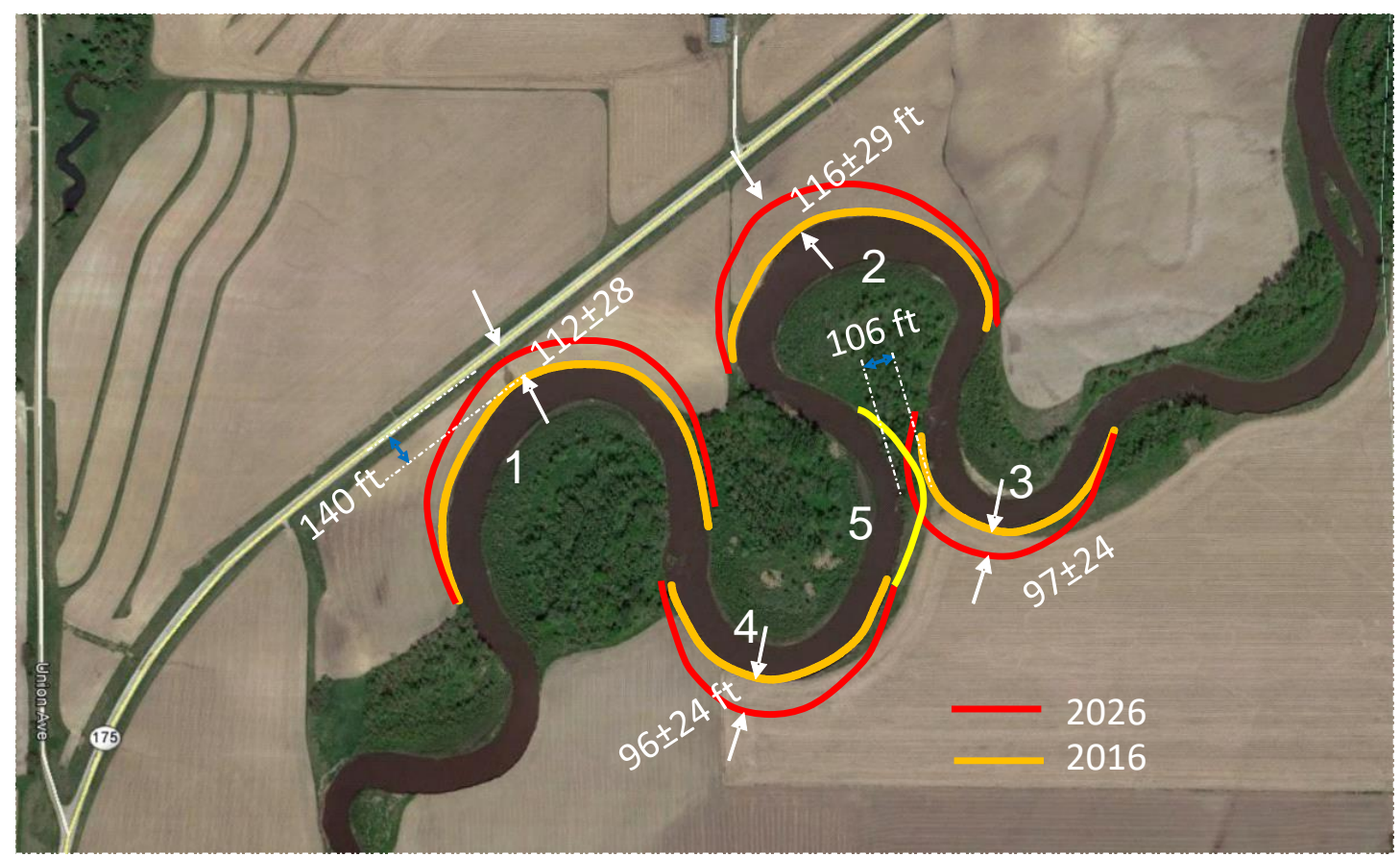

Figure 6-8: Aerial view of the Maple River from 2016. The forecasted bank lines for year 2026 according to the Scenario 4 were marked with red lines. Yellow line at bend- 5 is estimated bank location based on current migration rate.

Three-Dimensional Flow Analysis Methodology for Assessing Stream Stability and Channel Migration 


\subsection{Summary of Future Scenario Tests}

To illustrate use of the model, the response of the stream migration to several types of conditions was tested by constructing hydrographs and running the model with them. The hydrographs used for these tests were variations of the hydrograph that was used to tune the model. However, any hydrograph with flows within the range of the CFD results could be used. The four scenarios tested in previous sections are summarized in Table 5. Only four scenarios were tested to illustrate how the model can be used to assess risk and sensitivity of the migration of a stream to different trends in the weather. Many more tests should be run with variations for each type of change to the hydrographs as shown in Table 5 before general conclusions can be drawn with a high degree of confidence. The model was tuned with data from a time period of more than ten years. Therefore, the migrations for a base case scenario that uses the hydrograph of the previous ten years, assuming it will repeat over the next decade, are less than those of the period from 2005 to 2016 (nearly 11 years) used to tune the model shown in Figure 5-13.

Creating a hydrograph for the next decade that doubles the coefficient of variation but has the same mean daily discharge resulted in slightly lower bank migration in the bends. The case represents more extreme events for both high flow and low flow periods. To balance a relatively small number of higher flow events over ten years with lower low flow events, many more low flow periods had to be created to yield the same mean daily discharge of about $408 \mathrm{cfs}$. The small reduction in bend migration for this more extreme events case may have been a consequence of that.

Two scenarios increased the total volume of water conveyed through the stream over ten years. Adding $75 \mathrm{cfs}$ to the daily discharge for each day affects low flows proportionally more than high flows, increases the mean of the daily discharge by about 18 percent, and increases the migration of bend 1 by about 21 percent from 95 to 115 feet and the others increased similarly. This scenario reduced the coefficient of variation to 1.2, and in that sense, it represents conditions that are less extreme than those of the previous decade, but because the erosive flow increased significantly, the migration of the bends also increased significantly. Increasing the total volume of flow by adding a 10,000 cfs event during spring rains each May increased the mean of the daily discharge by about 16 percent and the migration of bend 1 increased by about 18 percent from 95 to 112 feet with migration of the other bends increasing similarly. In this scenario the coefficient of variation increased from the 1.5 of the base case to 1.8. While these conditions are more extreme than those of the previous decade, the results of the other scenarios suggest that the increase in stream bend migration may be due primarily to the increase in total amount of erosive flow and not a direct consequence of the increase in the coefficient of variation. 
Table 5: Summary of Future Ten Year Stream Flow Scenarios with Bend Migrations

\begin{tabular}{|c|c|c|c|c|c|c|c|c|c|}
\hline & $\begin{array}{c}\text { Total } \\
\text { Volume of } \\
\text { Discharge } \\
\text { [Bcf] }\end{array}$ & $\begin{array}{c}\text { Mean } \\
\text { Discharge } \\
\text { [cfs] }\end{array}$ & $\begin{array}{c}\text { Change } \\
\text { from } \\
\text { original } \\
\text { Mean }\end{array}$ & $\begin{array}{c}\text { SD } \\
\text { [cfs] }\end{array}$ & $\begin{array}{c}\text { Coefficient } \\
\text { of } \\
\text { Variation }\end{array}$ & $\begin{array}{c}\text { Bend } \\
1 \text { [ft] }\end{array}$ & $\begin{array}{c}\text { Bend } \\
2 \text { [ft] }\end{array}$ & $\begin{array}{c}\text { Bend } \\
3 \text { [ft] }\end{array}$ & $\begin{array}{c}\text { Bend } \\
4 \text { [ft] }\end{array}$ \\
\hline $\begin{array}{c}\text { Original } \\
\text { Hydrograph }\end{array}$ & 129 & 407.6 & 0.0 & 597 & 1.46 & 95 & 102 & 84 & 81 \\
\hline $\begin{array}{c}\text { More } \\
\text { extreme } \\
\text { events/same } \\
\text { mean }\end{array}$ & 129 & 407.6 & 0.0 & 1193 & 2.93 & 89 & 78 & 73 & 72 \\
\hline $\begin{array}{c}\text { Additional } \\
75 \text { cfs each } \\
\text { day }\end{array}$ & 152 & 482.6 & 18.4 & 591 & 1.22 & 115 & 124 & 102 & 97 \\
\hline $\begin{array}{c}\text { Add one 10k } \\
\text { event each } \\
\text { year }\end{array}$ & 149 & 472.0 & 15.8 & 855 & 1.81 & 112 & 116 & 97 & 96 \\
\hline
\end{tabular}

\section{Conclusions}

A new methodology for estimating stream migration over long periods of time based on $3 \mathrm{D}$ CFD analysis has been developed. The analysis is done for a set of discharge flows through the bends of the reach. The CFD results for each discharge provide bank shear stress close to the underlying physics and water depth or bankfull fraction for an assumed quasi-steady period of a day. The CFD results are combined with a hydrograph giving daily discharges that may cover a long period of time, ten years or more. Bank shear stresses and bankfull fraction are obtained for each day of the hydrograph by interpolation from the CFD results, and a daily migration distance value is obtained from a bank erosion rate function of bank shear stress and bankfull fraction. These daily migration values are then summed over the period of the hydrograph to obtain the total stream migration distance. The method assumes that the migration over the period is small compared to the radius of the bends and that no major changes in stream course occur during the migration period, such as cutting off a horseshoe bend. While the hydrograph can be any set of daily discharges, it would typically be obtained by taking an historical hydrograph from a measuring station as close to the stream reach as possible and modifying it to obtain an expected future hydrograph. With this methodology, "what if" scenarios can be run to test the effects of a variety of weather changes, including more extreme weather events on stream migration. The results can be used to assess the time frame of stream incursion on roads or other structures that might require mitigation actions in the future.

Historic and geomorphic evaluation are essential parts of the study. Assessment of historic river channel changes and past river behavior provide a basis for predicting the type of channel changes that could occur in the future. A method is presented to determine stream bank erosion rate constants for a typical erosion rate formula. Initial values for the erosion rate constants may be obtain from soil property data for the soil at the site. These values are then tuned by adjusting the constants to minimize the error in predicting stream bank migration using the CFD determined bank shear and bankfull fraction in combination with an historical hydrograph and known bank migration end points. The method shows robustness in its ability to predict the historical day-by-

Three-Dimensional Flow Analysis Methodology for Assessing Stream Stability and Channel Migration 
day migration trend when just the end point migration distance was used to determine erosion rate function constants.

Applications of the methodology to four "what if" scenarios for future weather patterns were demonstrated by modifying the historical hydrograph daily discharge values for a ten year period. They included (1) no change, the next ten years is the same as the previous ten years, (2) a small increase in daily discharge, (3) an increase in extreme events, floods and droughts, which is characterized by a doubling of standard deviation of the hydrograph, with no change in the mean discharge or total volume of discharge over a ten year period, and (4) the addition an extreme event each year during spring rains having a discharge of 10,000 cfs for a single day with ramp up and down over a few days. The results from these tests of different weather trends illustrate that the method can be used as a learning and exploratory tool to see how a stream prone to migration responds to different types of changes in weather patterns, and to help identify which changes carry more risk of impacting transportation and other infrastructure. Although many more tests would need to be carried out to be conclusive, the model indicates that bank migration may be primarily a function of the total volume of flow that is at erosive levels and not a function of how extreme the weather events are with respect the mean flow over time.

Three-Dimensional Flow Analysis Methodology for Assessing Stream Stability and Channel Migration 


\section{Acknowledgements}

The funding for this project came from the Turner-Fairbank Highway Research Center, through Interagency Agreement Number DTFH61-14-X-300002 between DOT and DOE, and the work was performed under DOE's contract with UChicago Argonne, LLC, contract no. DE-ACo2-o6CH11357.

\section{References}

[1] https://www.google.com/maps/@42.2651759,-95.6822759,248om/data=!3m1!1e3

[2] Hydrologic Engineering Center's (CEIWR-HEC) River Analysis System (HEC-RAS), http://www.hec.usace.army.mil/software/hec-ras/

[3] Lai Y.G., SRH-2D v.2: Theory and User's Manual. Sedimentation and River Hydraulics - TwoDimensional River Flow Modeling. U.S. Department of the Interior, Bureau of Reclamation, Technical Service Center, Denver, CO. November 2008

[4] Zevenberger L., Channel Migration Analysis of the Maple River, Iowa, using Stream Power and Energy Concepts, FHWA, 2017

[5] Star-CCM+ v.12.06 Documentation

[6] McGahey C., Samuels P.G., River roughness-the integration of diverse knowledge, River Flow 2004 - Greco, Carravetta \& Della Morte (eds.), Taylor\& Francis Group, London, ISBN 905809-658-0

[7] National Oceanic and Atmospheric Administration (NOAA) Coastal Services Center. 2012. "Lidar 101: An Introduction to Lidar Technology, Data, and Applications." Revised. Charlston, SC: NOAA Coastal Services Center

[8] LSPrePost manual

[9] Shan, H., Shen, J., Kilgore, R., Kerenyi, K., Scour in Cohesive Soils, Report No. FHWA-HRT15-033, U.S. Department of Transportation, May 2015.

[10] http://sourceforge.net/projects/xongrid/

[11] Girton, D. D., Hawkinson, T. R., \& Greimann, L. F. (1989). Validation of Design Recommendations for Integral Abutment Piles-Iowa DOT Project HR-292

[12] U.S. Geological Survey, 2018, National Water Information System data available on the World Wide Web (USGS Water Data for the Nation), accessed [January 16, 2018], at URL [http://waterdata.usgs.gov/nwis/]

Three-Dimensional Flow Analysis Methodology for Assessing Stream Stability and Channel Migration 


\section{Argonne}

Nuclear Engineering and Science Division

Argonne National Laboratory

9700 South Cass Avenue, Bldg. 208

Argonne, IL 60439-4815

www.anl.gov

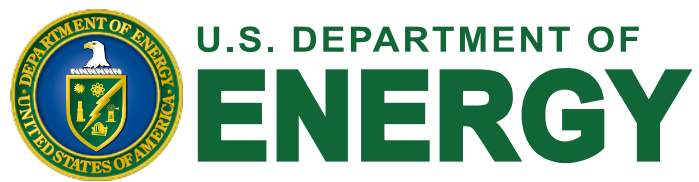

Argonne National Laboratory is a U.S. Department of Energy laboratory managed by UChicago Argonne, LLC

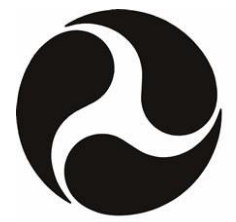

U.S. Department of Transportation

Federal Highway Administration 